
Índice de Desarrollo Regional

IDERE 2019 



\title{
ÍNDICE DE DESARROLLO REGIONAL IDERE 2019
}

\author{
M. CAMILO VIAL COSSANI \\ ( $\mathrm{E}$ D I T O R )
}
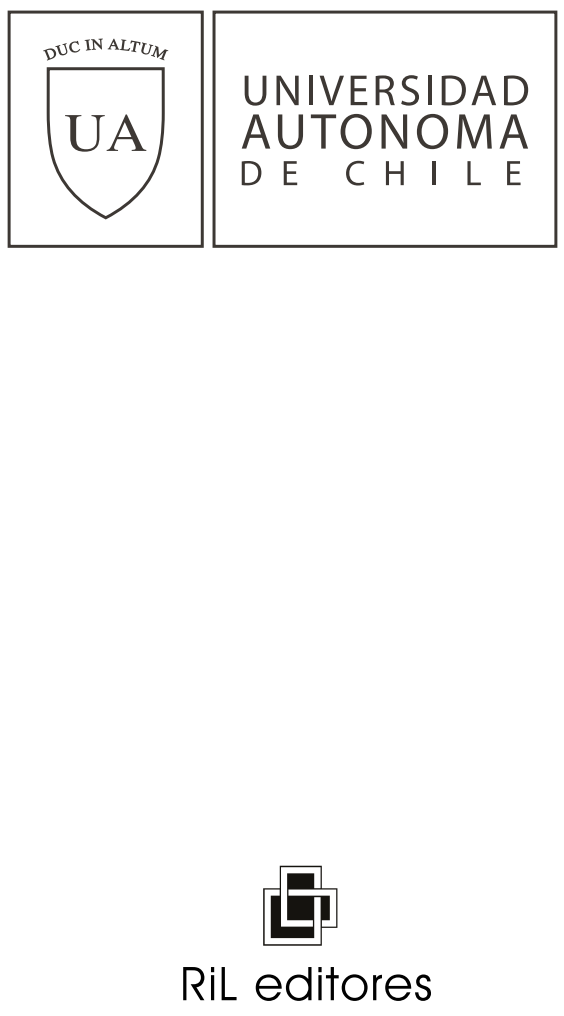


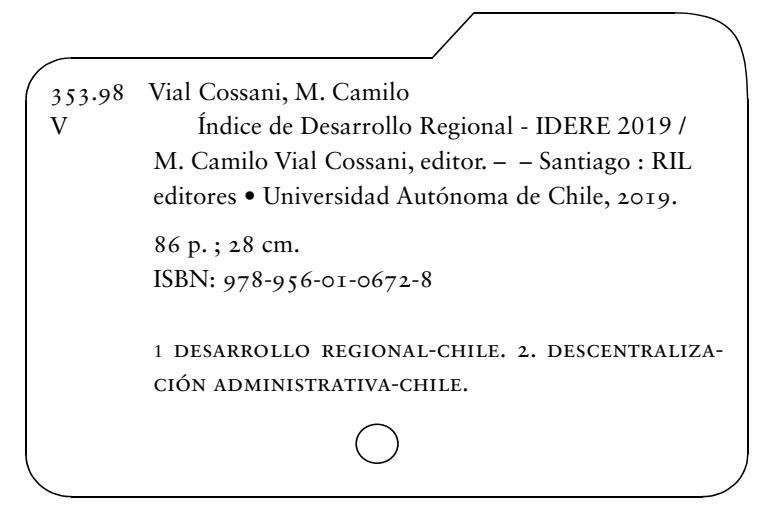

ÍNDICE DE DESARROLLO REGIONAL.

$$
\text { IDERE } 2019
$$

Primera edición: mayo de 2019

(C) M. Camilo Vial Cossani, 2019

Registro de Propiedad Intelectual

$\mathrm{N}^{\circ} 301.254$

(C) RIL® editores, 2019

Sede Santiago:

Los Leones 2258

CP 75 I 055 Providencia

Santiago de Chile

(J) (56) 222238 100

ril@rileditores.com・www.rileditores.com

Sede Valparaíso:

Cochrane 639, of. 92

CP 236 I 8 O I Valparaíso

(d) (56) 322746203

valparaiso@rileditores.com

Sede España:

europa@rileditores.com・Barcelona

(C) Centro de Comunicación de las Ciencias, 20I9

Universidad Autónoma de Chile

https://ciencias.uautonoma.cl I ciencias@uautonoma.cl

ISBN Universidad Autónoma 978-956-8454-29-6

Composición, diseño de portada e impresión: RIL® editores

Impreso en Chile $\bullet$ Printed in Chile

ISBN 978-956-OI-0672-8

Derechos reservados. 


\section{ÍNDICE}

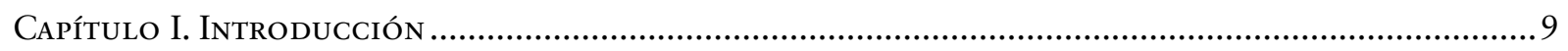

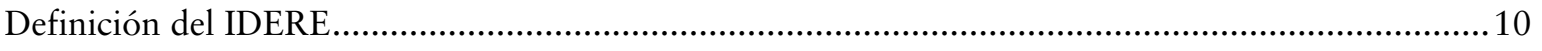

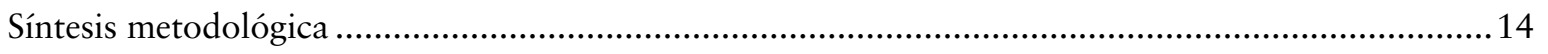

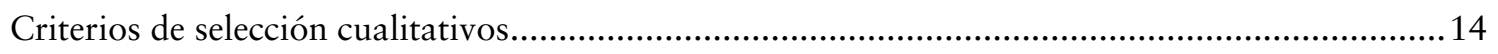

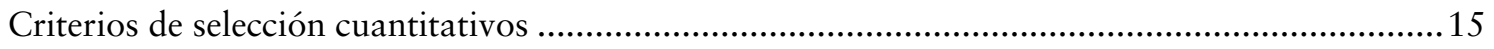

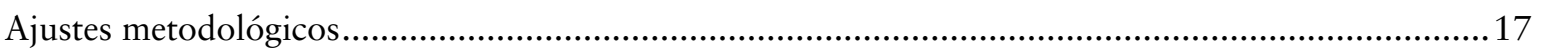

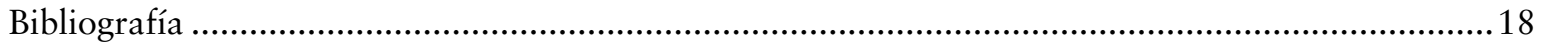

Capítulo II. La brecha de GÉNero en Chile: Algunas Reflexiones

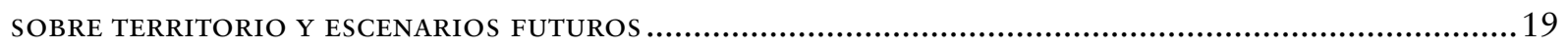

Una deuda pendiente: la baja participación en el mercado laboral ..................................................20

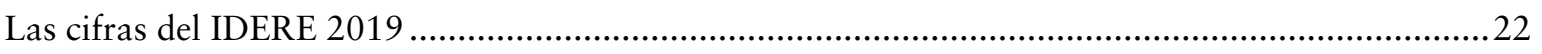

Mayor violencia intrafamiliar en regiones con menos desarrollo .....................................................25

La larga esperanza de vida de las mujeres chilenas ....................................................................26

Reflexiones: lo urgente, lo importante y el futuro en materia de género ..........................................28

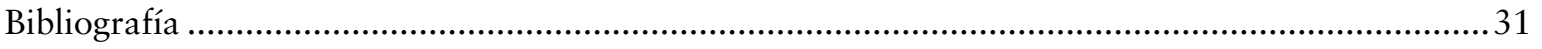

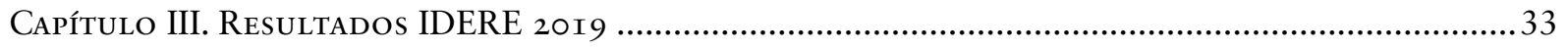

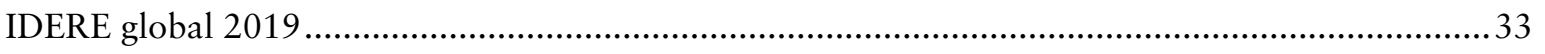

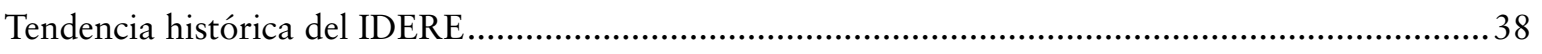

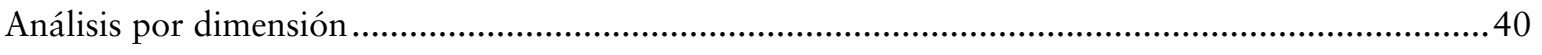

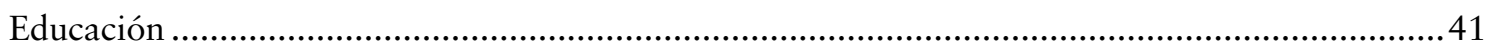

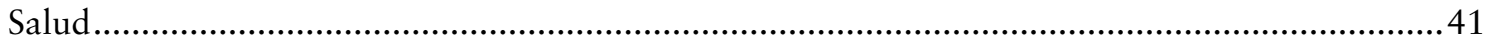

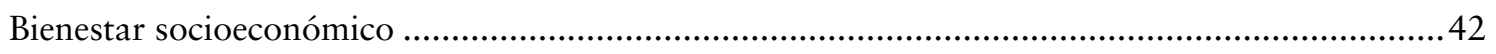

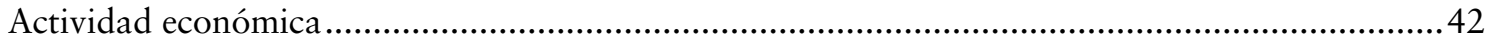

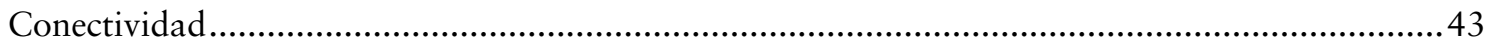

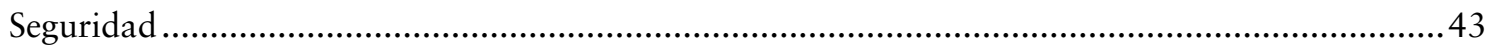

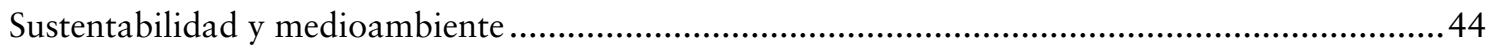

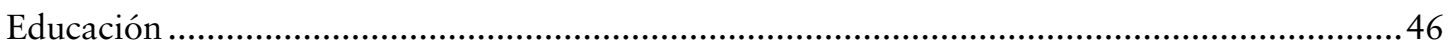

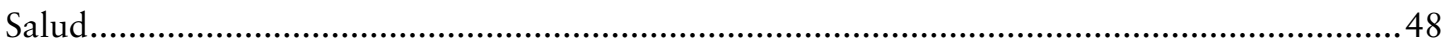

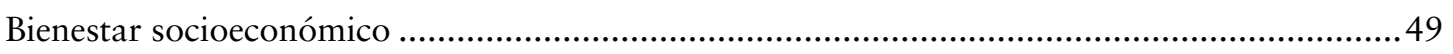

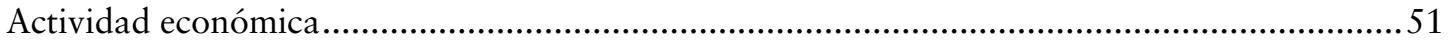

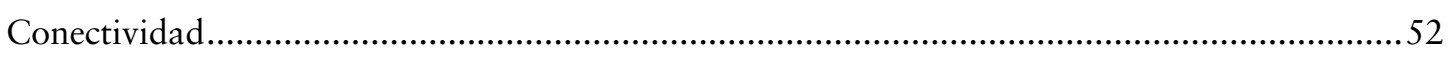

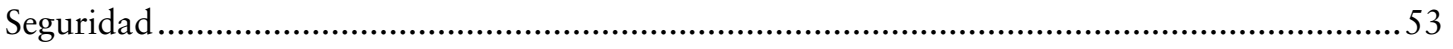

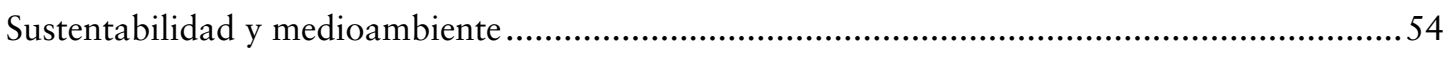

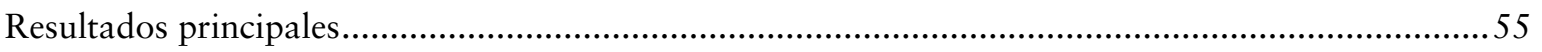




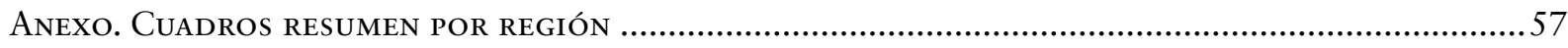

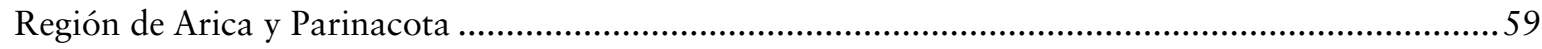

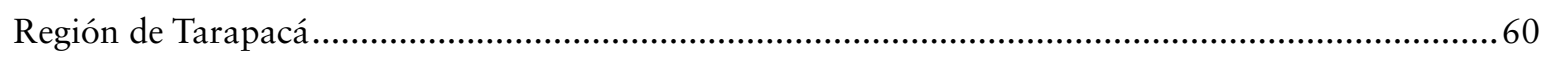

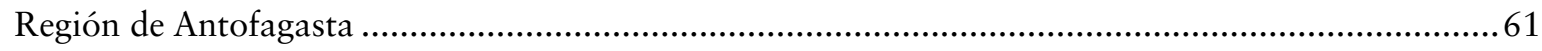

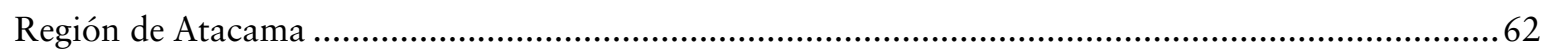

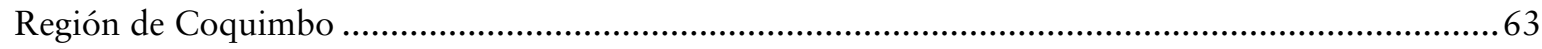

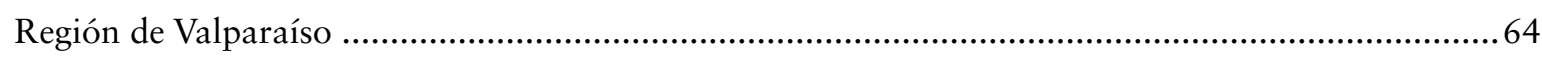

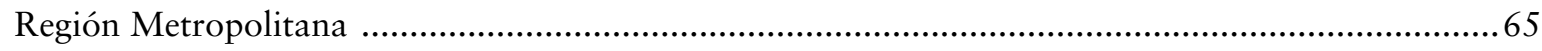

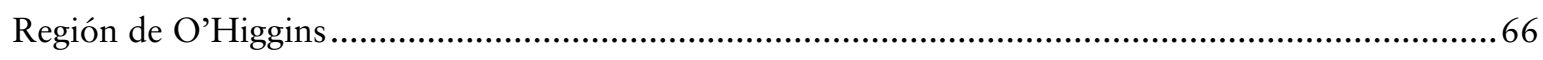

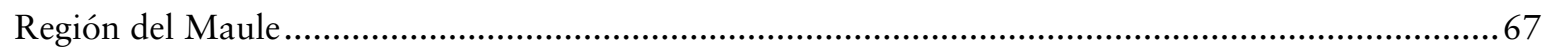

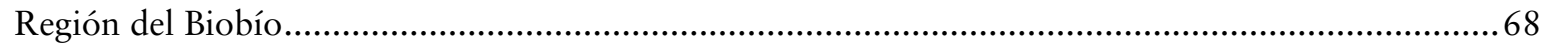

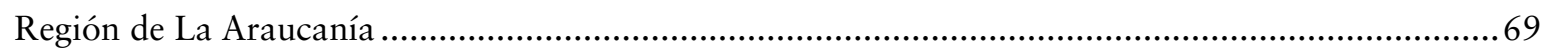

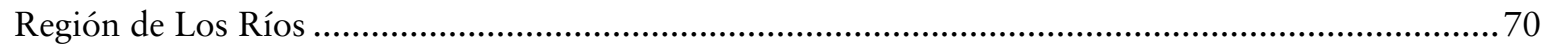

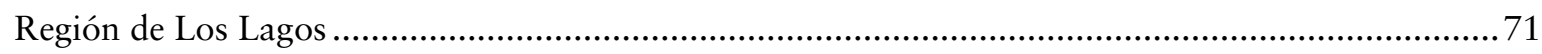

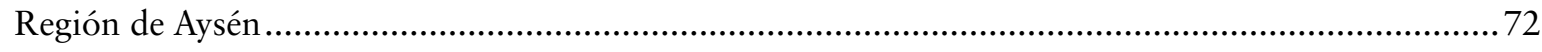

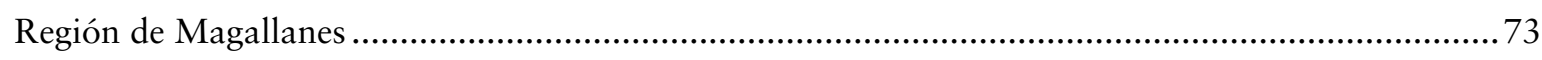

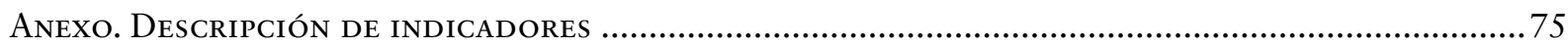

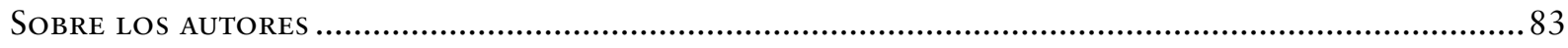




\section{CAPÍTULO I \\ INTRODUCCIÓN}

M. Camilo Vial Cossani ${ }^{1}$

Instituto Chileno de Estudios Municipales, Universidad Autónoma de Chile

En 2016 se lanzó por primera vez el Índice de Desarrollo Regional —IDERE—(Vial, 2016), concebido como una herramienta que mide el desarrollo a nivel territorial desde una perspectiva multidimensional. Gracias a esa publicación (y a la información contenida en www.idere.cl, donde se pueden observar las tendencias desde 2010 en adelante), se ha podido analizar desde una nueva perspectiva las trayectorias y asimetrías de dimensiones que se consideran críticas en el desarrollo de las personas, agrupadas según las regiones donde habitan.

La recepción ha sido muy positiva no solo en los círculos académicos, sino que también en autoridades políticas, gestores públicos, agrupaciones de la sociedad civil y medios de comunicación, tanto de alcance regional como nacional. Esto representa una motivación para perpetuar el objetivo de publicar anualmente una nueva versión del IDERE y así contar con información periódica sobre desarrollo de las regiones del país.

Pero el Índice por sí solo es, a todas luces, insuficiente para constatar cabalmente el estado de desarrollo de las regiones del país. El IDERE es una fotografía holística del desarrollo regional, pero no necesariamente un fiel reflejo de dicha realidad. El Índice es una herramienta que se debe complementar, ya sea con información adicional (que por sus características no ha sido posible incorporar en el mismo), con datos de diversos análisis cualitativos o con nociones adicionales al concepto de desarrollo regional al que adhiere esta propuesta. Por eso, también se definió que cada nueva edición debe ser acompañada de un estudio complementario. Así, en la versión 2017 del IDERE, se incorporó de manera estable la dimensión de Sustentabilidad y medioambiente.

1 El editor agradece el apoyo y financiamiento de la Comisión Nacional de Investigación Científica y Tecnológica (CONICYT), a través del Proyecto FONDECYT N 11160991: «Descentralización en Chile y su efecto en el desarrollo socioeconómico regional. Un análisis al período 1990-2015». 
El IDERE 2019 integra otra materia fundamental en las nociones contemporáneas del desarrollo: las brechas de género (ver Capítulo 2), elaborado por la doctora Andrea Gartenlaub. Su inclusión responde al creciente reconocimiento social de su incidencia efectiva como factor de desigualdad, en buena medida gracias a la visibilización lograda por las movilizaciones sociales de los últimos años. A partir del mencionado estudio complementario, se busca avanzar hacia una mirada más integral del desarrollo regional en Chile.

Cabe señalar que desde la presente edición se optó por publicar el Índice cada dos años, modificando así su periodicidad anual. Ello en base a dos grandes razones: a) de un año a otro la variabilidad de los resultados es muy baja, por lo que el Índice es más atractivo al analizar trayectorias en plazos menos acotados, en los que sí se pueden evidenciar algunos cambios tendenciales; b) una edición cada dos años permite contar con información más actualizada, reduciendo las variables que por metodología se deben estimar. Ello, a futuro, implicará menos «correcciones» de datos históricos en la medida que las fuentes vayan actualizando su información.

El Índice 2019 está compuesto por siete dimensiones y 32 variables. Ello, manteniendo los objetivos de visibilizar las profundas y multidimensionales desigualdades regionales, que reciben escasa atención; aportar datos para el debate público en el amplio abanico de temáticas relacionadas con el desarrollo de nuestras regiones; y generar nueva información que sea útil para futuros estudios e investigaciones.

Por último, el IDERE 2019 no considera la recientemente creada Región de Nuble, dado que no está disponible la totalidad de indicadores según los criterios de selección de variables que exige la metodología seguida. Por lo tanto, la presente versión del Índice, sigue contemplando a la región del Biobío con su configuración territorial anterior.

\section{Definición DEL IDERE}

El Índice de Desarrollo Regional (IDERE) es una herramienta que mide el desarrollo a nivel territorial desde una perspectiva multidimensional, a través de una medida geométrica de índices normalizados entre 0 y 1 (donde 0 expresa el desarrollo mínimo y 1 el máximo). Gracias a ello, el IDERE permite analizar las trayectorias y asimetrías de dimensiones consideradas críticas en el desarrollo de las personas, agrupadas según las regiones donde habitan, constatando las desigualdades territoriales y brechas existentes.

El IDERE basa su concepto de desarrollo en el enfoque de las capacidades humanas, entendiéndolo como las oportunidades que tienen las personas para ejercitar sus libertades de elección para la consecución de objetivos en distintas áreas vitales para sus vidas (Sen, 1999).

Para efectos de medir el desarrollo, tales capacidades se codifican en torno a diferentes dimensiones. Un amplio consenso respecto al mínimo de ellas son las seleccionadas por el Índice de Desarrollo Humano, IDH (PNUD, 2014). Así, la salud (tener la capacidad / 
oportunidad de disfrutar de una vida larga y saludable), la educación (tener la capacidad / oportunidad de acceder a una adecuada educación, que promueva el conocimiento y la cultura) y los ingresos (tener la capacidad / oportunidad de contar con los recursos suficientes para alcanzar un nivel de vida digno) son claves para evaluar la calidad de vida de las personas.

Para la medición de desarrollo regional en Chile, el IDERE empleó una rigurosa metodología (ver siguiente subtítulo) que culminó con la identificación de $7^{2}$ dimensiones claves para el bienestar de la población. Estas son:

\section{- $\quad$ Educación}

Se concibe como la capacidad de los habitantes de una región para acceder a una educación de calidad, que promueva el conocimiento, la cultura y amplíe el rango de oportunidades para la vida adulta. Por ende, se consideran variables de cobertura y calidad en educación preescolar, primaria, secundaria y superior.

\section{- $\quad$ Salud}

Se entiende como la capacidad de la población de disfrutar de una vida duradera y saludable, tanto desde el punto de vista físico como mental. Para ello se emplean variables tanto de cobertura como de calidad en salud.

\section{- Bienestar socioeconómico}

Concebido como la capacidad de acceso a ciertos estándares que aseguren una buena calidad de vida. Aquí, se consideran variables relativas a pobreza, ingresos y calidad de la vivienda. Si bien una gran parte de las variables del IDERE están relacionadas con el concepto de bienestar socioeconómico (especialmente las de salud y educación), estas se han constituido como dimensiones independientes dada su relevancia.

\section{- $\quad$ Actividad económica}

Entendido como la posibilidad de los habitantes de una región para vivir en un entorno cuya economía sea sana y estable, que promueva oportunidades laborales y mejoras salariales. Ello con el objeto de permitirles optar a bienes y servicios mínimos que aseguren un estándar en su calidad de vida. Así, se consideran variables relacionadas con renta, desempleo, diversificación de los sectores productivos y especialización en industria manufacturera y de servicios ${ }^{3}$.

2 Debido a los criterios metodológicos de selección aplicados a todas las variables susceptibles de componer el IDERE (ver próximo subtítulo), no se pudo incorporar la dimensión de Cultura y tiempo libre. Las variables preseleccionadas no lograron cumplir con tales exigencias.

3 Tal como se especificó en el informe IDERE 2016 (Vial, 2016), el Î́ndice no incluye PIB ni PIB per cápita, indicadores ampliamente utilizados en índices que miden el dinamismo y/o la actividad económica en un territorio. La exuberancia de las cifras producto de la minería — y su inestabilidad dada la fluctuación de precios— generan dos efectos negativos 


\section{- Conectividad}

Se concibe como la capacidad de vivir en un espacio geográfico debidamente conectado, tanto de manera física como virtual, de modo que favorezca el acceso a más oportunidades, servicios y bienes. En consecuencia, se consideran variables relacionadas con conectividad telefónica, de internet y de caminos y carreteras.

\section{- Seguridad}

Entendido como la capacidad que tiene la población de una región para vivir en un entorno seguro y confiable.

\section{- $\quad$ Sustentabilidad y medioambiente}

Entendida como la posibilidad que tienen los habitantes de una región para vivir en un contexto que permita satisfacer sus necesidades actuales, sin comprometer las de las futuras generaciones. Esto implica mantener una relación armónica entre desarrollo y medioambiente, para que el bienestar de la población sea sostenible en el tiempo.

Cabe destacar que cada variable ha sido ajustada por desigualdad a través de la medida de inequidad de Atkinson. Se tomó esta decisión porque la desigualdad impacta en todas las esferas del desarrollo y no solo en las variables asociadas al ingreso. La descripción de las variables se presenta en el anexo de este informe, mientras que la síntesis metodológica se puede observar en el siguiente subtítulo.

Por último, es necesario precisar el alcance del IDERE. Esta es una herramienta útil para medir el desarrollo de cada una de las regiones del país, de forma general o a través de sus dimensiones. Esto permite comparar dichos territorios, observar sus propias evoluciones en el tiempo y detectar cuáles han sido las dimensiones que más han empujado o aletargado este proceso. Sin embargo, el IDERE no es sinónimo inequívoco de desarrollo regional, más bien se trata de una buena aproximación para medirlo. Más allá de la necesaria discusión sobre la integración o reducción de variables y dimensiones (situación que se evaluará periódicamente en el futuro), la complejidad del concepto de desarrollo regional no se debe reducir a un número.

En consecuencia, el IDERE debe considerarse en su justa medida: una herramienta útil, construida a partir de datos objetivos, que se puede (y debe) contrastar y complementar con otros insumos para tener una concepción más integral de un fenómeno tan complejo y polisémico como el desarrollo regional.

para esta medición: a) se torna poco recomendable comparar a las regiones mineras con el resto del país; b) dichos números están alejados de la realidad diaria de la población que vive en tales territorios. 


\section{Figura 1.}

Dimensiones y variables del IDERE

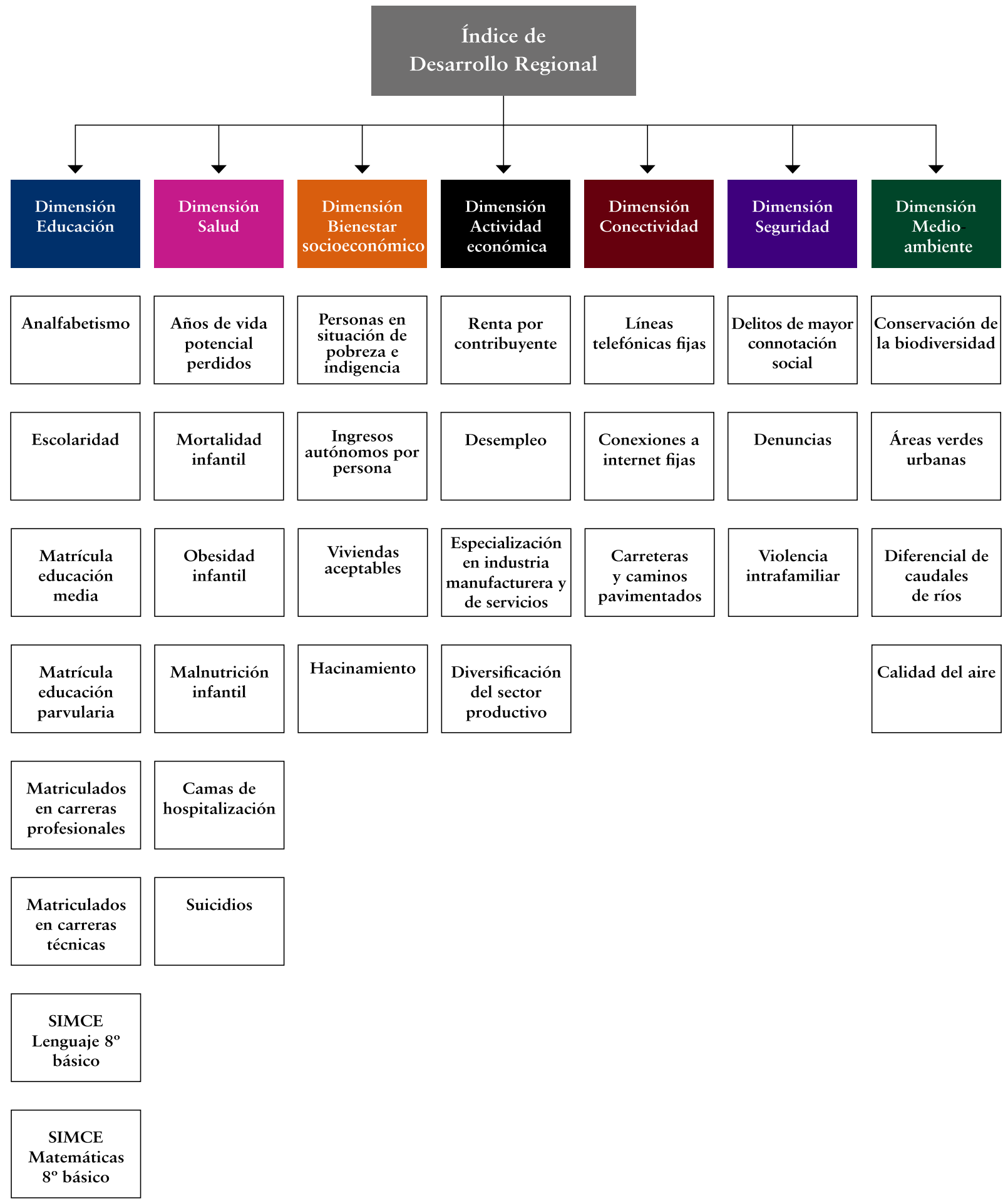

Fuente: elaboración propia. 


\section{SÍNTESIS METODOLÓGICA}

Considerando el concepto de desarrollo regional ya definido y una propuesta inicial elaborada por el autor (Vial, 2014), se procedió a establecer cuatro grandes etapas para la posible incorporación de variables y dimensiones en el IDERE:

- Revisión de bibliografía que amplía el abanico de dimensiones y variables a considerar, entre ellas las discutidas por Nussbaum (2003), Alkire (2010), Pagliani (2010), Neumayer (2010), Graham (2010), Cheibub (2010) y Burd Sharps et al. (2010).

- Análisis de otros informes e índices de características similares, como el Informe Latinoamericano de Pobreza y Desigualdad (RIMISP, 2014), el Índice de Calidad de Vida Urbana (Orellana, 2015) y los índices de competitividad regional (SUBDERE, 2009) y comunal (SUBDERE, 2013).

- Revisión de información estadística disponible en el país.

- Consulta a 62 expertos en la materia, especializados en la realidad de Chile y sus regiones.

Este proceso incluyó la preselección de 164 posibles variables en 8 dimensiones. Luego, en base a las recomendaciones para la construcción de índices compuestos de OCDE (2008), EUROSTAT (2011) y FMI (2012), además de la literatura revisada de otros índices de arquitecturas similares al IDERE, se determinó que cada indicador debía cumplir con 10 criterios metodológicos (7 cualitativos, 3 cuantitativos) para garantizar los estándares mínimos de calidad, sobre los cuales posteriormente se construyeron las respectivas variables y dimensiones. A continuación se presentan los criterios metodológicos:

\section{Criterios de selección cualitativos}

- Pertinencia: los indicadores seleccionados deben ser coherentes y relevantes con la definición de desarrollo regional a la cual se adscribe esta investigación.

- Confiabilidad de la información: las fuentes de información deben ser confiables y no responder a intereses institucionales de ningún tipo. En consecuencia, se tomó la decisión de utilizar solo fuentes oficiales del Estado de Chile, sin excepción alguna. Se excluyen entonces aquellas fuentes de información secundaria (sin importar su pertinencia) provenientes de universidades, centros de estudio u opinión, institutos, corporaciones, gremios, fundaciones y otros. 
- Accesibilidad: la información debe ser pública, de fácil acceso y expuesta de manera clara, a fin de evitar errores de interpretación. Por ende, se optó por bases de datos en línea de organismos del Estado de Chile e información reunida a través de solicitudes vía Ley de Transparencia.

- Oportunidad y periodicidad: la información seleccionada debe, por una parte, reflejar una realidad reciente (o cercana al año de recolección de datos) y, por otra, tener una periodicidad anual, bianual o, como máximo, trianual. Tanto para periodicidades bianaules como trianuales, se debe contar con al menos tres mediciones anteriores, con el objeto de estimar los valores perdidos mediante regresiones lineales.

- Disponibilidad: la información debe estar disponible a nivel regional (o al menos se debe poder componer a esta escala) para todas las regiones del país, con el objeto de realizar comparaciones horizontales.

- Reflejo de resultados: la información reunida debe mostrar resultados concretos y observables, determinados ya sea por esfuerzos públicos y/o privados.

- Datos objetivos: se optó por considerar solo datos objetivos, excluyendo variables relativas a percepción ciudadana, debido al impacto que producen algunas situaciones puntuales o hechos mediáticos en la opinión pública, sin necesariamente correlacionarse con trayectorias de información objetiva asociadas a tales eventos.

\section{Criterios de selección cuantitativos ${ }^{4}$}

- Coherencia estadística: la información recolectada debe ser coherente 1) a lo largo del tiempo cuando se trata de una misma unidad de análisis (región) y 2) entre unidades de análisis (regiones) en un mismo año. Para ello, se construyeron matrices 2009-2014 de las 67 variables seleccionadas, donde se pudo observar aquellas variables que presentaban comportamientos anómalos.

$4 \quad$ Los criterios cuantitativos de coherencia estadística y de comportamientos diferenciados se aplicaron a la totalidad de variables, con excepción de Calidad del aire, de la dimensión Sustentabilidad y medioambiente, donde se aplicaron parcialmente. Se tomó esta decisión porque solo existen mediciones de PM2,5 en la Región de Tarapacá desde 2016; en Arica y Parinacota y Magallanes desde 2014; Maule y Aysén desde 2013; y Biobío desde 2010. Solo en estos casos no se pudo completar el set de análisis 2009-2014 de los criterios antes mencionados. Por ende, se aplicaron los criterios a la totalidad de datos y regiones disponibles. Ello implicó, también, que el criterio cuantitativo de análisis de componentes principales no se pudiera aplicar a las variables de la dimensión Sustentabilidad y medioambiente. 
- Comportamientos diferenciados: una vez solventada la coherencia estadística, los indicadores seleccionados deben mostrar rendimientos con cierto nivel de diferenciación entre las unidades de análisis, ello a fin de no medir futuras variables con comportamientos muy estables para todas las regiones en un mismo año. Por ello, se optó por prescindir de indicadores que tuvieran diferenciaciones menores a $5 \%$ entre todas las regiones para cada uno de los años del período 2009-2014.

- Análisis de componentes principales: el objetivo de esta técnica es agrupar la información dispuesta en un conjunto de variables por medio de componentes principales intercorrelacionados entre sí. Para su construcción, se tienen en cuenta las características comunes y la especificidad de cada una de las variables. La medida a utilizar (y que dará cuenta de las relaciones) es la propia varianza de los factores, que mediante su interpretación permite determinar: a) dimensiones subyacentes, b) importancia relativa de variables y c) variables que pueden ser extraídas sin afectar la composición del modelo.

Tras esta etapa se terminó definiendo la composición del IDERE, que en 2019 está compuesto por 32 variables en 7 dimensiones, las cuales se pueden observar en la Tabla 29 del Anexo. En la última columna se observa el año del último dato disponible para cada variable. Aquellos que no corresponden a 2017 se estimaron mediante regresiones lineales, considerando datos desde 2009.

Cada variable fue normalizada a un ratio entre 0 y 1 mediante el método min-max y luego fue ajustada por desigualdad a través de la medida de inequidad de Atkinson. La agregación de variables a cada dimensión fue de manera aritmética (cada una con peso o participación equivalente), mientras que la agregación de dimensiones al IDERE final fue geométrica. Originalmente, los pesos de cada una respondieron a la moda observada en las respuestas de una segunda consulta a expertos mediante encuesta en línea. Posteriormente, la ponderación se ajustó para permitir la incorporación de la dimensión Sustentabilidad y medioambiente, respetando la proporcionalidad de los pesos originales. Así, la ponderación de cada dimensión es la siguiente: Educación, 17,5\%; Salud, 17,5\%; Bienestar socioeconómico, 17,5\%; Actividad económica, 17,5\%; Conectividad, 10\%; Seguridad, 10\%; Sustentabilidad y medioambiente, $10 \%$. 


\section{Ajustes metodológicos}

El IDERE 2019 presenta dos variaciones metodológicas respecto a su versión anterior. La primera es la omisión de la variable Consultas por morbilidad en la dimesión Salud, debido a la escasa actualización del valor, así como también porque es una variable que tiende a ser elevada en aquellos territorios donde existe mayor cobertura de salud. Por lo mismo, el positivo hecho de una alta presencia de centros médicos en determinadas zonas hace que las consultas por morbilidad también crezcan por mayor capacidad de diagnóstico, generando un efecto negativo en el rendimiento de esta dimensión en la respectiva región. De esta manera, la dimensión Salud pasa de tener siete a seis variables.

El segundo ajuste se refiere a una nueva forma de medir la variable Diversificación del sector productivo, de la dimensión Actividad económica. La fórmula empleada es:

$$
x_{i, t}=\sum_{j}\left|\frac{y_{j, i, t}}{w_{i, t}} * 100 \%-z\right|
$$

Donde:

$i=$ región

$j=$ actividad económica

$t=$ año

$x_{i, t}=$ indicador de diversificación económica por región por año

$y_{i, j, t}=$ ventas de empresas por actividad económica por región por año

$w_{i, t}=\sum_{j} y_{j, i, t}$ : suma de las ventas por actividad económica por región por año

$\mathrm{z}=$ constante que representa el porcentaje de cada actividad en una estructura regional equitativa.

En ella se van a considerar 16 de 19 actividades económicas. Las actividades excluidas fueron Consejo de administración de edificios y condominios, Organizaciones y órganos extraterritoriales y $\operatorname{Sin}$ información, debido a que obtenían valores en torno a 0.

Así, la región teórica equitativamente diversificada debería presentar un $6,25 \%$ de participación en todas sus actividades económicas (100/16). Para identificar las regiones más y menos diversificadas, se tomó el valor absoluto de la diferencia de cada actividad respecto a $6,25 \%$ y luego fueron sumadas. De ese modo, el valor menor mostraría una menor diferencia con la «región ideal», lo cual reflejaría un sector productivo más diversificado.

Dado que los resultados de esta fórmula dan cercanos a 100, para evitar confusiones que hagan pensar que son porcentajes, se ha optado posteriormente por multiplicar por una constante los resultados (aspecto no representado en la fórmula). 


\section{Bibliografía}

Alkire, S. (2010). Human Development: definitions, critiques, and related concepts. Human Development Research Paper, 2010/01.

Burd-Sharps, S., Lewis, K., Guyer, P., \& Lechterman, T. (2010). Twenty years of human development in six affluent countries: Australia, Canada, Japan, New Zeland, the United Kingdom, and the United States. Human Development Research Paper, 2010/27.

Cheibub, J. A. (2010). How to include political capabilities in te HDI? An evaluation of alternatives. Human Development Research Paper, 2010/41.

EUROSTAT (2011). European Statistics Code of Practice. (Recuperado el 08 de octubre de 2015). http:// ec.europa.eu/eurostat/documents/3859598/5921861/KS-32-11-955-EN.PDF/5fa1ebc6-90bb-43fa888f-dde032471e15

IMF (2012). Data Quality Assessment Framework (DQAF) for National Accounts Statistics. (Recuperado el 08 de octubre de 2015). http://dsbb.imf.org/images/pdfs/dqrs_nag.pdf

Neumayer, E. (2010). Human Development and Sustentability. Human Development Research Paper, 2010/05.

Nussbaum, M. (2003). Capabilities as fundamental entitlements: Sen and social justice. Feminist Economics, $9(2-3)$.

OECD. (2008). Handbook on constructing composite indicators: methodology and user guide. Paris: OECD, JRC European Commission.

Orellana, A. (2015). ICVU 2015 - Índice de Calidad de Vida Urbana. Ciudades Chilenas. (Recuperado el 12 de enero de 2016). http://www.estudiosurbanos.uc.cl/images/noticias-actividades/2015/Mayo_2015/ PPT_ICVU_2015_Conferencia.pdf

Pagliani, P. (2010). Influence of regional, national and sub-national HDRs. Human Development Research Paper, 2010/19.

PNUD. (2014). Informe sobre desarrollo humano 2014. (Recuperado el 11 de mayo de 2015). http://www. undp.org/content/dam/undp/library/corporate/HDR/2014HDR/HDR-2014-Spanish.pdf

RIMISP (2014). Informe Latinoamericano de Pobreza y Desigualdad 2013. Santiago: RIMISP - Centro Latinoamericano para el Desarrollo Rural.

Sen, A. (1999). Desarrollo y Libertad. Madrid: Editorial Planeta.

SUBDERE (2009). Informe Índice de Competitividad Regional 2008. Santiago de Chile: Subsecretaría de Desarrollo Regional y Administrativo, Ministerio del Interior; Instituto Nacional de Estadísticas; Ministerio de Planificación.

SUBDERE (2013). Diseño metodológico de Índice de Comptetitividad Comunal / de Ciudades. (Recuperado el 10 de mayo de 2015).http://www.subdere.gov.cl/sites/default/files/documentos/indice_competitividad_ de_comunas_ciudades_metodologia.pdf

Vial, C. (2016). Índice de Desarrollo Regional - IDERE 2016. Santiago de Chile: Universidad Autónoma de Chile.

Vial, C. (2017). Índice de Desarrollo Regional - IDERE 2017. Santiago de Chile: Universidad Autónoma de Chile.

Vial, C. (2014). El proceso de descentralización en Chile y el desarrollo regional: un análisis del período 1990-2010. Memoria para optar al grado de Doctor, Universidad Complutense de Madrid, Madrid. 


\section{Capítulo II \\ LA BRECHA DE GÉNERO EN CHILE: ALGUNAS REFLEXIONES SOBRE TERRITORIO Y ESCENARIOS FUTUROS}

Andrea Gartenlaub Universidad Autónoma de Chile

Los últimos años del siglo XXI han sido el tiempo en que la causa de la mujer se convirtió nuevamente en emblema, no solo en Chile sino en todo el mundo. Por esta razón, este capítulo del Índice de Desarrollo Regional 2019 tiene como objetivo presentar el estado de algunas de las brechas que hoy afectan a la mujer en nuestro país y, de paso, trazar posibles escenarios frente al cambio demográfico y tecnológico que nos espera para las próximas décadas.

Sin embargo, antes de empezar explíquemos algunos conceptos básicos por los cuales aún existe cierta confusión, particularmente acerca de la diferencia entre igualdad y equidad de género.

En primer término, entendamos por «género» a la construcción sociocultural que configura el rol, comportamiento, estatus, y percepciones sobre mujeres y hombres en una sociedad. Esta construcción ha sostenido que las diferencias entre hombres y mujeres son naturales, y por esta razón, se ha puesto a la mujer en una posición subordinada durante siglos.

Este punto de partida es básico, siendo el origen de la emancipación femenina el pensamiento de mujeres ilustradas que comenzaron a cuestionar la condición de la mujer en la sociedad durante la Ilustración, ideas que posteriormente cuajaron, en un segundo período, en los movimientos sufragistas que lucharon por la obtención del derecho a voto a mediados del siglo XIX. Estos hitos constituyen el inicio de un gran arco (o de las llamadas olas del feminismo) que se extiende a un tercer período focalizado en la liberalización de los derechos reproductivos y sexuales entre las décadas de 1960 al 1980, para reaparecer, en 
esta última década, con movimientos mundiales — articulados a través de redes socialescontra el acoso sexual y la violencia machista.

En suma, a través de la historia, cada generación de mujeres ha reclamado su «igualdad» frente a la posición política, económica y social de sus pares masculinos.

Bajo esta premisa, la Asamblea General de la Naciones Unidas estableció durante la Convención sobre la Eliminación de todas las Formas de Discriminación contra la Mujer (CEDAW) de 1979, la necesidad de trabajar por la «igualdad de género». Este concepto — según consta en el glosario de ONU Mujeres- señala que el principio de «igualdad no significa que las mujeres y los hombres serán iguales, sino que los derechos, responsabilidades y oportunidades de mujeres y hombres no dependerán de si nacieron con determinado sexo»(Glosario del Centro de Capacitación de ONU Mujeres). Para enfatizar este principio, y tras la conferencia de Beijing del año 1985, se acordó no utilizar el término de "equidad de género", debido a que su interpretación muchas veces sesgada, se traduce en un detrimento hacia las mujeres, con ideas basadas en la tradición, costumbres, religión o cultura, que muchas veces no confluyen en la idea de igualdad.

Para ilustrar estas diferencias conceptuales en forma simple, señalemos las palabras de la filósofa española Amelia Valcárcel, quien resume el debate con la siguiente frase: "la igualdad es ética y la equidad es política" (Valcárcel, 2010, 98). Sin embargo, hasta hoy, la discusión sobre estos términos continúa, y aún es parte del debate académico. No obstante, lo que debe resaltar es el aporte del pensamiento feminista para los derechos de las mujeres, en el denominado principio de equivalencia humana (García, 2008, 42), es decir, como reconocemos a mujeres y hombres, como equivalentes en tanto seres humanos y sujetos de derechos.

\section{UNA DEUDA PENDIENTE: LA BAJA PARTICIPACIÓN EN EL MERCADO LABORAL}

Las cifras que entrega el IDERE 2019 reafirman algunos datos conocidos y, a la vez, nos permiten evidenciar cómo estas brechas se visibilizan cuando introducimos la variable territorial. Por ejemplo, y tal como ya lo sabemos - y han señalado consistentemente mediciones nacionales e internacionales_- las mujeres chilenas cuentan con más años de escolaridad en promedio que los hombres, sin embargo, la brecha salarial es alta y la participación laboral es baja en comparación con el resto de América Latina, y más aún, frente a la mayoría de los países de la Organización para la Cooperación y el Desarrollo Económicos (OCDE).

Pero este tema va más allá de la simple estadística y de los rankings internacionales. Es una muestra de lo urgente de proponer medidas para lograr una paridad entre géneros en las distintas dimensiones asociadas al desarrollo de un país, pero especialmente en la brecha que mide la actividad económica. 
Sabemos que globalmente las mujeres son menos propensas que los hombres a participar en el mercado laboral, es decir, a estar empleadas o estar en la búsqueda activa de un empleo. Según la Organización Internacional de Trabajo, el año 2017 la tasa global de participación de las mujeres en la fuerza laboral representó solo el $49 \%$ de la fuerza laboral mundial, con una diferencia de 27 puntos más para los hombres, quienes alcanzaron el 76\%; y no esperándose mejoras para las mediciones del año 2018 (OIT, 2017, 5).

Chile no escapa a esta tendencia mundial: en nuestro país las mujeres constituyen más del 50\% de la población según el Censo del año 2017, contando a unas 8.972 .014 habitantes. Sin embargo, su participación promedio en el mercado laboral apenas alcanza el $48 \%$, muy por debajo del $71 \%$ que representan los hombres (INE, 2017). Lo anterior, a pesar de que en los últimos 30 años se incorporaron 2.4 millones de mujeres al mercado del trabajo nacional. De hecho, la Encuesta Laboral de la Dirección de Trabajo (ENCLA) de 2014 nos señala un persistente incremento a lo largo de tres décadas, con una tasa de participación que creció desde un 29,1\%, en 1986, a un 48,7\% para el año 2015.

Pese a ello, Chile aún está muy lejos de alcanzar las tasas de participación de los países de la OCDE, que para el año 2017 situaron a Chile como el sexto país con menor participación laboral femenina del bloque, con apenas un 54,1\%, muy lejos de Holanda con casi un $80 \%$. A esto debemos sumar ser uno de los países peor posicionados en el porcentaje de mujeres que poseen cargos de responsabilidad. Por ejemplo, el estudio nacional realizado por Comunidad Mujer, para el año 2018, revela la escasa representación femenina en los gobiernos corporativos de las grandes empresas chilenas transadas en la bolsa, la cual alcanza un reducido 6,2\% como promedio (Comunidad Mujer, 2018, 7), muy ajeno al promedio mundial de $17,5 \%$ y muchísimo menos que el $25 \%$ que exhiben países europeos para este tipo de cargos y su distribución por género.

Este problema no debe mirarse solo como la necesidad de reconocimiento de la bajísima representación de la mujer en los puestos de trabajo, sino también como un asunto de justicia equitativa. Es decir, la brecha de salario y posibilidad de lograr empleo (un empleo de calidad, justamente remunerado y con servicios sociales adicionales), no solo debería ser relevante para las mujeres, sino para toda la sociedad en su conjunto.

Sobre este punto, hay consecuencias muy evidentes al no incorporar a más mujeres a la fuerza laboral, ya que más allá de la pérdida de talento, lo que aquí se produce es una pérdida de recursos. Varios estudios señalan que una posible mayor participación de la mujer en el mercado laboral ayudaría a los países a mejorar sus resultados económicos. Por ejemplo, la pérdida de ingreso por la falta de incorporación de mujeres a la fuerza laboral se calcula, en promedio, para el mundo en un 13,5\% (Cuberes \& Teignier, 2014). Siendo la región con mayores pérdidas de ingreso, el Medio Oriente y el norte de África, con un promedio del 27\%, seguido por países del Sudeste Asiático, con un 19\%, y la región Latinoamérica y el Caribe, con pérdidas estimadas de un 14\% (Cuberes \& Teignier, 2014, 21). 
Bajo esta mirada, un estudio del año 2014 del Servicio Nacional de la Mujer (SERNAM) nos dice que la variable asociada a un posible aumento en la participación económica estaría relacionada con una mayor escolaridad. Según este informe, «las mujeres con educación básica completa tienen una tasa de participación de 36,9\%, que asciende a un $52,7 \%$ para las que completaron su educación media humanista, y a 76,8\% para las que han completado estudios de técnico superior o profesionales» (SERNAM, 2014, 18). Sin embargo, esto no se refleja en sus salarios ni en el alto porcentaje de población femenina inactiva. En Chile, por ejemplo, 4 de cada 10 mujeres está fuera de la fuerza de trabajo por «razones familiares permanentes» (INE, 2017).

Se suma a ello, la alta brecha salarial. Recientemente, el Programa de las Naciones Unidas para el Desarrollo (PNUD) —en su análisis correspondiente al año 2018—entregó nuevos datos sobre la brecha salarial que afecta a las chilenas, por medio del cálculo del Producto Interno Bruto per cápita por sexo. El resultado concluyó que para el año 2017, el PIB per cápita por sexo, estimado para los hombres chilenos, alcanzó 28.809 dólares americanos (unos 19 millones de pesos anuales), mientras que para las mujeres llegó solo a la mitad, unos 15.137 USD (un poco más de 10 millones de pesos chilenos).

\section{LAS CIFRAS DEL IDERE 2019}

Lamentablemente, las cifras entregadas por el IDERE 2019 tampoco nos traen buenas noticias.

Por ejemplo, la dimensión de Educación desarrollada por el IDERE evidencia que las chilenas efectivamente poseen mejores niveles, siendo de 0.691 para las mujeres, en comparación a 0.620 para los hombres, tal como se puede observar en la Tabla 1. En tanto, si hablamos de la incorporación al mercado laboral, nuevamente la brecha de empleo se evidencia al analizar los resultados de la dimensión de Actividad económica del IDERE 2019 , la cual presenta una diferencia desfavorable para las mujeres con 0.410 puntos, en comparación a 0.523 para los hombres, según se expresa en la Tabla 2. 
Índice de Desarrollo Regional $\bullet$ IDERE 2019

Tabla 1

Brechas de género en dimensión Educación - IDERE 2019

\begin{tabular}{lcc}
\hline \multirow{2}{*}{ Región } & \multicolumn{2}{c}{ Educación } \\
\cline { 2 - 3 } & Hombres & Mujeres \\
\hline Arica y Parinacota & 0.742 & 0.826 \\
Tarapacá & 0.636 & 0.689 \\
Antofagasta & 0.748 & 0.780 \\
Atacama & 0.614 & 0.697 \\
Coquimbo & 0.598 & 0.660 \\
Valparaíso & 0.699 & 0.746 \\
Metropolitana & 0.735 & 0.769 \\
O’Higgins & 0.512 & 0.603 \\
Maule & 0.501 & 0.620 \\
Biobío & 0.610 & 0.686 \\
Araucanía & 0.563 & 0.631 \\
Los Ríos & 0.592 & 0.636 \\
Los Lagos & 0.609 & 0.673 \\
Aysén & 0.494 & 0.613 \\
Magallanes & 0.654 & 0.739 \\
\hline
\end{tabular}

Fuente: elaboración propia. 
Tabla 2

Brechas de género en dimensión Actividad económica - IDERE 2019

\begin{tabular}{lcc}
\hline \multirow{2}{*}{ Región } & \multicolumn{2}{c}{ Actividad económica } \\
\cline { 2 - 3 } & Hombres & Mujeres \\
\hline Arica y Parinacota & 0.610 & 0.380 \\
Tarapacá & 0.329 & 0.347 \\
Antofagasta & 0.169 & 0.244 \\
Atacama & 0.319 & 0.392 \\
Coquimbo & 0.334 & 0.283 \\
Valparaíso & 0.392 & 0.270 \\
Metropolitana & 0.423 & 0.367 \\
O’Higgins & 0.529 & 0.291 \\
Maule & 0.642 & 0.457 \\
Biobío & 0.384 & 0.265 \\
Araucanía & 0.415 & 0.096 \\
Los Ríos & 0.717 & 0.570 \\
Los Lagos & 0.807 & 0.674 \\
Aysén & 0.916 & 0.701 \\
Magallanes & 0.861 & 0.813 \\
\hline
\end{tabular}

Fuente: elaboración propia.

En este punto, es interesante observar cómo se comporta la brecha de incorporación a la actividad económica por regiones. Por ejemplo, las mayores diferencias entre índices para la dimensión de Actividad económica entre hombres y mujeres se presentan en las regiones de Arica y Parinacota (0.230), O’Higgins (0.238), Araucanía (0.319) y Aysén (0.215), siendo particularmente importante el diferencial en La Araucanía (Tabla 2). Esto permite visualizar cómo el sesgo de género repercute en la empleabilidad femenina, ya que la principal actividad económica de la región es la ganadería, área donde las mujeres están débilmente incorporadas (SERNAM, 2016).

Las menores diferencias, por su parte, están en la zona norte, en las regiones de Tarapacá (-0.018), Antofagasta (-0.075) y Coquimbo (0.051), y también en la Región Metropolitana (0.056) y Magallanes (0.048). En todas estas regiones la principal actividad económica de las mujeres se ubica principalmente en la rama de Comercio, tanto como trabajadoras asalariadas y/o por cuenta propia (SERNAM, 2016). Así también en la Región Metropolitana, la segunda actividad económica más usual en las mujeres se concentra en la manufactura, mientras que en Magallanes, en las ramas de construcción y transporte (SERNAM, 2016).

Por un lado, estas cifras reafirman la idea que —en general— los trabajadores más calificados tienden a moverse a las áreas más densas y con mayor desarrollo (Glaeser \& 
Maré, 2001; Combes et al., 2008), lo cual es coherente con el menor diferencial entre los índices de actividad económica entre hombres y mujeres en la zona norte, Magallanes y Región Metropolitana, resultados esperables debido a que son las zonas con mayor desarrollo del país.

Cabe señalar que, hasta ahora, es escasa la literatura que ha estudiado la diferencia salarial de género desde la perspectiva territorial (Castaño \& Paredes, 2015), siendo las estadísticas del IDERE una contribución valiosa para futuros trabajos en esta materia.

\section{MAYOR VIOLENCIA INTRAFAMILIAR EN REGIONES CON MENOS DESARROLLO}

La Seguridad es otra de las grandes brechas que enfrenta la mujer chilena. En este sentido, la inseguridad es, por cierto, un tema de género, y que está muy vinculado con el acceso al empleo y, por ende, con la autonomía económica, especialmente cuando analizamos las causas de los índices de violencia intrafamiliar (VIF) que afectan a las chilenas, ya que «la autonomía relativa que otorga a las mujeres el ganar dinero por cuenta propia, independientemente de la pareja, es una situación precursora de menor incidencia de la violencia conyugal» (SERNAM, 2009, 87).

Así por ejemplo, investigaciones como la realizada por el Servicio Nacional de la Mujer en el año 2009, ya evidenciaban la estrecha vinculación de la mayor prevalencia de violencia intrafamiliar en áreas rurales y en sectores económicos menos desarrollados, esto debido a la mayor dependencia económica de la mujer frente a sus parejas. Los resultados del informe del IDERE 2019 confirman lo anterior, tal como se puede ver en la Tabla 3. Los territorios menos dinámicos en términos económicos poseen mayores grados de prevalencia de VIF. En este sentido, hay implicancias de políticas públicas para este resultado, principalmente, en la visualización de la relación de la dependencia económica y la violencia al interior de la pareja o los hogares, lo cual empuja a pensar en alternativas de empleo para las regiones con mayor prevalencia de VIF, particularmente Arica y Parinacota, Tarapacá, La Araucanía, Los Lagos y Aysén. Así, por el contrario, la menor prevalencia se encuentra en las regiones de Coquimbo, de Valparaíso, Metropolitana, Biobío y Magallanes, zonas económicamente más activas y con más oportunidades laborales. 
Tabla 3

Brechas de género en dimensión Seguridad - IDERE 2019

\begin{tabular}{lcc}
\hline \multirow{2}{*}{ Región } & \multicolumn{2}{c}{ Seguridad } \\
\cline { 2 - 3 } & Hombres & Mujeres \\
\hline Arica y Parinacota & 0.720 & 0.389 \\
Tarapacá & 0.520 & 0.171 \\
Antofagasta & 0.613 & 0.377 \\
Atacama & 0.704 & 0.468 \\
Coquimbo & 0.649 & 0.493 \\
Valparaíso & 0.602 & 0.485 \\
Metropolitana & 0.518 & 0.499 \\
O’Higgins & 0.676 & 0.467 \\
Maule & 0.725 & 0.555 \\
Biobío & 0.694 & 0.570 \\
Araucanía & 0.694 & 0.389 \\
Los Ríos & 0.728 & 0.469 \\
Los Lagos & 0.752 & 0.407 \\
Aysén & 0.811 & 0.439 \\
Magallanes & 0.866 & 0.653 \\
\hline
\end{tabular}

Fuente: elaboración propia.

\section{LA LARGA ESPERANZA DE VIDA DE LAS MUJERES CHILENAS}

Según el reporte del año 2017 de la Organización Panamericana de la Salud (OPS), la esperanza de vida de una mujer chilena alcanzó los 85 años, mientras que para los hombres llegó a los 80. Ambas cifras nos ubica entre los países del mundo con mayor esperanza de vida, pero nos enfrenta a nuevos y urgentes desafíos en esta materia.

Bajo este nuevo escenario, y como era de esperar, los resultados para la dimensión de Salud del IDERE nos muestran brechas a favor de la mujer, señalando un resultado de 0.785 para la población femenina, en comparación con un 0.314 para los hombres, como nos presenta la Tabla 4. 
Tabla 4

Brechas de género en dimensión Salud - IDERE 2019

\begin{tabular}{lcc}
\hline \multirow{2}{*}{ Región } & \multicolumn{2}{c}{ Salud } \\
\cline { 2 - 3 } & Hombres & Mujeres \\
\hline Arica y Parinacota & 0.334 & 0.790 \\
Tarapacá & 0.349 & 0.956 \\
Antofagasta & 0.309 & 0.741 \\
Atacama & 0.671 & 0.739 \\
Coquimbo & 0.208 & 0.833 \\
Valparaíso & 0.441 & 0.840 \\
Metropolitana & 0.429 & 0.819 \\
O’Higgins & 0.301 & 0.769 \\
Maule & 0.338 & 0.783 \\
Biobío & 0.248 & 0.816 \\
Araucanía & 0.225 & 0.690 \\
Los Ríos & 0.146 & 0.564 \\
Los Lagos & 0.167 & 0.814 \\
Aysén & 0.237 & 0.972 \\
Magallanes & 0.313 & 0.642 \\
\hline
\end{tabular}

Fuente: elaboración propia.

Lo interesante de esta dimensión — a diferencia de otras como Educación, Actividad económica, Seguridad - es que exhibe un comportamiento muy homogéneo a lo largo del territorio nacional, no presentando mayores variaciones asociadas a zonas extremas o menos desarrolladas económicamente, exceptuando un promedio menor solo para la Región de Los Ríos.

De forma clara, este resultado nacional se explica a causa de la mayor esperanza de vida de los chilenos en general, pero la brecha entre géneros posiblemente se entienda mejor debido al uso dentro del Índice de unos de los indicadores más representativos para determinar la salud de las poblaciones: Años de Vida Potenciales Perdidos (AVPP), el cual calcula el número de fallecimientos prematuros y/o la muerte de personas jóvenes. El supuesto en que se basa el AVPP, es que cuando más prematura es una muerte, mayor es la pérdida de vida. El AVPP permite señalar las desigualdades en salud, buscando conocer las diferencias entre grupos, especialmente las expectativas de vida para ambos sexos. Como era de esperar, la diferencia para los Años de Vida Potenciales Perdidos fue favorable para la mujer 0.907, en comparación con 0.131 para los hombres.

Pero, ¿cuáles son las implicancias de este resultado? Si bien ser mujer en Chile puede entenderse como un factor de protección, lo anterior no asegura que vivir más años sea un sinónimo de una buena sobrevida, especialmente debido a que el envejecimiento se 
encuentra asociado a múltiples factores que podrían acortar la esperanza de vida de las chilenas mayores.

Esto no solo tiene que ver con cuadros asociados a multimorbilidad — muy usuales en los adultos mayores-, sino también están vinculados a factores económicos y sociales, más importantes que, por ejemplo, contar con un ingreso alto y mayor poder adquisitivo. En este sentido, la mantención de redes familiares y vínculos sociales (amigos y participación en la comunidad) incentivan la búsqueda de atención médica y permiten una mejor adherencia a los tratamientos, dos puntos cruciales para disfrutar de una mayor longevidad y, por cierto, con mejor calidad de vida. Siendo, sin duda, el mayor grado de inserción y sociabilidad lo que a la larga serán las claves que impactarán en la menor mortalidad de los adultos mayores (Moreno et al., 2017).

Tener en cuenta la interrelación de estas variables, serán las referencias que como sociedad nos ayudarán a enfrentar nuevos desafíos en el diseño de políticas públicas pensadas no solo en la cantidad y diseño de servicios disponibles para dar respuesta, no solo desde la medicina, sino también desde la comunidad a las distintas dimensiones sociales y emocionales que configuran la vida humana.

\section{REFLEXIONES: LO URGENTE, LO IMPORTANTE Y EL FUTURO EN MATERIA DE GÉNERO}

A nivel mundial, los últimos cinco años han sido cruciales para reconfigurar, rearticular y dar un nuevo impulso al movimiento feminista alrededor del mundo, y sobre todo posicionar en la agenda global el enfoque de género. Esto ocurrió gracias a la onda expansiva de un círculo virtuoso de movimientos y demandas sociales que — por muy distintas razones- confluyeron e instalaron la necesidad de establecer una cultura de respeto y de igualdad para la mujer en diversos ámbitos de su vida diaria, y que han buscado reafirmar su presencia durante este nuevo siglo.

Estos movimientos han tenido un impacto internacional, aunque sus gatillantes fuesen problemas locales: casos de extrema violencia sexual en India; la campaña contra los feminicidios iniciada en el 2015 en Argentina, «Ni una menos», que se extendió por toda América Latina; el movimiento «Me too» contra la instalada práctica del acoso sexual en la sociedad norteamericana; o el reciente movimiento universitario chileno en pos de eliminar el acoso sexual de las aulas, son algunos de los ejemplos de esta rearticulación global.

En suma, las demandas femeninas alrededor del planeta se tomaron la agenda, reflejando que el reciente y masivo movimiento no es tema de una élite o de un grupo de estudiantes, es un hecho rotundo, que se manifiesta en distintos espacios sociales y en la práctica social del día a día, resignificando la simbología cultural de lo «femenino» y lo «masculino». 
Particularmente esencial en esta simbología, es que se refuerza de forma dramática dentro del mundo laboral. Tanto expertos en el tema como la propia Organización Internacional del Trabajo han señalado que la división sexual del trabajo no solo mantiene a las mujeres en las tareas domésticas y de cuidado, sino también explica la razón de la concentración de población femenina en ciertas actividades vinculadas a su estereotipo de género (el llamado «Muro de cristal»), y donde podemos apreciar la diferencia de asignación por puesto y por distribución por rama de actividad económica, particularmente ubicadas en las áreas de Salud, Educación y Comercio.

Se suma a esto la dificultad de las mujeres de lograr puestos de poder o influencia. Así, siendo el mundo laboral un espacio jerarquizado, hasta hoy las posiciones gerenciales o de influencia siguen a cargo de hombres, produciéndose lo que llamamos «Techo de cristal».

Ambas metáforas, el «Muro...» como el «Techo de cristal», son ilustrativas para entender por qué el trabajo remunerado de las mujeres aún es una prolongación del rol de cuidado tradicionalmente asignado a ellas a lo largo de la historia.

Este punto es esencial e importante, porque nos permite entender cuáles son los factores que explican la baja participación de las mujeres en la actividad económica dentro del país. De hecho, la perspectiva de género nos ha permitido comprender que no es que las mujeres trabajen menos que los hombres; lo hacen, de hecho, y a veces en jornadas más largas. Sin embargo, su trabajo doméstico y de cuidado ha sido invisibilizado y desvalorizado, debido a que (aparentemente) no produce excedentes ni es cuantificable. Es allí, justamente, donde radica una de las mayores desigualdades de género que afectan a las mujeres en Chile y en todo el mundo.

En suma, en un corto plazo existen esperanzas fundadas en que la participación laboral pueda aumentar con la llegada de nuevas generaciones de mujeres y hombres, más educados y conscientes, que comenzarán a exigir y crear mejores condiciones laborales, particularmente en conciliar de mejor forma el trabajo no remunerado con trabajos de calidad, y con una repartición equitativa de las labores de crianza y cuidado. Por otro lado, los gobiernos y la sociedad civil deberán llegar a nuevos acuerdos para pensar en cómo convivirán con una gran proporción de su población envejecida, y donde la mayoría de estos ancianos serán, de hecho, mujeres.

Antes de terminar, es necesario recalcar que hay otras barreras que no se ahondan en este informe, y que tienen que ver con la baja representación política de las mujeres chilenas en los cargos de representación popular, siendo esta una labor deseada y necesaria para relevar y proponer estos temas en la agenda pública, de legisladores/as y en los gabinetes ministeriales. Es una deuda pendiente para próximos informes conocer cómo interactúan, por ejemplo, las diferencias regionales con las variables educacionales, de incorporación a la actividad económica, frente a la participación política, tanto como mujeres-votantes y en su rol de candidatas a puestos de representación popular, para conocer si efectivamente la Ley de Cuotas ha jugado un rol en la incorporación de mujeres en el Congreso nacional. 
En definitiva, la brecha de género no es solo asunto de mujeres: el envejecimiento de la población y la necesidad de crear trabajos que puedan compatibilizar la vida familiar, nos desafía prontamente a pensar cambios notables en las rutinas laborales y en el transporte de la población que cada día se encarecen, son poco eficientes, poco ecológicos, en suma, obsoletos. Junto a ello, deberemos idear reformas urgentes en materia de previsión social, telemedicina y de autocuidado en casa para nuestros adultos mayores.

No hay duda que son varios los cambios que nos esperan en este siglo. Pero de algo sí estamos seguros. La sociedad que nos espera tendrá rostro de mujer. 


\section{BibLIOGRAFÍA}

Brechas, barreras e inequidades de género de mujeres por Región (2016). Documento de Trabajo de la División de Estudios y Capacitación en Género. Ministerio de la Mujer y la Equidad de Género. Santiago, Chile.

Cuberes, D. \& Teignier, M. (2014). Aggregate effect of the gender gaps in labor market: a quantitative estimate. UB Economics Working Papers 2014/308. Universitat de Barcelona.

Castaño, A. \& Paredes, D. (2015). The effect of the spatial density of firms on gender wage gap. Documentos de Trabajo en Economía y Ciencia Regional. No55, Universidad Católica del Norte, Chile, Departamento de Economía. Antofagasta, Chile.

Detección y Análisis de la Prevalencia de la Violencia Intrafamiliar en la Región de Los Lagos (2009). Servicio Nacional de la Mujer / Corporación Humanas. Documento de trabajo. № 106. Santiago, Chile.

Encuesta Laboral (2014). Informe de Resultados Octava Encuesta Laboral. Departamento de Estudios de la Dirección del Trabajo. Santiago, Chile.

Estructura de Restricciones a la Participación Laboral y a la Autonomía Económica de las Mujeres: Estudio orientado a Mejorar las Políticas de Equidad de Género (2014). Serie de Estudios. Servicio Nacional de la Mujer, SERNAM. Departamento de Estudios y Capacitación. Santiago, Chile.

García, E. (2008). Políticas de Igualdad, Equidad y Gender Mainstreaming ¿de qué estamos hablando?. Documento del Área de Género del Centro Regional del PNUD para América Latina y el Caribe, Agència Catalana de Cooperació al Desenvolupament y Fondo Fiduciario España-PNUD «Hacia un desarrollo integrado e inclusivo en América Latina y el Caribe».

Glosario del Centro de Capacitación de ONU Mujeres. Recuperado de: https://trainingcentre.unwomen. org/mod/glossary/view.php.

International Labour Organization, ILO (2017). World Employment and Social Outlook: Trends for women 2017. International Labour Office - Geneva.

Moreno, X.; Albala, C.; Lera, L.; Sánchez, H.; Fuentes-García, A. \& Dangour, A. (2017). The role of gender in the association between self-rated health and mortality among older adults in Santiago. Chile: A cohort study. PLoS ONE 12(7): e0181317. https://doi.org/10.1371/journal.pone.0181317

Mujeres en Chile y mercado del trabajo: Participación laboral femenina y brechas salariales (2015). Departamento de Estudios Laborales y Departamento de Estudios Sociales. Instituto Nacional de Estadísticas. Santiago, Chile.

Ranking de Mujeres en la Alta Dirección (2018). Autores: Empresas IPSA. Comunidad Mujer, Chile.

Valcárcel, Amelia (2010). Citada por G. Villegas \& J. Toro, en La igualdad y la equidad: dos conceptos claves en la agenda de trabajo de los profesionales de la familia. Revista de Estudios de la Familia. Vol. 2, enero - diciembre, 2010, pp. 98-116. 



\section{CAPÍTUlo III Resultados IDERE 2019}

M. Camilo Vial Cossani Instituto Chileno de Estudios Municipales, Universidad Autónoma de Chile Alejandra Parrao Instituto Chileno de Estudios Municipales, Universidad Autónoma de Chile

A continuación, se exponen los resultados del IDERE $2019^{5}$. Estos se dividen en dos partes: análisis del IDERE global y apertura por dimensiones. Además, en los anexos se presentan los principales resultados por región a través de cuadros resúmenes.

Como se ha realizado anteriormente, además del ranking propio de un índice de estas características, se han establecido tres niveles de desarrollo relativo para comparar regiones: alto, intermedio y bajo. Esos rangos se aplican tanto al IDERE global como a cada una de sus dimensiones y, además, varían entre sí. Los rangos de dichos niveles se construyeron a partir del método natural breaks (cortes o umbrales naturales), estableciendo los parámetros de acuerdo a los resultados de cada dimensión. Se tomó esta decisión porque el IDERE no es un indicador inequívoco que refleje los niveles de desarrollo. Más bien, tiene el propósito de ser orientativo sobre los estadios de desarrollo de cada región.

\section{IDERE GLOBAL 2019}

La Tabla 5 muestra los resultados del IDERE 2019 y sus siete dimensiones, con las regiones ordenadas de mayor a menor de acuerdo al índice global, en un ratio que va de 0 a 1 (donde 0 es mínimo desarrollo y 1 el máximo). Además, los colores atribuidos a las regiones representan los niveles relativos de desarrollo, donde el más oscuro representa mayor desarrollo y el más claro menor desarrollo.

5 Los datos utilizados para la construcción del Índice son de 2017, ya sean reales o estimados a dicho año (ver Anexo). 
Respecto del IDERE 2017, en la presente edición todas las regiones tuvieron un mejor desempeño que en la medición anterior, salvo Tarapacá, que pasó de 0,529 a 0,508. El promedio del país en el índice de 2017 fue de 0,503, mientras que en 2019 es 0,534.

En segundo lugar, Magallanes se posiciona como la región con mayor desarrollo en el país, obteniendo 0,648 en el Índice, por sobre la Región Metropolitana (0,615), que ostentaba el primer lugar el año pasado. Luego, Valparaíso $(0,577)$ y Antofagasta $(0,567)$ completan el conjunto de regiones de mayor desarrollo relativo.

A continuación, en el grupo mayoritario, se encuentran ocho regiones con un nivel de desarrollo medio. Estas corresponden a Los Ríos — que sube dos posiciones- $(0,542)$, Atacama y Aysén (0,539), Biobío (0,538), Coquimbo (0,517), Los Lagos (0,510), Tarapacá $(0,508)$ y Arica y Parinacota $(0,505)$. Los casos con cambios significativos respecto del año pasado son Tarapacá, que pasa de ubicarse de la $5^{\circ}$ a la $11^{\circ}$ posición, y Aysén, que ingresa a la parte alta de este grupo $\left(7^{\circ}\right)$ tras haber estado en la zona de rezago $\left(13^{\circ}\right)$. Finalmente, en el grupo de menor desarrollo se encuentran las regiones de O'Higgins $(0,486)$-que ingresa este año-, Maule $(0,471)$ y La Araucanía $(0,458)$ — que se mantienen de manera consistente en este grupo-. 


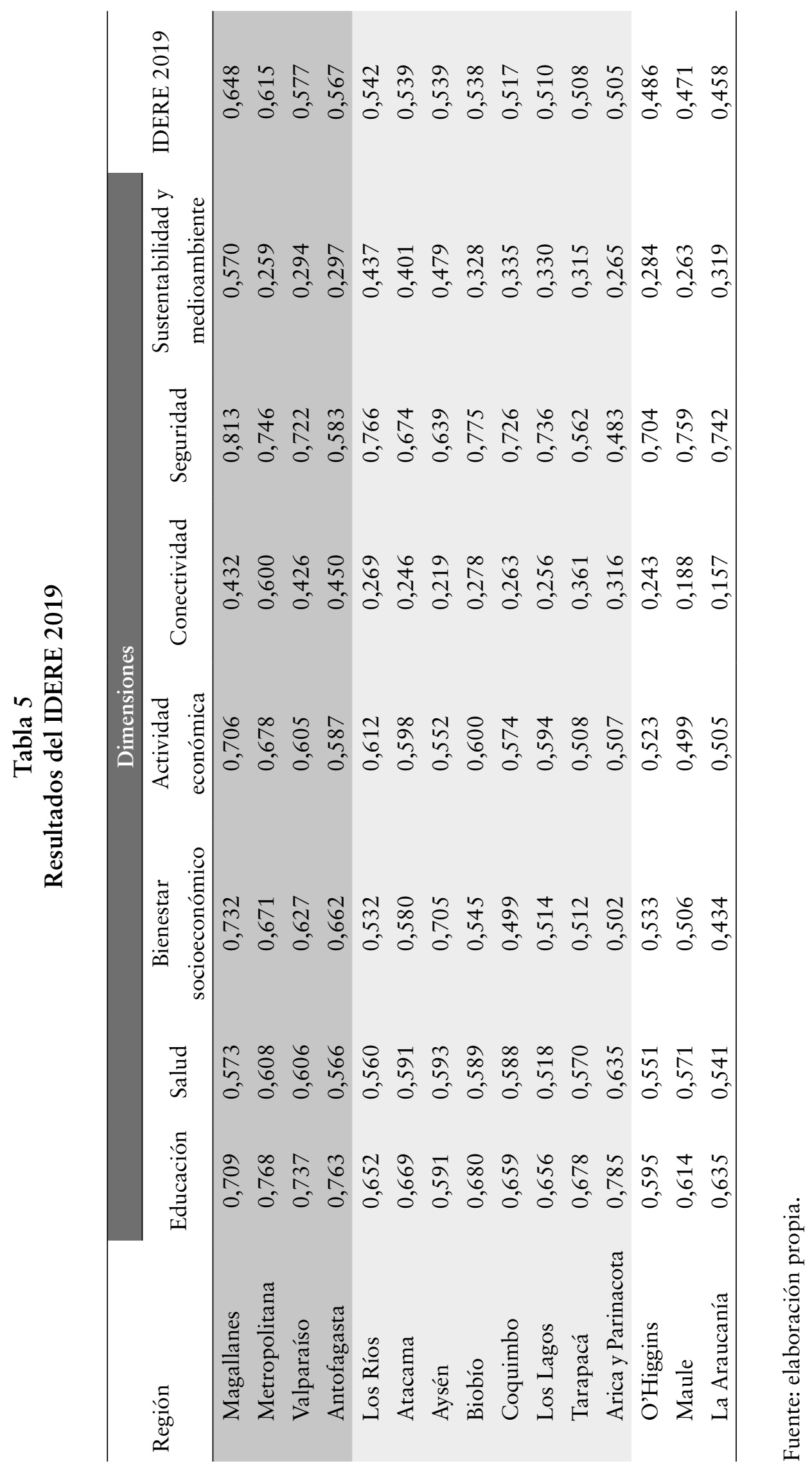


Desde el punto de vista de la distribución espacial del IDERE (ver Figura 2), se aprecia que la mayor concentración de desarrollo se despliega en el centro y en algunas regiones del norte grande y la zona austral, mientras que la zona centro-sur es la que se presenta en peor posición relativa. 


\section{Figura 2}

\section{Distribución espacial del IDERE $2019^{6}$}
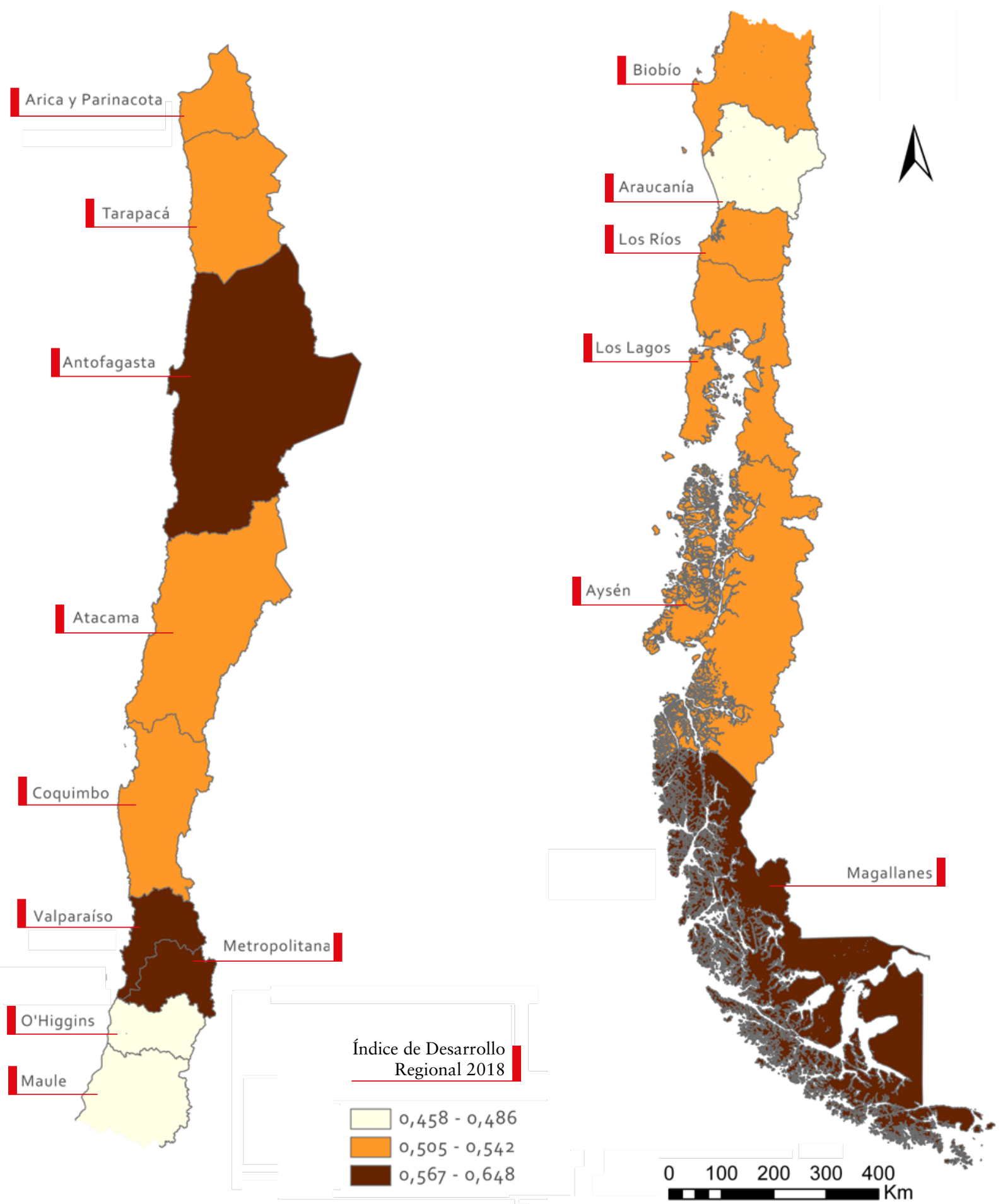

Fuente: elaboración propia a partir de fuente cartográfica de la biblioteca del Congreso Nacional dde Chile.

6 Tanto para esta figura como para las próximas, por solución cartográfica se suprimieron algunos territorios insulares, como fiordos en el sur de Chile. Asimismo, los rangos de las figuras presentadas se construyeron a partir del método natural breaks (umbrales o cortes naturales) mediante el programa ArcGIS 10.5. 


\section{TENDENCIA HISTÓRICA DEL IDERE}

El análisis de la evolución histórica del IDERE solo se puede realizar sin considerar la dimensión Sustentabilidad y medioambiente. Dada la falta de disponibilidad de datos para la totalidad de variables y regiones en los años previos, esta dimensión solo ha estado disponible desde la versión 2017 en adelante. Con el objeto de que las cifras expuestas a continuación sean comparables, se considerará únicamente el IDERE en su versión original, es decir, excluyendo la dimensión Sustentabilidad y medioambiente. La Figura 5 y la Tabla 6 muestran la evolución del IDERE global de 2010 a 2019.

\section{Figura 3}

Evolución del IDERE 2010-2019 (sin dimensión Sustentabilidad y medioambiente)

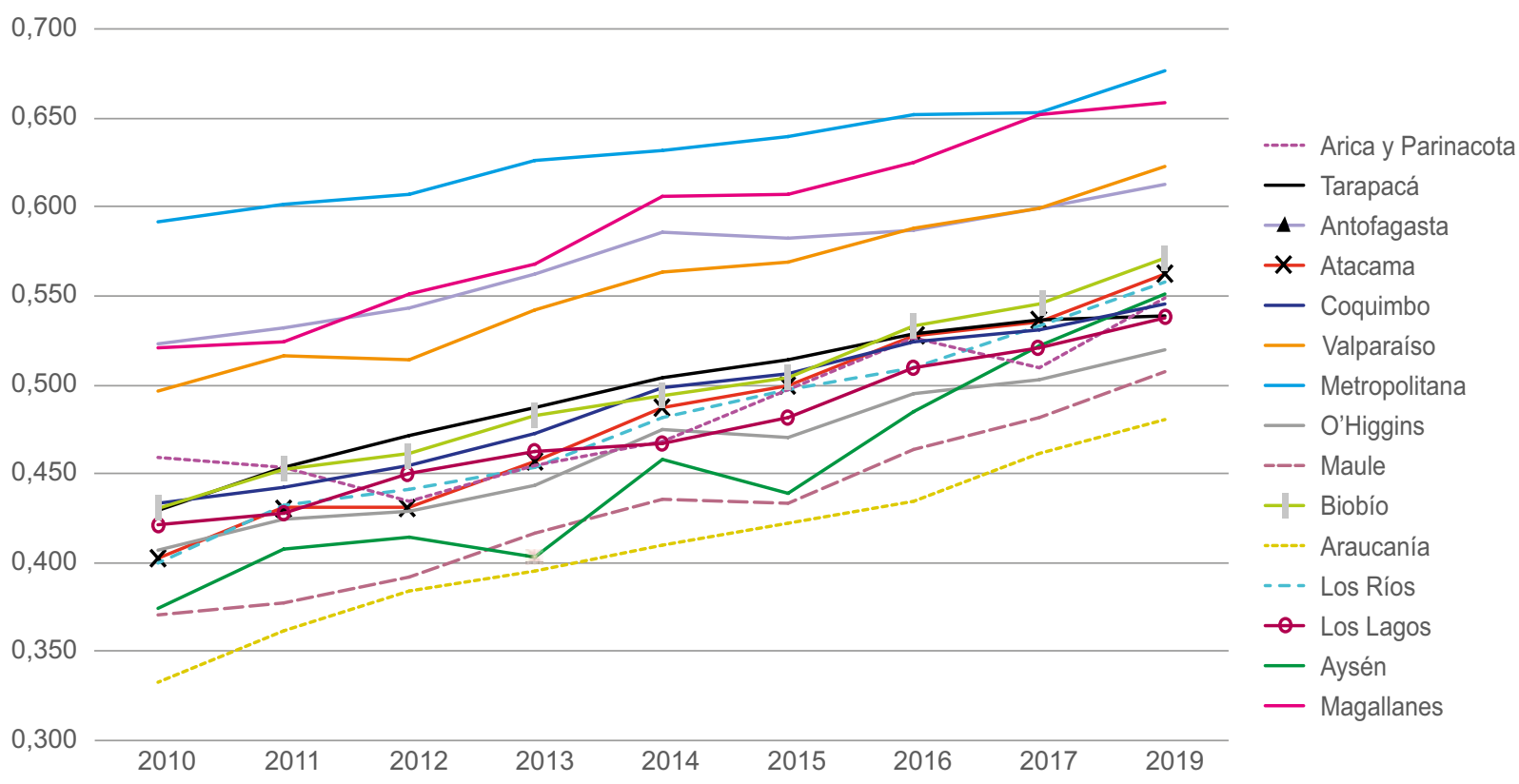

Fuente: elaboración propia. 
Índice de Desarrollo Regional • IDERE 2019

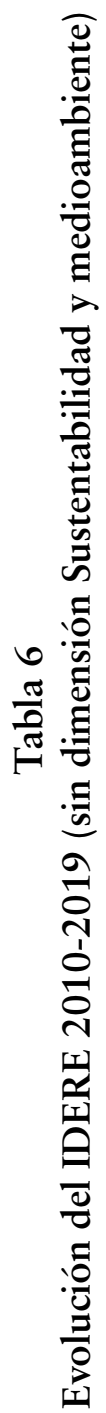

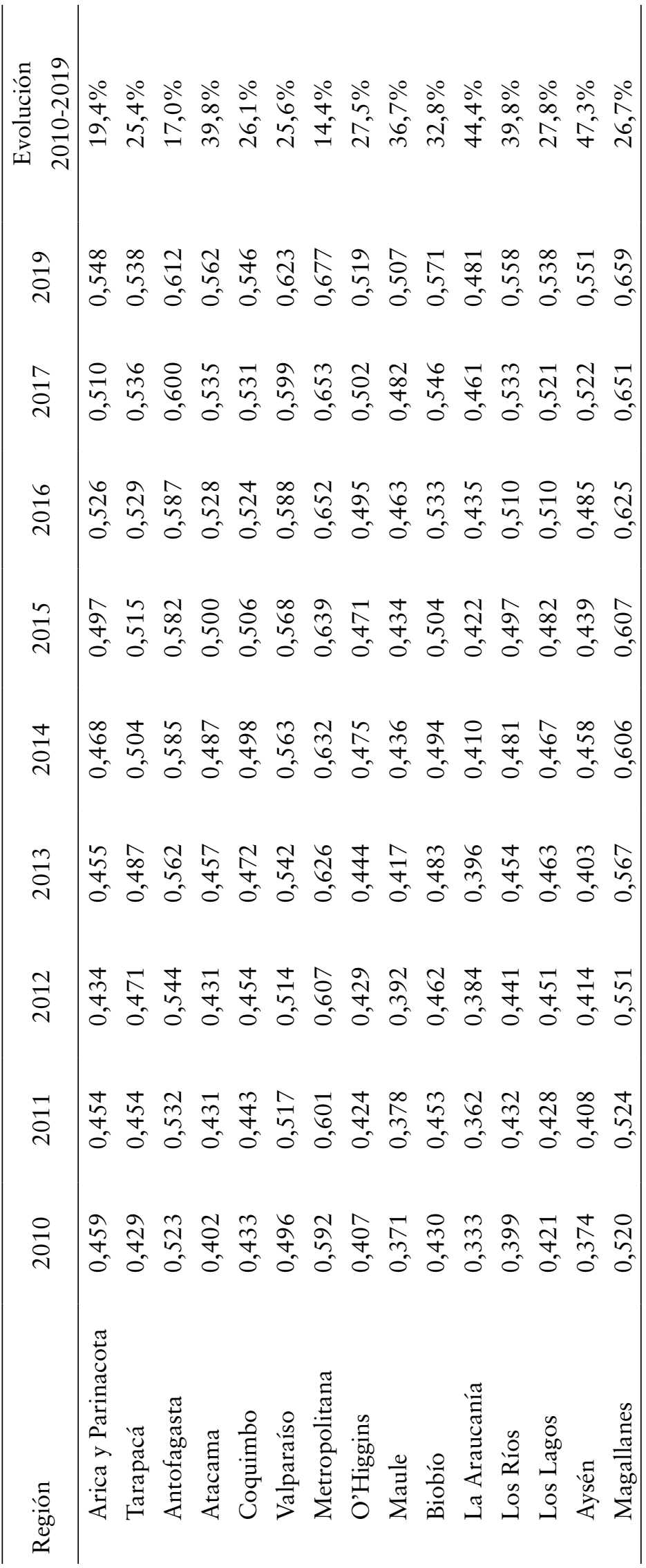

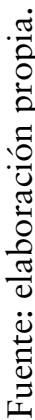


Durante el período 2010-2019, la tendencia de todas las regiones ha sido la mejora de sus indicadores (ver Figura 5). No obstante, existen diferentes ritmos de desarrollo. La Región Metropolitana, que durante las versiones 2016 y 2017 se ubicó en el primer lugar del índice y en la actual se encuentra segunda, es la que ha presentado los cambios más moderados, mostrando un incremento de un $14,4 \%$. Las otras regiones de la parte alta presentan una evolución más bien moderada dentro del conjunto, como Magallanes (26,7\%), Valparaíso $(25,6 \%)$ y en menor medida Antofagasta $(17,0 \%)$.

Por el contrario, varias regiones han presentado una mejora sustancial en el período 2010-2019. Dentro de las regiones con menos índice de desarrollo, destaca —a nivel nacional- especialmente la evolución de La Araucanía (44,4\%), cuya cifra es alentadora si se considera que dicha región ha estado sistemáticamente en el último lugar del Índice. La Región del Maule (penúltima en el Índice) también presenta una evolución bastante favorable $(36,7 \%)$, lo cual ocurre en menor medida con O'Higgins $(27,5 \%)$. Si bien se cuenta con un período muy reducido para hacer un análisis de convergencia, al parecer algunas de las regiones con menor desarrollo son las que más evolucionan con el tiempo (La Araucanía y Maule, principalmente), mientras que las de mayor desarrollo tienen un progreso más lento (Metropolitana, Antofagasta, Valparaíso y Magallanes). La gran excepción a esta tendencia general es Arica y Parinacota, que también se encuentra en una posición rezagada, pero su evolución ha sido más bien moderada-baja respecto del conjunto, tendencia que podría empeorar en el mediano plazo su ubicación.

Las regiones en el nivel de desarrollo medio oscilan entre un nivel de desarrollo medio y medio-alto, destacando regiones como Aysén (47,3\%), Los Ríos (39,8\%), Atacama $(39,8 \%)$ y Biobío $(32,8 \%)$. La evolución de las dimensiones del IDERE para todas las regiones en el período 2010-2019, así como toda la información del Índice, se puede analizar en línea y descargar del sitio www.idere.cl.

\section{ANÁLISIS POR DIMENSIÓN}

En las siguientes páginas se realiza un breve análisis según cada dimensión. La Figura 6 sintetiza los resultados de cada una de las dimensiones en las regiones del país. 
Índice de Desarrollo Regional • IDERE 2019

\section{Figura 4}

Dimensiones del IDERE 2019

Educación

$0,591-0,635$

$0,652-0,709$

$0,737-0,785$

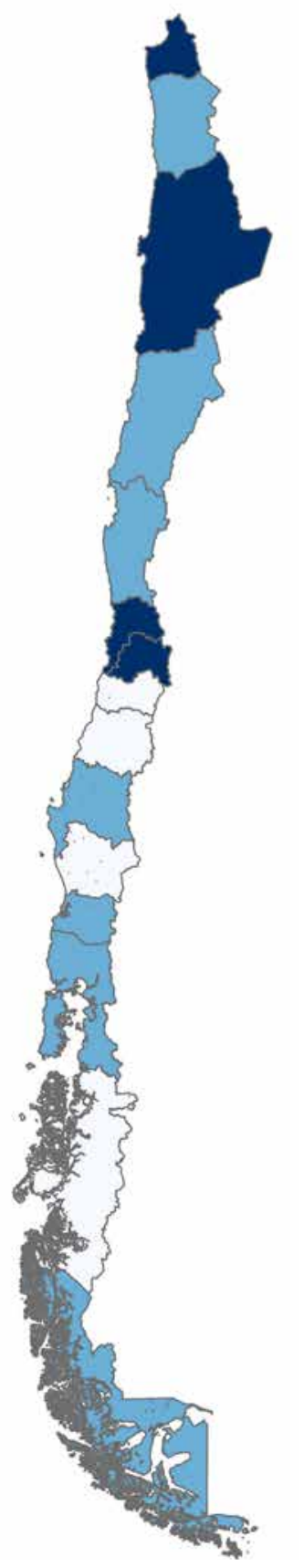

SALUD
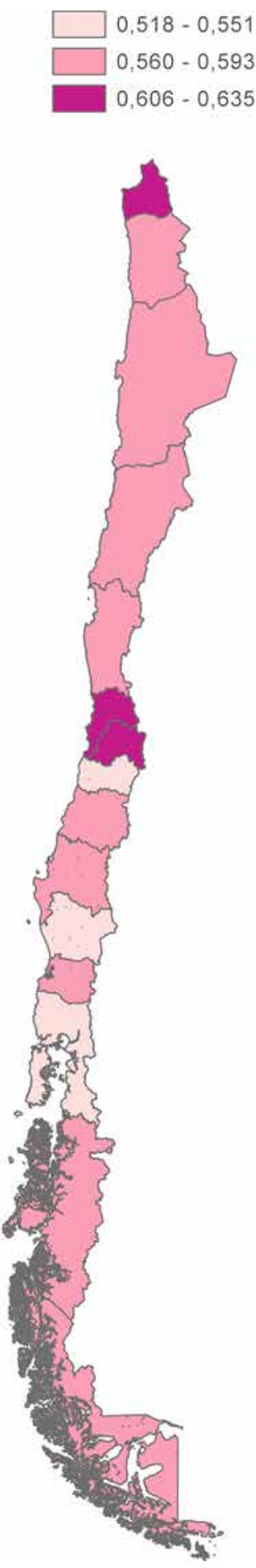

250 
BIENESTAR

SOCIOECONÓMICO

ACTIVIDAD

ECONÓMICA

$0,434-0,514$

$0,532-0,580$

$0,627-0,732$

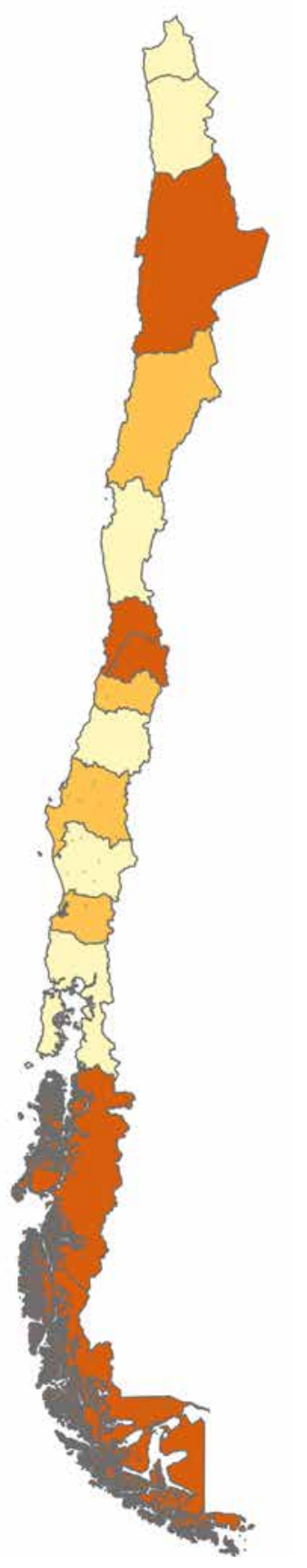

$0,499-0,552$

$0,574-0,612$

$0,678-0,706$
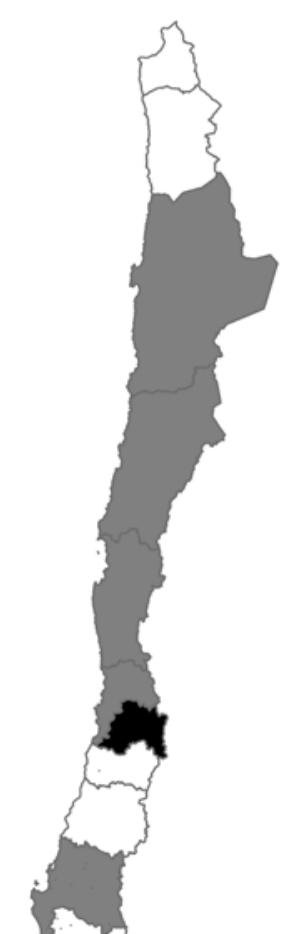

\begin{tabular}{lllll}
0 & 250 & 500 & 750 & 1.000 \\
\hline & &
\end{tabular} 
Conectividad

$0,157-0,219$

$0,243-0,361$

$0,426-0,600$

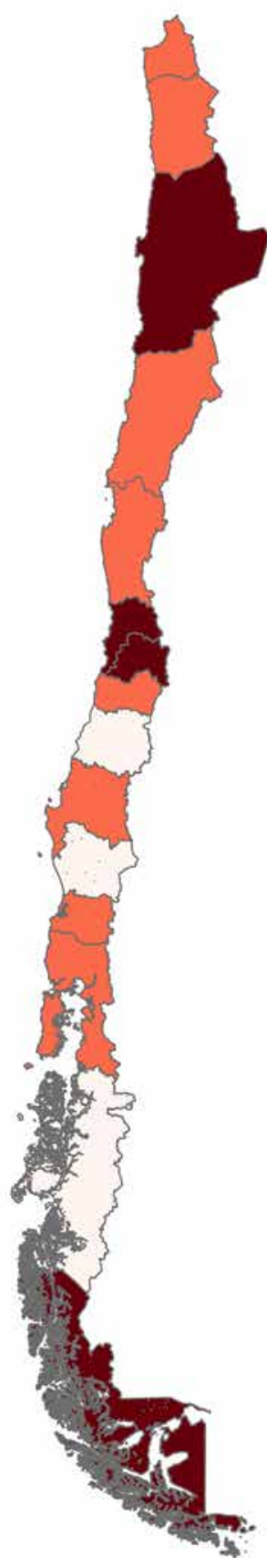

SEguridad

$0,483-0,583$

$0,639-0,704$

$0,722-0,813$

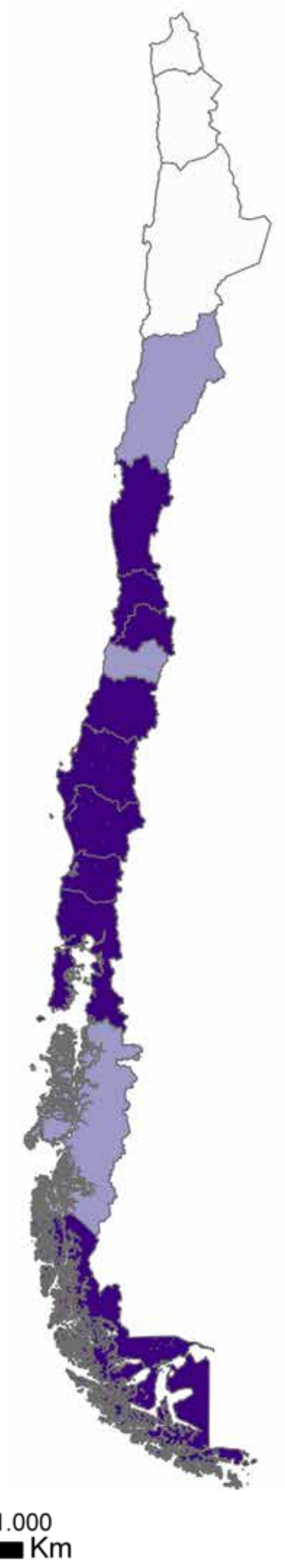


SUSTENTABILIDAD

Y MEDIOAMBIENTE

$\square, 259-0,297$
$0,315-0,401$
$0,437-0,570$

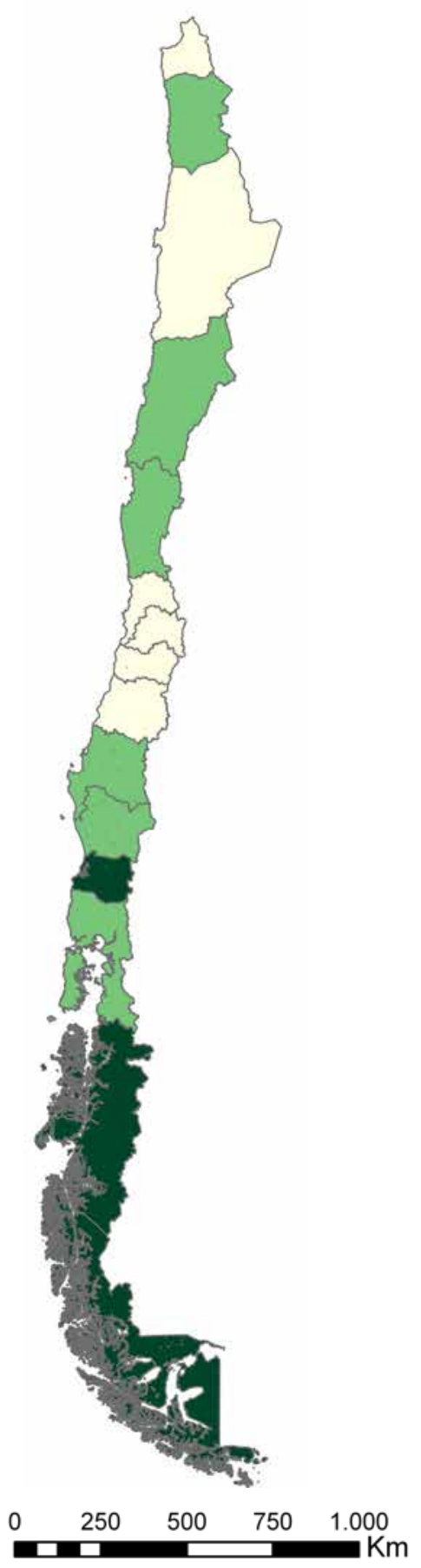

Fuente: elaboración propia a partir de fuente cartográfica de la biblioteca del Congreso Nacional de Chile. 
A modo general, cabe mencionar que las dimensiones que muestran mayores diferencias a nivel regional son Conectividad, Seguridad, Sustentabilidad y Bienestar socioeconómico (ver Figura 7). En otras palabras, son las dimensiones que tienen mayores brechas interregionales. Por su parte, las que muestran disparidades algo más reducidas son Actividad económica, Educación y —especialmente— Salud.

Figura 5

Desviación estándar de las dimensiones del IDERE 2019

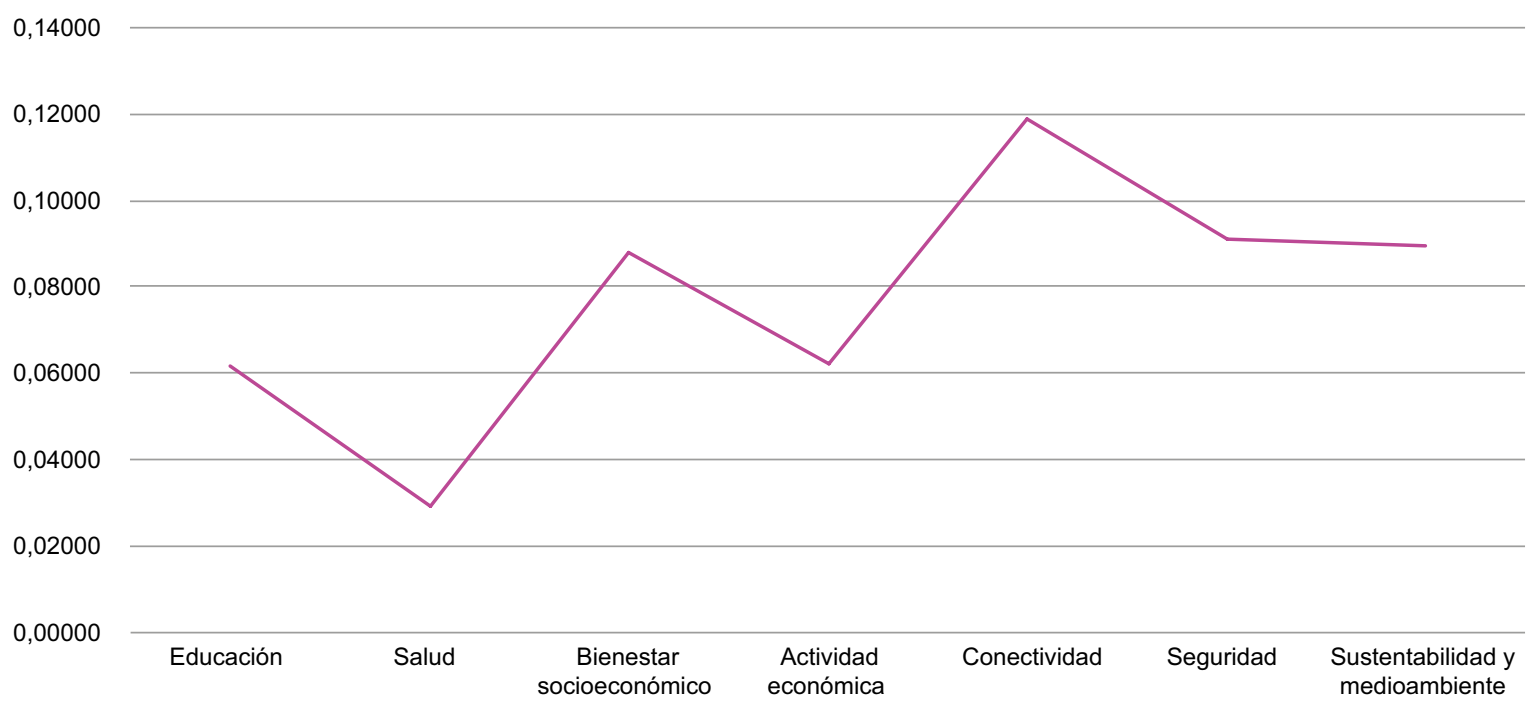

Fuente: elaboración propia.

Los resultados de cada una de las dimensiones del IDERE, considerando la totalidad de variables que las componen, se presentan entre las tablas 7 y 13. Las regiones están en orden decreciente de acuerdo al índice general de la dimensión analizada. Además, los colores atribuidos a las regiones representan los niveles relativos de desarrollo, donde el más oscuro representa mayor desarrollo y el más claro menor desarrollo. 


\section{Educación}

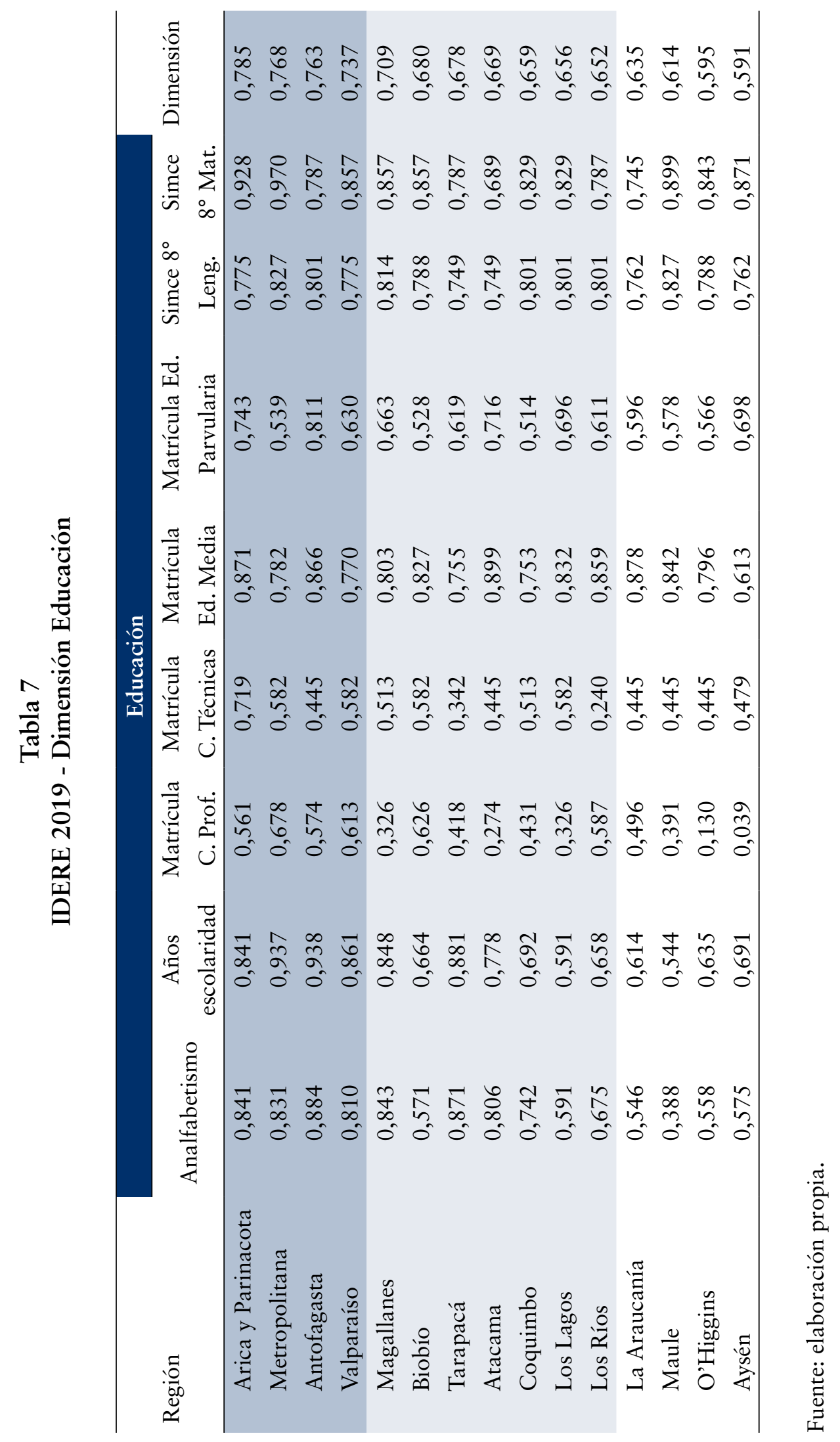


Esta dimensión presenta variables con diferencias significativas, como analfabetismo, con situaciones tan disímiles como las de Antofagasta $(0,884)$ y Maule $(0,388)$.

El grupo de mayor desarrollo está compuesto por varias regiones. Arica y Parinacota $(0,785)$ destaca en matrículas en carreras técnicas $\left(1^{\circ}\right)$ y educación parvularia $\left(2^{\circ}\right)$, además del SIMCE de Matemáticas en 8 vo. básico $\left(2^{\circ}\right)$. La Región Metropolitana $(0,768)$ presenta también excelentes indicadores, por ejemplo, en cuanto al SIMCE de Matemáticas $\left(1^{\circ}\right)$, años de escolaridad de la población $\left(2^{\circ}\right)$ y matrículas en carreras profesionales $\left(1^{\circ}\right)$ y técnicas $\left(2^{\circ}\right)$. Antofagasta $(0,763)$, tercera en esta dimensión, destaca por tener la menor tasa de analfabetismo del país y la población con más años de escolaridad. Finalmente, dentro del grupo de mayor desarrollo se encuentra la Región de Valparaíso $(0,737)$, que se ubica en posiciones intermedias en todos los indicadores.

En el grupo de desarrollo medio se encuentran las regiones de Magallanes $(0,709)$, Biobío $(0,680)$, Tarapacá $(0,678)$, Atacama $(0,669)$, Coquimbo $(0,659)$, Los Lagos $(0,656)$ y Los Ríos $(0,652)$.

En el grupo de menor desarrollo se encuentran las regiones de La Araucanía $(0,635)$, Maule $(0,614)$, O’Higgins $(0,595)$ y Aysén $(0,591)$. En el caso de la primera, las mayores debilidades se presentan en su alta tasa de analfabetismo $\left(14^{\circ}\right)$ y en los bajos resultados en las pruebas SIMCE de Lenguaje y Matemáticas (penúltima en ambas).

Maule presenta la peor tasa de analfabetismo y los menores años de escolaridad del país, aunque destaca como segunda en el SIMCE de Lenguaje. Las regiones de O'Higgins y Aysén — las últimas_- presentan tasas muy bajas de matriculados en carreras profesionales, debido a que la oferta de educación superior ha sido muy débil hasta fecha reciente. Aysén cuenta además con la menor tasa de matrícula de educación media en el país $\left(15^{\circ}\right)$. 
Salud

Tabla 8

IDERE 2019 - Dimensión Salud

\begin{tabular}{|c|c|c|c|c|c|c|c|}
\hline \multirow[b]{2}{*}{ Región } & \multicolumn{6}{|c|}{ Salud } & \multirow[b]{2}{*}{ Dimensión } \\
\hline & $\begin{array}{l}\text { Años de } \\
\text { vida p. } \\
\text { perdidos }\end{array}$ & $\begin{array}{c}\text { Camas de } \\
\text { hospital }\end{array}$ & $\begin{array}{c}\text { Malnutrición } \\
\text { infantil }\end{array}$ & $\begin{array}{l}\text { Mortalidad } \\
\text { infantil }\end{array}$ & $\begin{array}{l}\text { Obesidad } \\
\text { infantil }\end{array}$ & Suicidios & \\
\hline $\begin{array}{l}\text { Arica y } \\
\text { Parinacota }\end{array}$ & 0,704 & 0,155 & 0,697 & 0,716 & 0,643 & 0,894 & 0,635 \\
\hline Metropolitana & 0,764 & 0,314 & 0,428 & 0,760 & 0,617 & 0,763 & 0,608 \\
\hline Valparaíso & 0,706 & 0,174 & 0,584 & 0,837 & 0,598 & 0,737 & 0,606 \\
\hline Aysén & 0,812 & 0,388 & 0,494 & 0,897 & 0,257 & 0,712 & 0,593 \\
\hline Atacama & 0,760 & 0,247 & 0,340 & 0,856 & 0,561 & 0,786 & 0,591 \\
\hline Biobío & 0,659 & 0,269 & 0,651 & 0,741 & 0,469 & 0,746 & 0,589 \\
\hline Coquimbo & 0,718 & 0,129 & 0,552 & 0,685 & 0,554 & 0,889 & 0,588 \\
\hline Magallanes & 0,595 & 0,442 & 0,610 & 0,690 & 0,433 & 0,666 & 0,573 \\
\hline Maule & 0,680 & 0,137 & 0,673 & 0,745 & 0,519 & 0,670 & 0,571 \\
\hline Tarapacá & 0,696 & 0,110 & 0,313 & 0,850 & 0,551 & 0,902 & 0,570 \\
\hline Antofagasta & 0,630 & 0,191 & 0,234 & 0,740 & 0,751 & 0,852 & 0,566 \\
\hline Los Ríos & 0,630 & 0,378 & 0,656 & 0,551 & 0,383 & 0,765 & 0,560 \\
\hline O'Higgins & 0,643 & 0,143 & 0,583 & 0,763 & 0,569 & 0,603 & 0,551 \\
\hline La Araucanía & 0,585 & 0,263 & 0,693 & 0,676 & 0,418 & 0,614 & 0,541 \\
\hline Los Lagos & 0,564 & 0,255 & 0,674 & 0,704 & 0,349 & 0,560 & 0,518 \\
\hline
\end{tabular}

Fuente: elaboración propia.

La dimensión salud es la que presenta menores disparidades entre las distintas regiones. El grupo de desarrollo alto está compuesto por Arica y Parinacota, la Región Metropolitana y Valparaíso. La primera destaca especialmente en los bajos índices de malnutrición infantil $\left(1^{\circ}\right)$, obesidad infantil $\left(2^{\circ}\right)$ y tasa de suicidios $\left(2^{\circ}\right)$. La R.M., por su parte, muestra cifras alentadoras respecto de la baja cantidad de años de vida potencial perdidos $\left(2^{\circ}\right)$, presentando en general una buena posición en el resto de los indicadores. La Región de Valparaíso, en tanto, presenta posiciones intermedias en cada uno de los indicadores.

El grupo de desarrollo medio está compuesto por las regiones de Aysén $(0,593)$, Atacama (0,591), Biobío (0,589), Coquimbo (0,588), Magallanes (0,573), Maule $(0,571)$, Tarapacá $(0,570)$, Antofagasta $(0,566)$ y Los Ríos $(0,560)$. En general combinan posiciones altas y bajas en las distintas variables. 
El grupo de desarrollo bajo está compuesto por las regiones de O'Higgins $(0,551)$, La Araucanía $(0,541)$ y Los Lagos $(0,518)$. Las tres presentan los peores indicadores en cuanto a tasa de suicidios, mientras que las dos últimas lo hacen también respecto de años de vida potencial perdidos $\left(14^{\circ}\right.$ y $15^{\circ}$, respectivamente).

\section{Bienestar socioeconómico}

Tabla 9

IDERE 2019 - Dimensión Bienestar socioeconómico

\begin{tabular}{|c|c|c|c|c|c|}
\hline \multirow[b]{2}{*}{ Región } & \multicolumn{4}{|c|}{ Bienestar socioeconómico } & \multirow[b]{2}{*}{ Dimensión } \\
\hline & Hacinamiento & $\begin{array}{l}\text { Ingresos autónomos } \\
\text { por hogar }\end{array}$ & $\begin{array}{l}\text { Pobreza e } \\
\text { indigencia }\end{array}$ & $\begin{array}{c}\text { Calidad de la } \\
\text { vivienda }\end{array}$ & \\
\hline Magallanes & 0,811 & 0,634 & 0,941 & 0,542 & 0,732 \\
\hline Aysén & 0,804 & 0,577 & 0,866 & 0,572 & 0,705 \\
\hline Metropolitana & 0,577 & 0,700 & 0,843 & 0,563 & 0,671 \\
\hline Antofagasta & 0,713 & 0,579 & 0,850 & 0,506 & 0,662 \\
\hline Valparaíso & 0,775 & 0,398 & 0,791 & 0,545 & 0,627 \\
\hline Atacama & 0,651 & 0,422 & 0,767 & 0,479 & 0,580 \\
\hline Biobío & 0,789 & 0,250 & 0,610 & 0,533 & 0,545 \\
\hline O’Higgins & 0,736 & 0,269 & 0,702 & 0,426 & 0,533 \\
\hline Los Ríos & 0,769 & 0,287 & 0,641 & 0,431 & 0,532 \\
\hline Los Lagos & 0,746 & 0,297 & 0,654 & 0,360 & 0,514 \\
\hline Tarapacá & 0,345 & 0,461 & 0,812 & 0,430 & 0,512 \\
\hline Maule & 0,724 & 0,245 & 0,623 & 0,433 & 0,506 \\
\hline $\begin{array}{l}\text { Arica y } \\
\text { Parinacota }\end{array}$ & 0,594 & 0,291 & 0,752 & 0,369 & 0,502 \\
\hline Coquimbo & 0,680 & 0,255 & 0,648 & 0,414 & 0,499 \\
\hline La Araucanía & 0,673 & 0,220 & 0,490 & 0,353 & 0,434 \\
\hline
\end{tabular}

Fuente: elaboración propia.

En la dimensión Bienestar socieconómico, las variables ingresos autónomos por hogar, pobreza e indigencia y hacinamiento presentan grandes disparidades a nivel regional, mientras que la variable calidad de la vivienda es algo menos desigual.

El grupo de desarrollo alto está compuesto por las regiones de Magallanes $(0,732)$, Aysén (0,705), R.M. $(0,671)$, Antofagasta $(0,662)$ y Valparaíso $(0,627)$. La Región de Magallanes presenta cifras destacables en todas la variables: menores niveles de hacinamiento $\left(1^{\circ}\right)$, altos ingresos autónomos por hogar $\left(2^{\circ}\right)$, baja tasa de pobreza e indigencia $\left(1^{\circ}\right)$ y buena calidad de la vivienda $\left(4^{\circ}\right)$. La Región de Aysén muestra un cuadro similar: mejor 
calidad de vivienda $\left(1^{\circ}\right)$, bajo nivel de hacinamiento $\left(1^{\circ}\right)$, baja pobreza e indigencia $\left(2^{\circ}\right)$ e ingresos autónomos sobre el promedio nacional $\left(4^{\circ}\right)$. La R.M., por su parte, es la que muestra los mayores ingresos autónomos por hogar del país y buena calidad de vivienda $\left(2^{\circ}\right)$, aunque uno de los peores niveles de hacinamiento $\left(14^{\circ}\right)$. Antofagasta destaca en cuanto a ingresos autónomos por hogar y la tasa de pobreza e indigencia ( $3^{\circ}$ en ambas). Finalmente, cierra el grupo de desarrollo alto la Región de Valparaíso, que se ubica en la parte alta en todas las variables.

El grupo de desarrollo medio está compuesto de solo cuatro regiones: Atacama $(0,580)$, Biobío $(0,545)$, O’Higgins $(0,533)$ y Los Ríos $(0,532)$. Presentan características muy similares, ubicándose en la parte media de la tabla en todas las variables, con la sola excepción de Biobío, bien posicionada en cuanto al bajo nivel de hacinamiento $\left(3^{\circ}\right)$.

Finalmente, en el grupo de menor desarrollo se encuentran las regiones de Los Lagos $(0,514)$, Tarapacá $(0,512)$, Maule $(0,506)$, Arica y Parinacota $(0,502)$, Coquimbo $(0,499)$ y La Araucanía (0,434). El caso más crítico es La Araucanía, que se ubica última en tres de las cuatro variables: ingresos autónomos por hogar, pobreza e indigencia y calidad de la vivienda. Tarapacá, por su parte, posee los peores niveles de hacinamiento $\left(15^{\circ}\right)$, similar a Arica y Parinacota $\left(13^{\circ}\right)$. Maule da cuenta de bajos niveles de ingreso autónomo familiar $\left(14^{\circ}\right)$ y gran presencia de pobreza e indigencia $\left(13^{\circ}\right)$. Coquimbo y Los Lagos se encuentran en posiciones bajas en las respectivas variables. 
Tabla 10

IDERE 2019 - Dimensión Actividad económica

\begin{tabular}{lccccc}
\hline Región & \multicolumn{5}{c}{ Actividad económica } \\
Desempleo & $\begin{array}{c}\text { Diversificación } \\
\text { del sector } \\
\text { productivo }\end{array}$ & $\begin{array}{c}\text { Especialización } \\
\text { en industria } \\
\text { manufacturera y } \\
\text { de servicios }\end{array}$ & $\begin{array}{c}\text { Renta por } \\
\text { contribuyente }\end{array}$ & Dimensión \\
\hline Magallanes & 0,910 & 0,744 & 0,456 & 0,713 & 0,706 \\
Metropolitana & 0,609 & 0,747 & 0,428 & 0,928 & 0,678 \\
\hline Los Ríos & 0,781 & 0,596 & 0,418 & 0,654 & 0,612 \\
Valparaíso & 0,571 & 0,610 & 0,386 & 0,851 & 0,605 \\
Biobío & 0,567 & 0,664 & 0,452 & 0,718 & 0,600 \\
Atacama & 0,573 & 0,595 & 0,296 & 0,928 & 0,598 \\
Los Lagos & 0,849 & 0,481 & 0,417 & 0,630 & 0,594 \\
Antofagasta & 0,475 & 0,686 & 0,259 & 0,928 & 0,587 \\
Coquimbo & 0,552 & 0,709 & 0,184 & 0,850 & 0,574 \\
Aysén & 0,899 & 0,523 & 0,197 & 0,588 & 0,552 \\
O’Higgins & 0,635 & 0,520 & 0,268 & 0,668 & 0,523 \\
Tarapacá & 0,567 & 0,356 & 0,272 & 0,837 & 0,508 \\
Arica y & 0,681 & 0,500 & 0,192 & 0,656 & 0,507 \\
Parinacota & 0,530 & 0,618 & 0,266 & 0,608 & 0,505 \\
La Araucanía & 0,723 & 0,446 & 0,283 & 0,542 & 0,499 \\
Maule & 0 & &
\end{tabular}

Fuente: elaboración propia.

En esta dimensión, en el grupo de desarrollo alto solo se encuentran Magallanes y la R. Metropolitana. La primera, destaca por tener el menor desempleo del país $\left(1^{\circ}\right)$, la mayor especialización en industria manufacturera y de servicios $\left(1^{\circ}\right)$ y alta diversificación del sector productivo $\left(2^{\circ}\right)$. La R.M., por su parte, destaca por contar con la mayor diversificación del sector productivo $\left(1^{\circ}\right)$ y la renta por contribuyente más alta $\left(1^{\circ}\right)$.

En el grupo de desarrollo medio se encuentran las regiones de Los Ríos $(0,612)$, Valparaíso (0,605), Biobío (0,600), Atacama (0,598), Los Lagos (0,594), Antofagasta $(0,587)$ y Coquimbo $(0,574)$. En el caso de Biobío, esta región es segunda en especialización 
en industria manufacturera y de servicios. Los casos de Atacama y Antofagasta corresponden a la segunda y tercera posición en renta por contribuyente.

El grupo de desarrollo bajo esta dimensión es numeroso. Corresponde a las regiones de Aysén $(0,552)$, O'Higgins (0,523), Tarapacá (0,508), Arica y Parinacota (0,507), Araucanía $(0,505)$ y Maule $(0,499)$. Maule tiene la renta por contribuyente más baja del país y junto con Tarapacá, la menor diversificación del sector productivo $\left(14^{\circ}\right.$ y $15^{\circ}$, respectivamente). La Araucanía, por su parte, presenta una de las mayores tasas de desempleo del país $\left(14^{\circ}\right)$.

\section{Conectividad}

\section{Tabla 11}

IDERE 2019 - Dimensión Conectividad

\begin{tabular}{lcccc}
\hline \multirow{2}{*}{ Región } & \multicolumn{3}{c}{ Conectividad } & \\
& $\begin{array}{c}\text { Conexiones a } \\
\text { internet fijas }\end{array}$ & $\begin{array}{c}\text { Carreteras y caminos } \\
\text { pavimentados }\end{array}$ & $\begin{array}{c}\text { Líneas telefónicas } \\
\text { fijas }\end{array}$ & Dimensión \\
\hline Metropolitana & 0,617 & 0,629 & 0,553 & 0,600 \\
Antofagasta & 0,643 & 0,327 & 0,379 & 0,450 \\
Magallanes & 0,689 & 0,124 & 0,481 & 0,432 \\
Valparaíso & 0,536 & 0,403 & 0,340 & 0,426 \\
Tarapacá & 0,486 & 0,284 & 0,312 & 0,361 \\
Arica y Parinacota & 0,561 & 0,125 & 0,262 & 0,316 \\
Biobío & 0,445 & 0,183 & 0,206 & 0,278 \\
Los Ríos & 0,390 & 0,172 & 0,246 & 0,269 \\
Coquimbo & 0,360 & 0,252 & 0,175 & 0,263 \\
Los Lagos & 0,371 & 0,189 & 0,207 & 0,256 \\
Atacama & 0,405 & 0,100 & 0,234 & 0,246 \\
O’Higgins & 0,233 & 0,405 & 0,091 & 0,243 \\
Aysén & 0,455 & 0,044 & 0,158 & 0,219 \\
Maule & 0,233 & 0,244 & 0,086 & 0,188 \\
La Araucanía & 0,267 & 0,064 & 0,140 & 0,157 \\
\hline
\end{tabular}

Fuente: elaboración propia.

Esta es la dimensión con la mayor desigualdad entre las regiones. El grupo de desarrollo alto está compuesto por la Metropolitana, con excelentes indicadores en cada variable: carreteras y caminos pavimentados $\left(1^{\circ}\right)$, líneas telefónicas fijas $\left(1^{\circ}\right)$ y conexiones a internet fijas $\left(2^{\circ}\right)$, lo cual la posiciona con mucha distancia en el primer lugar de la dimensión. Antofagasta está ubicada en las primeras posiciones en todas las variables. Magallanes, por su parte, tiene la mayor proporción de conexiones a internet 
(fijas), aunque queda a la zaga en cuanto a carreteras y caminos pavimentados $\left(13^{\circ}\right)$. Finalmente, Valparaíso presenta una situación similar a la de Antofagasta, con posiciones altas en cada variable.

El grupo de desarrollo medio es el más numeroso. Está compuesto de ocho regiones: Tarapacá (0,361), Arica y Parinacota (0,316), Biobío (0,278), Los Ríos (0,269), Coquimbo (0,263), Los Lagos (0,256), Atacama (0,246) y O’Higgins (0,243). La Región de O’higgins se presenta especialmente débil en cuanto a conexiones a internet fijas y a líneas telefónicas (14 ${ }^{\circ}$ en ambas).

Finalmente, en el grupo de menor nivel de desarrollo se encuentran Aysén, Maule y Araucanía. La primera presenta con claridad la menor proporción de carreteras y caminos pavimentados. Maule se muestra especialmente débil en esta dimensión. En cuanto a conexiones a internet fijas y líneas telefónicas fijas, dicha región es la última del país. La Araucanía se encuentra muy a la zaga en todas las variables.

Seguridad

Tabla 12

IDERE 2019 - Dimensión Seguridad

\begin{tabular}{lcccc}
\hline Región & \multicolumn{3}{c}{ Seguridad } \\
Menuncias & $\begin{array}{c}\text { Delitos de mayor } \\
\text { connotación social }\end{array}$ & $\begin{array}{c}\text { Violencia } \\
\text { intrafamiliar }\end{array}$ & Dimensión \\
\hline Magallanes & 0,717 & 0,888 & 0,835 & 0,813 \\
Liobío & 0,759 & 0,729 & 0,839 & 0,775 \\
Maule & 0,829 & 0,767 & 0,702 & 0,766 \\
Metropolitana & 0,716 & 0,758 & 0,804 & 0,759 \\
La Araucanía & 0,831 & 0,543 & 0,864 & 0,746 \\
Los Lagos & 0,788 & 0,736 & 0,701 & 0,742 \\
Coquimbo & 0,711 & 0,778 & 0,720 & 0,736 \\
Valparaíso & 0,696 & 0,649 & 0,834 & 0,726 \\
O’Higgins & 0,753 & 0,574 & 0,840 & 0,722 \\
Atacama & 0,650 & 0,691 & 0,771 & 0,704 \\
Aysén & 0,653 & 0,627 & 0,742 & 0,674 \\
Antofagasta & 0,489 & 0,876 & 0,551 & 0,639 \\
Tarapacá & 0,495 & 0,492 & 0,761 & 0,583 \\
Arica y Parinacota & 0,579 & 0,512 & 0,595 & 0,562 \\
\hline
\end{tabular}

Fuente: elaboración propia. 
Esta dimensión también presenta diferencias significativas entre regiones. El grupo de desarrollo alto es mayoritario. Está compuesto por las regiones de Magallanes $(0,813)$, Biobío (0,775), Los Ríos (0,766), Maule (0,759), Metropolitana (0,746), La Araucanía $(0,742)$, Los Lagos $(0,736)$, Coquimbo $(0,726)$ y Valparaíso $(0,722)$. Como se aprecia, buena parte de estas se encuentran en la zona sur del país.

El grupo de desarrollo medio está compuesto por las regiones de O’higgins (0,704), Atacama $(0,674)$ y Aysén $(0,639)$. El caso de esta última llama la atención, debido a los pésimos resultados en las variables denuncias y violencia intrafamiliar $\left(14^{\circ}\right.$ en ambas), junto a la baja tasa de delitos de mayor connotación social $\left(2^{\circ}\right)$.

El grupo de desarrollo bajo está compuesto por las regiones del Norte Grande del país, como son Antofagasta (0,583), Tarapacá $(0,562)$ y Arica y Parinacota $(0,483)$. Antofagasta y Tarapacá tienen las peores tasas de delitos de mayor connotación social $\left(14^{\circ}\right.$ y $15^{\circ}$, respectivamente), mientras que Arica y Parinacota se ubica en el último lugar en las variables denuncias y violencia intrafamiliar.

Sustentabilidad y medioambiente

Tabla 13

IDERE 2019 - Dimensión Sustentabilidad y medioambiente

\begin{tabular}{lccccc}
\hline \multirow{2}{*}{ Región } & \multicolumn{5}{c}{ Sustentabilidad y medioambiente } \\
& $\begin{array}{c}\text { Conservación de la } \\
\text { biodiversidad }\end{array}$ & $\begin{array}{c}\text { Áreas verdes } \\
\text { urbanas }\end{array}$ & $\begin{array}{c}\text { Diferenciales de } \\
\text { caudales de ríos }\end{array}$ & $\begin{array}{c}\text { Calidad } \\
\text { del aire }\end{array}$ & Dimensión \\
\hline Magallanes & 0,239 & 0,386 & 0,713 & 0,943 & 0,570 \\
Aysén & 0,301 & 0,605 & 0,609 & 0,401 & 0,479 \\
Los Ríos & 0,040 & 0,343 & 0,780 & 0,586 & 0,437 \\
Atacama & 0,005 & 0,056 & 0,683 & 0,860 & 0,401 \\
Coquimbo & 0,001 & 0,179 & 0,320 & 0,841 & 0,335 \\
Los Lagos & 0,097 & 0,214 & 0,423 & 0,588 & 0,330 \\
Biobío & 0,015 & 0,173 & 0,413 & 0,710 & 0,328 \\
La Araucanía & 0,033 & 0,201 & 0,415 & 0,626 & 0,319 \\
Tarapacá & 0,049 & 0,022 & 0,335 & 0,852 & 0,315 \\
Antofagasta & 0,011 & 0,043 & 0,227 & 0,906 & 0,297 \\
Valparaíso & 0,007 & 0,142 & 0,189 & 0,839 & 0,294 \\
O’Higgins & 0,012 & 0,187 & 0,219 & 0,718 & 0,284 \\
Arica y Parinacota & 0,087 & 0,074 & 0,035 & 0,862 & 0,265 \\
Maule & 0,003 & 0,185 & 0,142 & 0,722 & 0,263 \\
Metropolitana & 0,023 & 0,182 & 0,166 & 0,666 & 0,259 \\
\hline
\end{tabular}

Fuente: elaboración propia. 
En esta dimensión se aprecia el mejor posicionamiento de las regiones de la zona austral del país, Magallanes $(0,570)$ y Aysén $(0,479)$, junto a la Región de Los Ríos $(0,437)$. La primera se destaca en la variable conservación de la biodiversidad y áreas verdes urbanas $\left(2^{\circ}\right)$. Aysén, por su parte, junto con la peor calidad del aire $\left(15^{\circ}\right)$, encabeza la variable conservación de la biodiversidad y áreas verdes urbanas $\left(1^{\circ}\right)$. En el caso de Los Ríos, se posiciona primera en cuanto a la variable diferenciales de caudales de ríos, seguida por Magallanes.

En el grupo de desarrollo medio se encuentran las regiones de Atacama $(0,401)$, Coquimbo (0,335), Los Lagos (0,330), Biobío (0,328), La Araucanía $(0,319)$ y Tarapacá $(0,315)$.

Finalmente, el grupo de desarrollo bajo está formado por Antofagasta, Valparaíso, O'Higgins, Arica y Parinacota, Maule y la Metropolitana. En general, presentan posiciones en la parte baja de todas las variables. Las tres últimas presentan las peores posiciones en cuanto a diferenciales de caudales de ríos $\left(15^{\circ}, 14^{\circ}\right.$ y $13^{\circ}$, respectivamente).

En particular en la variable áreas verdes urbanas, la localización geográfica es determinante, presentando las peores posiciones las regiones del Norte Grande del país.

\section{RESULTADOS PRINCIPALES}

- La Región de Magallanes es la que lidera el IDERE 2019 (0,648). El grupo de regiones de desarrollo alto se completa con las regiones Metropolitana $(0,615)$, Valparaíso $(0,577)$ y Antofagasta $(0,567)$.

- La Araucanía se mantiene como la región con menor desarrollo del país $(0,458)$. Junto a ella, en el grupo de desarrollo bajo, se encuentran las regiones de O'Higgins $(0,486)$ y Maule $(0,471)$. O'Higgins pasó de ubicarse de la posición $11^{\circ}$ (IDERE, 2017) a la $13^{\circ}$ (IDERE, 2019).

- En términos generales, se observa un mayor grado de desarrollo en el centro y norte del país (con la excepción de Arica y Parinacota). Hacia el sur los niveles de desarrollo tienden a disminuir, con la notoria excepción de Magallanes.

- En comparación con la medición de 2017 (sin considerar la nueva dimensión de Sustentabilidad y medioambiente), todas las regiones aumentaron sus IDERES globales, salvo Tarapacá, que pasó de 0,529 a 0,508.

- $\quad \mathrm{Al}$ analizar las trayectorias del IDERE entre 2010 y 2019 (sin la dimensión de Sustentabilidad y medioambiente), se observa una tendencia al alza sostenida de todas las regiones. En general, las regiones de mayor desarrollo mantienen un 
crecimiento más moderado, frente a los mayores crecimientos experimentados por las regiones con menor desarrollo. La gran excepción es Arica y Parinacota, que a pesar de encontrarse en el lugar $12^{\circ}$ (última del grupo de desarrollo medio), su crecimiento ha sido más bien bajo. La Región Metropolitana es la que ha experimentado las alzas menores en el período.

- Las dimensiones de Salud, Educación, Actividad económica y Sustentabilidad y medioambiente son las que presentan los estándares más homogéneos a nivel interregional.

- El comportamiento de la dimensión Actividad económica rompe con las percepciones generalizadas: al no considerar el PIB, que genera una distorsión asociada al efecto de la minería en la economía, e incluir solo variables que pueden tener impactos más directos en la realidad que vive la mayor parte de la población, se observa que las regiones mineras no son las que muestran mejores estándares. Por el contrario, comparten estadios intermedios de desarrollo junto a un grupo de regiones del centro y del sur de Chile.

- Las regiones de los extremos del país (a excepción de Arica y Parinacota) son las que presentan mayor Bienestar socioeconómico, con una notoria superioridad de la Región de Magallanes.

- Se mantiene una enorme brecha en cuanto a Conectividad entre la Región Metropolitana y el resto del país.

- $\quad$ El norte del país tiene los peores estándares en Seguridad, principalmente en Arica y Parinacota y Tarapacá, seguido de Antofagasta y Atacama.

- Llama poderosamente la atención la variable calidad del aire, en la dimensión Sustentabilidad y medioambiente. La Región Metropolitana, comúnmente presente en la agenda pública en esta materia, no forma parte de las regiones con peores estándares. Por el contrario, la situación en Aysén es dramática, y en las capitales de Los Ríos, La Araucanía, Maule y O’Higgins la realidad es similar o incluso más grave que en Santiago. 


\section{AneXo \\ CuAdros Resumen POR REgIÓN}



Región de Arica y Parinacota

Tabla 14

Resumen de indicadores Región de Arica y Parinacota - IDERE 2019

\begin{tabular}{|c|c|c|c|c|c|c|c|c|}
\hline & \multicolumn{7}{|c|}{ Dimensiones } & \multirow[b]{2}{*}{$\begin{array}{c}\text { IDERE } \\
2019\end{array}$} \\
\hline & $\begin{array}{c}\text { Bienestar } \\
\text { socio- } \\
\text { económico }\end{array}$ & $\begin{array}{l}\text { Conec- } \\
\text { tividad }\end{array}$ & $\begin{array}{l}\text { Actividad } \\
\text { económica }\end{array}$ & Educación & Salud & Seguridad & $\begin{array}{l}\text { Sustenta- } \\
\text { bilidad } \\
\text { y medio- } \\
\text { ambiente }\end{array}$ & \\
\hline IDERE & 0,502 & 0,316 & 0,507 & 0,785 & 0,635 & 0,483 & 0,265 & 0,505 \\
\hline Ranking & 13 & 6 & 13 & 1 & 1 & 15 & 13 & 12 \\
\hline $\begin{array}{l}\text { Nivel } \\
\text { relativo de } \\
\text { desarrollo }\end{array}$ & Bajo & $\begin{array}{l}\text { Inter- } \\
\text { medio }\end{array}$ & Bajo & Alto & Alto & Bajo & Bajo & Bajo \\
\hline
\end{tabular}

Fuente: elaboración propia.

Figura 6

Región de Arica y Parinacota - Dimensiones IDERE 2019

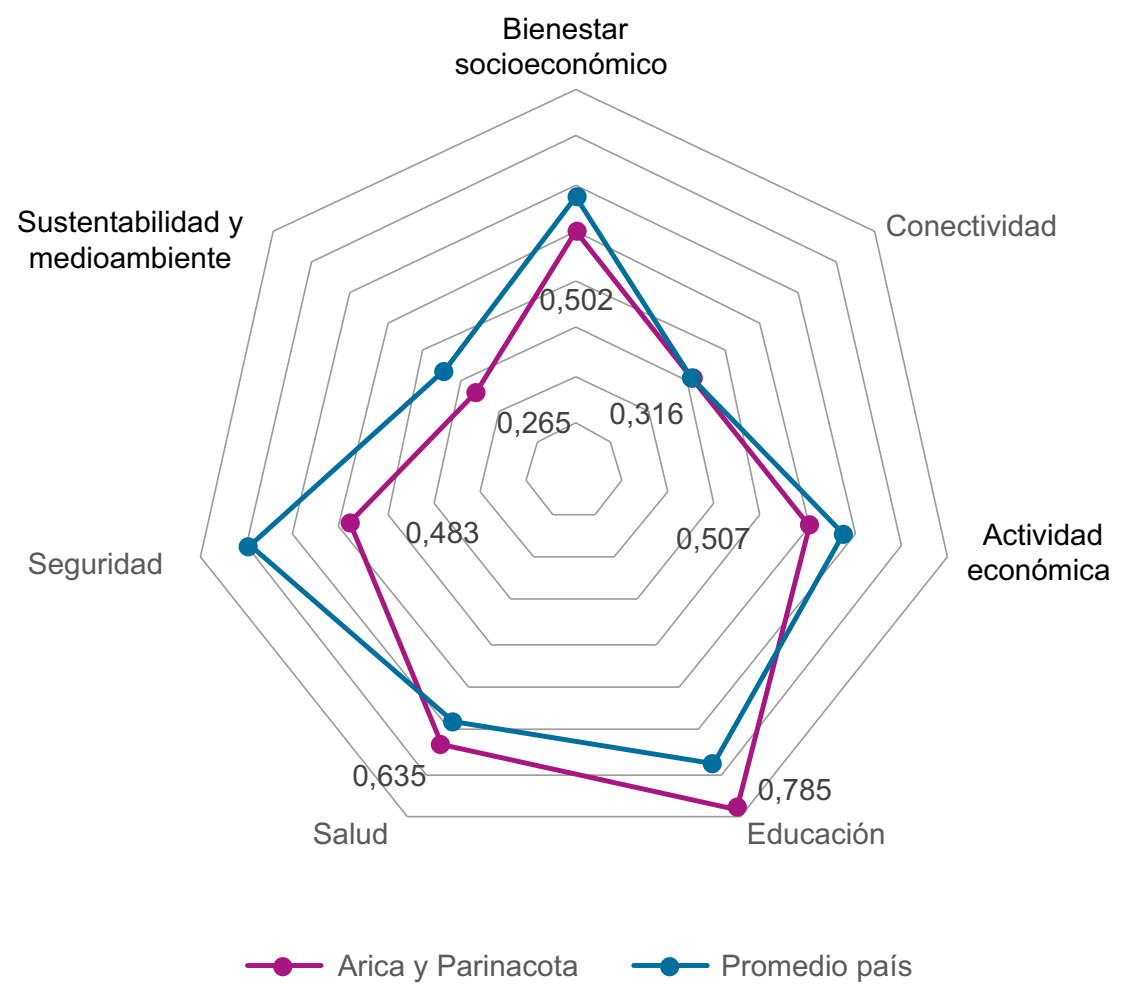

Fuente: elaboración propia. 


\section{REgión de TARAPACÁ}

\section{Tabla 15}

Resumen de indicadores Región de Tarapacá - IDERE 2019

\begin{tabular}{lcccccccc}
\hline & \multicolumn{9}{c}{ Dimensiones } & & \\
\cline { 2 - 7 } & $\begin{array}{c}\text { Bienestar } \\
\text { socio- } \\
\text { económico }\end{array}$ & $\begin{array}{c}\text { Conec- } \\
\text { tividad }\end{array}$ & $\begin{array}{c}\text { Actividad } \\
\text { económica }\end{array}$ & Educación & Salud & Seguridad & $\begin{array}{c}\text { Sustenta- } \\
\text { bilidad } \\
\text { y medio- } \\
\text { ambiente }\end{array}$ & $\begin{array}{c}\text { IDERE } \\
2019\end{array}$ \\
\hline $\begin{array}{l}\text { IDERE } \\
\text { Ranking }\end{array}$ & 0,512 & 0,361 & 0,508 & 0,678 & 0,570 & 0,562 & 0,315 & 0,508 \\
$\begin{array}{l}\text { Nivel } \\
\text { relativo de } \\
\text { desarrollo }\end{array}$ & 11 & 5 & 12 & 7 & 10 & 14 & 9 & 11 \\
\hline
\end{tabular}

Fuente: elaboración propia.

Figura 7

\section{Región de Tarapacá - Dimensiones IDERE 2019}

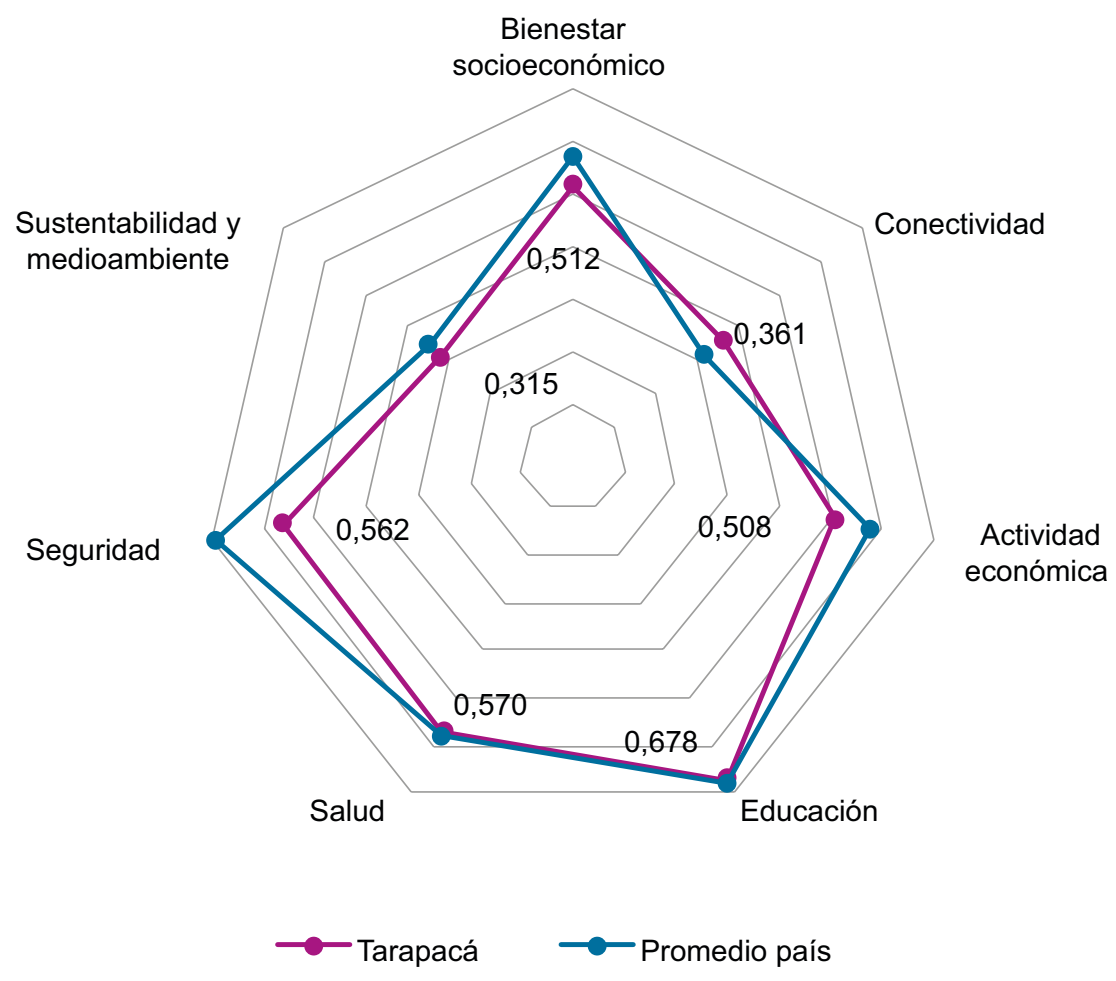

Fuente: elaboración propia. 


\section{Región de Antofagasta}

Tabla 16

Resumen de indicadores Región de Antofagasta - IDERE 2019

\begin{tabular}{|c|c|c|c|c|c|c|c|c|}
\hline & \multicolumn{7}{|c|}{ Dimensiones } & \multirow[b]{2}{*}{$\begin{array}{c}\text { IDERE } \\
2019\end{array}$} \\
\hline & $\begin{array}{c}\text { Bienestar } \\
\text { socio- } \\
\text { económico }\end{array}$ & $\begin{array}{l}\text { Conec- } \\
\text { tividad }\end{array}$ & $\begin{array}{l}\text { Actividad } \\
\text { económica }\end{array}$ & Educación & Salud & Seguridad & $\begin{array}{l}\text { Sustenta- } \\
\text { bilidad } \\
\text { y medio- } \\
\text { ambiente }\end{array}$ & \\
\hline IDERE & 0,662 & 0,450 & 0,587 & 0,763 & 0,566 & 0,583 & 0,297 & 0,567 \\
\hline Ranking & 4 & 2 & 8 & 3 & 11 & 13 & 10 & 4 \\
\hline $\begin{array}{l}\text { Nivel } \\
\text { relativo de } \\
\text { desarrollo }\end{array}$ & Alto & Alto & $\begin{array}{l}\text { Inter- } \\
\text { medio }\end{array}$ & Alto & $\begin{array}{l}\text { Inter- } \\
\text { medio }\end{array}$ & Bajo & Bajo & $\begin{array}{l}\text { Inter- } \\
\text { medio }\end{array}$ \\
\hline
\end{tabular}

Fuente: elaboración propia.

Figura 8

Región de Antofagasta - Dimensiones IDERE 2019

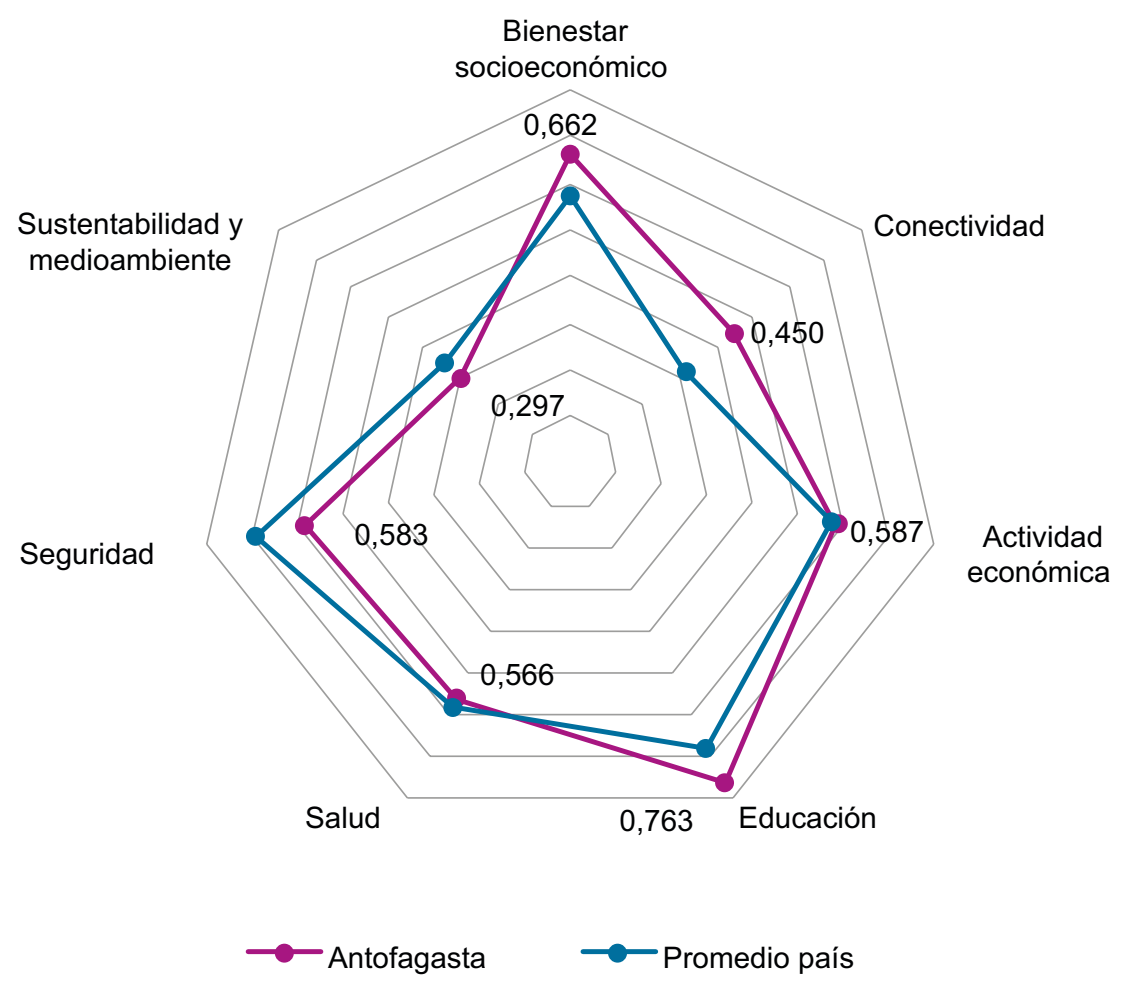

Fuente: elaboración propia. 
Región de ATACAMA

\section{Tabla 17}

Resumen de indicadores Región de Atacama - IDERE 2019

\begin{tabular}{lcccccccc}
\hline & \multicolumn{9}{c}{ Dimensiones } & & \\
\cline { 2 - 7 } & $\begin{array}{c}\text { Bienestar } \\
\text { socio- } \\
\text { económico }\end{array}$ & $\begin{array}{c}\text { Conec- } \\
\text { tividad }\end{array}$ & $\begin{array}{c}\text { Actividad } \\
\text { económica }\end{array}$ & Educación & Salud & Seguridad & $\begin{array}{c}\text { Sustenta- } \\
\text { bilidad } \\
\text { y medio- } \\
\text { ambiente }\end{array}$ & $\begin{array}{c}\text { IDERE } \\
2019\end{array}$ \\
\hline $\begin{array}{l}\text { IDERE } \\
\text { Ranking }\end{array}$ & 0,580 & 0,246 & 0,598 & 0,669 & 0,591 & 0,674 & 0,401 & 0,539 \\
$\begin{array}{l}\text { Nivel } \\
\text { relativo de } \\
\text { desarrollo }\end{array}$ & 6 & 11 & 6 & 8 & 5 & 11 & 4 & 6 \\
\hline
\end{tabular}

Fuente: elaboración propia.

Figura 9

Región de Atacama - Dimensiones IDERE 2019

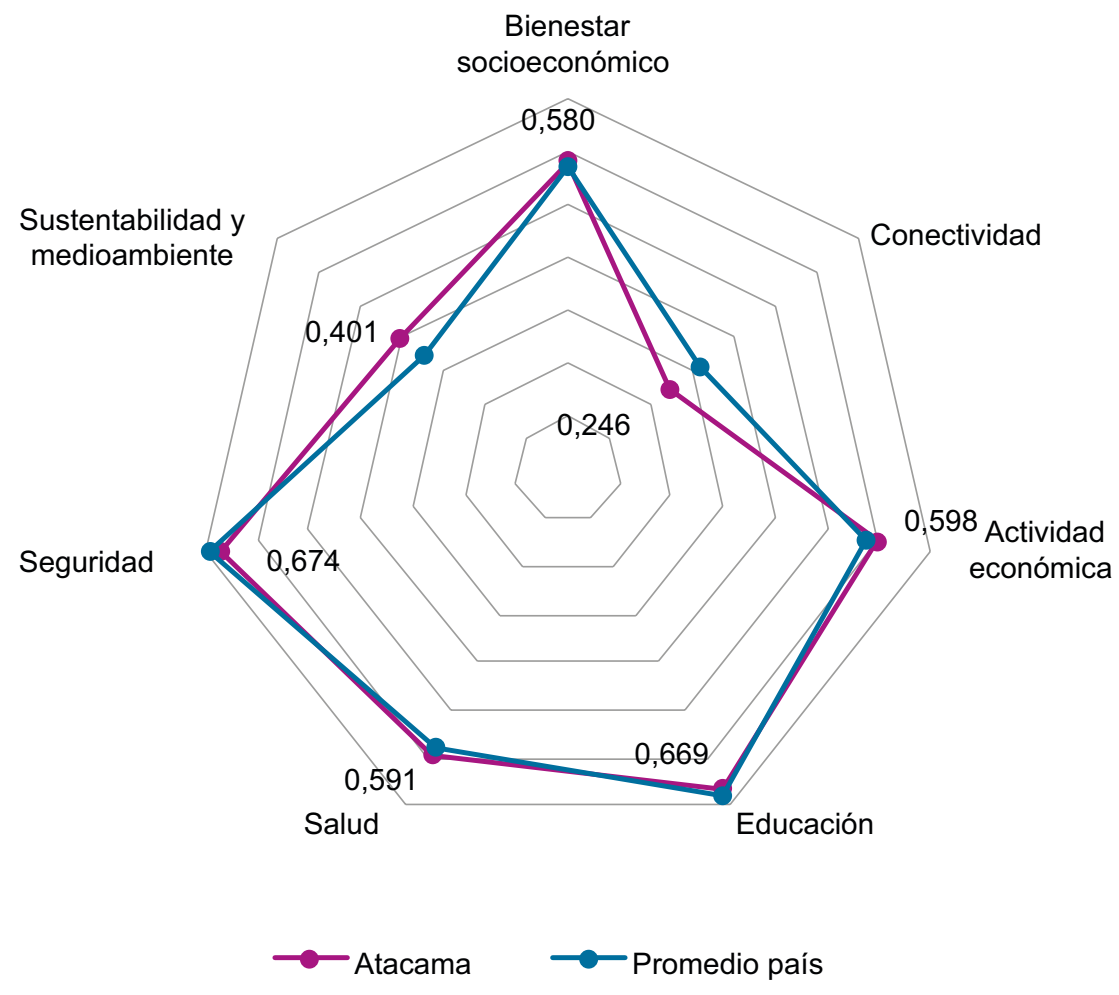

Fuente: elaboración propia. 


\section{Región de Coquimbo}

Tabla 18

Resumen de indicadores Región de Coquimbo - IDERE 2019

\begin{tabular}{lcccccccc}
\hline & \multicolumn{9}{c}{ Dimensiones } & & & \\
\cline { 2 - 7 } & $\begin{array}{c}\text { Bienestar } \\
\text { socio- } \\
\text { económico }\end{array}$ & $\begin{array}{c}\text { Conec- } \\
\text { tividad }\end{array}$ & $\begin{array}{c}\text { Actividad } \\
\text { económica }\end{array}$ & Educación & Salud & $\begin{array}{c}\text { Sustenta- } \\
\text { bilidad } \\
\text { y medio- } \\
\text { IDERE }\end{array}$ & $\begin{array}{c}\text { Seguridad } \\
2019\end{array}$ \\
\hline $\begin{array}{l}\text { IDERE } \\
\text { Ranking }\end{array}$ & 0,499 & 0,263 & 0,574 & 0,659 & 0,588 & 0,726 & 0,335 & 0,517 \\
$\begin{array}{l}\text { Nivel } \\
\text { relativo de } \\
\text { desarrollo }\end{array}$ & Bajo & 9 & 9 & 9 & 7 & 8 & 5 & 9 \\
\hline
\end{tabular}

Fuente: elaboración propia.

Figura 10

Región de Coquimbo - Dimensiones IDERE 2019

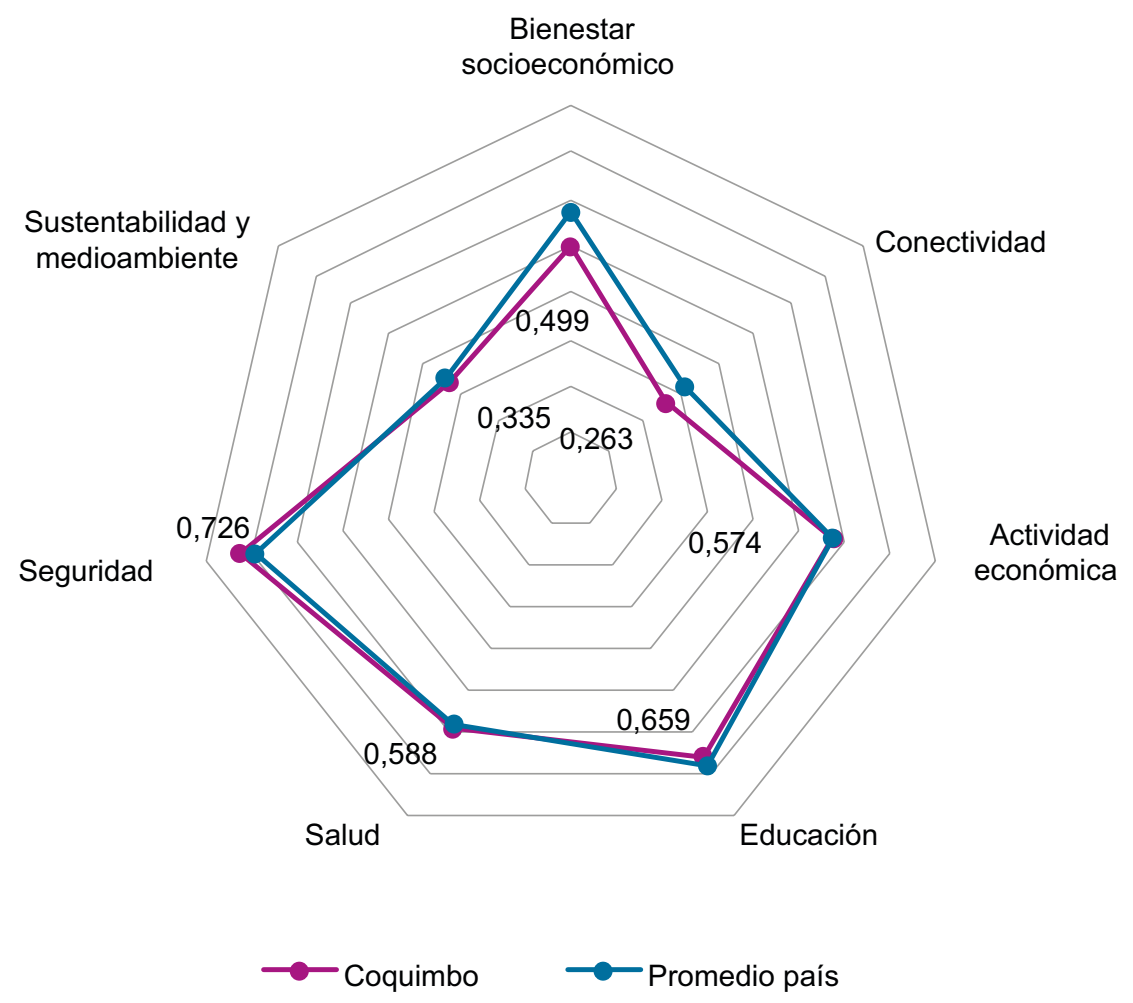

Fuente: elaboración propia. 
REgión DE VALPARAÍso

\section{Tabla 19}

Resumen de indicadores Región de Valparaíso - IDERE 2019

\begin{tabular}{lcccccccc}
\hline & \multicolumn{1}{c}{ Dimensiones } & & \\
\cline { 2 - 6 } & $\begin{array}{c}\text { Bienestar } \\
\text { socio- } \\
\text { económico }\end{array}$ & $\begin{array}{c}\text { Conec- } \\
\text { tividad }\end{array}$ & $\begin{array}{c}\text { Actividad } \\
\text { económica }\end{array}$ & Educación & Salud & Seguridad & $\begin{array}{c}\text { Sustenta- } \\
\text { bilidad } \\
\text { y medio- } \\
\text { ambiente }\end{array}$ & $\begin{array}{c}\text { IDERE } \\
2019\end{array}$ \\
\hline $\begin{array}{l}\text { IDERE } \\
\text { Ranking }\end{array}$ & 0,627 & 0,426 & 0,605 & 0,737 & 0,606 & 0,722 & 0,294 & 0,577 \\
$\begin{array}{l}\text { Nivel } \\
\text { relativo de } \\
\text { desarrollo }\end{array}$ & Alto & Alto & $\begin{array}{c}\text { Inter- } \\
\text { medio }\end{array}$ & Alto & Alto & Alto & Bajo & Inter- \\
\end{tabular}

Fuente: elaboración propia.

Figura 11

Región de Valparaíso - Dimensiones IDERE 2019

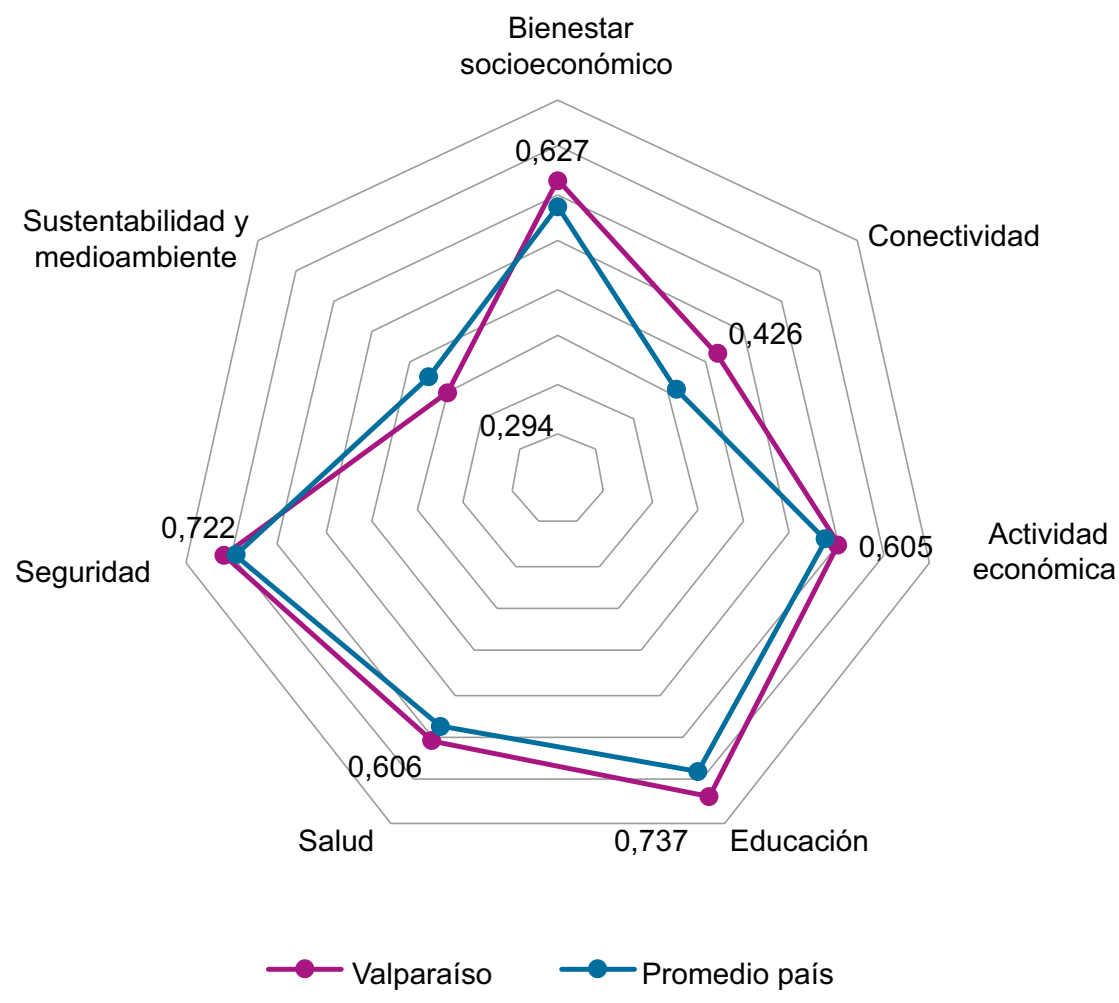

Fuente: elaboración propia. 


\section{Región Metropolitana}

Tabla 20

Resumen de indicadores Región Metropolitana - IDERE 2019

\begin{tabular}{|c|c|c|c|c|c|c|c|c|}
\hline & \multicolumn{7}{|c|}{ Dimensiones } & \multirow[b]{2}{*}{$\begin{array}{c}\text { IDERE } \\
2019\end{array}$} \\
\hline & $\begin{array}{l}\text { Bienestar } \\
\text { Socio- } \\
\text { económico }\end{array}$ & $\begin{array}{l}\text { Conec- } \\
\text { tividad }\end{array}$ & $\begin{array}{l}\text { Actividad } \\
\text { económica }\end{array}$ & Educación & Salud & Seguridad & $\begin{array}{c}\text { Sustenta- } \\
\text { bilidad } \\
\text { y medio- } \\
\text { ambiente }\end{array}$ & \\
\hline IDERE & 0,671 & 0,600 & 0,678 & 0,768 & 0,608 & 0,746 & 0,259 & 0,615 \\
\hline Ranking & 3 & 1 & 2 & 2 & 2 & 5 & 15 & 2 \\
\hline $\begin{array}{l}\text { Nivel } \\
\text { relativo de } \\
\text { desarrollo }\end{array}$ & Alto & Alto & Alto & Alto & Alto & Alto & Bajo & Alto \\
\hline
\end{tabular}

Fuente: Elaboración propia.

Figura 12

Región Metropolitana - Dimensiones IDERE 2019

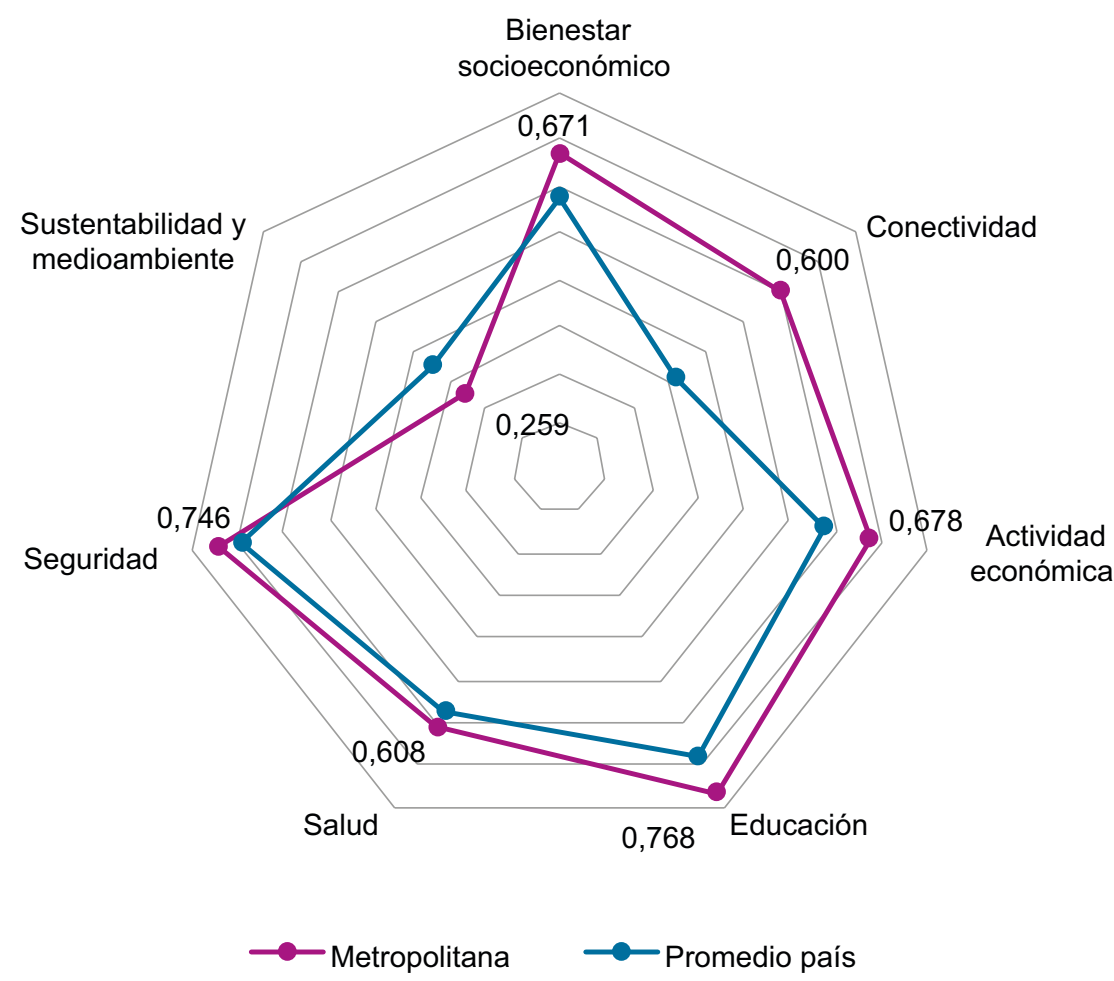

Fuente: elaboración propia. 


\section{Región De O’Higgins}

\section{Tabla 21}

Resumen de indicadores Región de O’Higgins - IDERE 2019

\begin{tabular}{lcccccccc}
\hline & \multicolumn{9}{c}{ Dimensiones } & & \\
\cline { 2 - 7 } & $\begin{array}{c}\text { Bienestar } \\
\text { socio- } \\
\text { económico }\end{array}$ & $\begin{array}{c}\text { Conec- } \\
\text { tividad }\end{array}$ & $\begin{array}{c}\text { Actividad } \\
\text { económica }\end{array}$ & Educación & Salud & Seguridad & $\begin{array}{c}\text { Sustenta- } \\
\text { bilidad } \\
\text { y medio- } \\
\text { ambiente }\end{array}$ & $\begin{array}{c}\text { IDERE } \\
2019\end{array}$ \\
\hline $\begin{array}{l}\text { IDERE } \\
\text { Ranking }\end{array}$ & 0,533 & 0,243 & 0,523 & 0,595 & 0,551 & 0,704 & 0,284 & 0,486 \\
$\begin{array}{l}\text { Nivel } \\
\text { relativo de } \\
\text { desarrollo }\end{array}$ & Inter- & 12 & 11 & 14 & 13 & 10 & 12 & 13 \\
\hline
\end{tabular}

Fuente: elaboración propia.

Figura 13

Región de O’Higgins - Dimensiones IDERE 2019

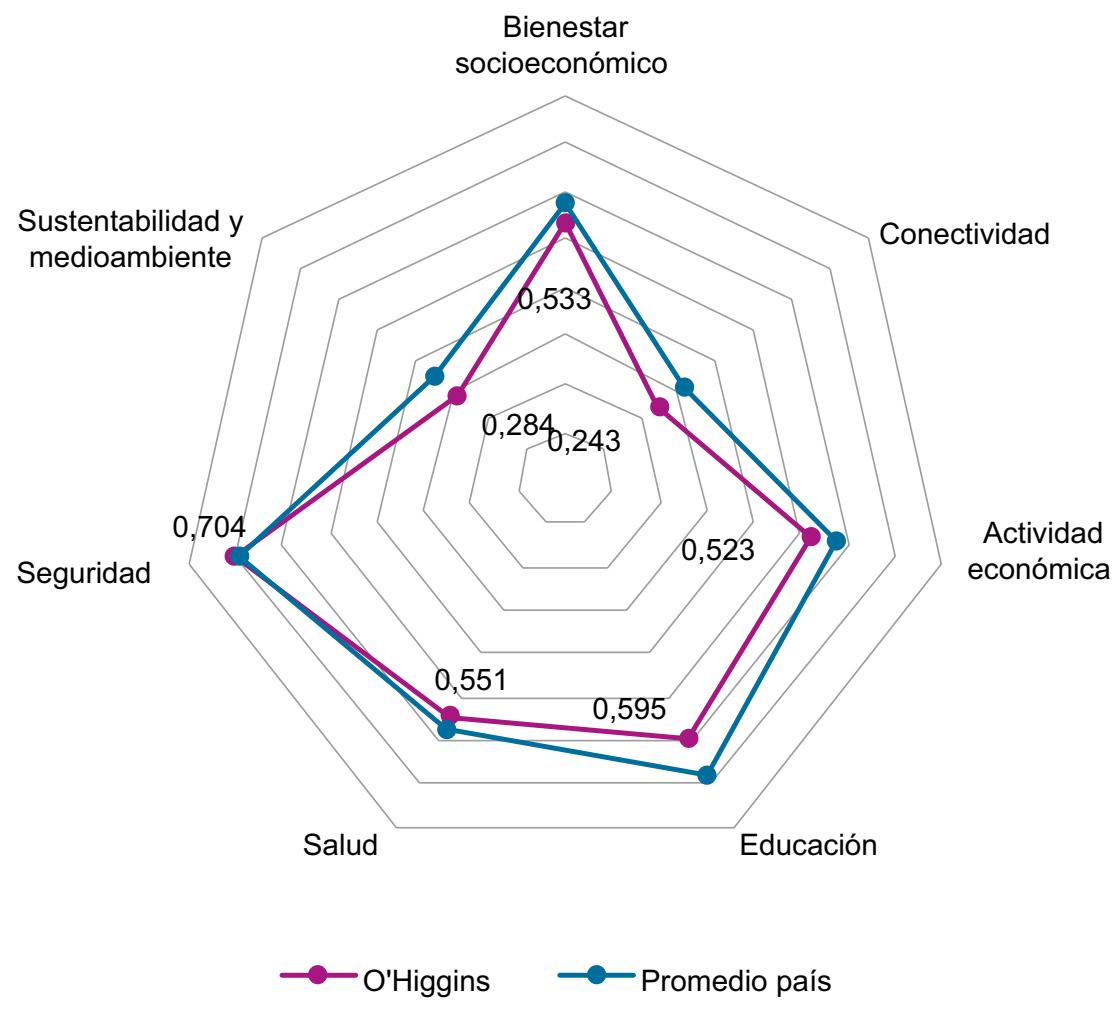

Fuente: elaboración propia. 
Región del Maule

Tabla 22

Resumen de indicadores Región del Maule - IDERE 2019

\begin{tabular}{lcccccccc}
\hline & \multicolumn{9}{c}{ Dimensiones } & & \\
\cline { 2 - 7 } & $\begin{array}{c}\text { Bienestar } \\
\text { socioe- } \\
\text { conómico }\end{array}$ & $\begin{array}{c}\text { Conec- } \\
\text { tividad }\end{array}$ & $\begin{array}{c}\text { Actividad } \\
\text { económica }\end{array}$ & Educación & Salud & Seguridad & $\begin{array}{c}\text { Sustenta- } \\
\text { bilidad } \\
\text { y medio- } \\
\text { ambiente }\end{array}$ & $\begin{array}{c}\text { IDERE } \\
2019\end{array}$ \\
\hline $\begin{array}{l}\text { IDERE } \\
\begin{array}{l}\text { Ranking } \\
\text { Nivel }\end{array}\end{array}$ & 0,506 & 0,188 & 0,499 & 0,614 & 0,571 & 0,759 & 0,263 & 0,471 \\
$\begin{array}{l}\text { relativo de } \\
\text { desarrollo }\end{array}$ & Bajo & Bajo & Bajo & $\begin{array}{c}\text { Inter- } \\
\text { medio }\end{array}$ & $\begin{array}{c}\text { Inter- } \\
\text { medio }\end{array}$ & Alto & Bajo & Bajo \\
\hline
\end{tabular}

Fuente: elaboración propia.

Figura 14

Región del Maule - Dimensiones IDERE 2019

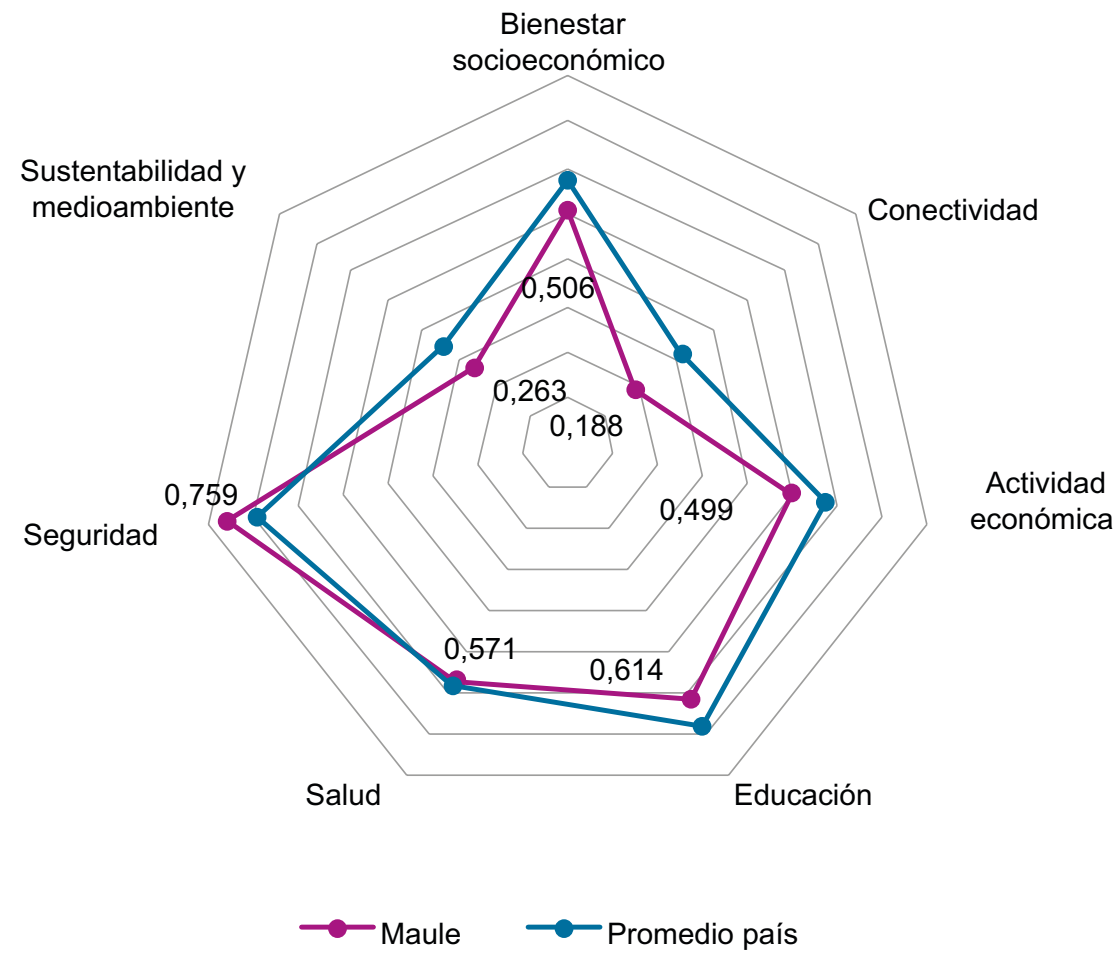

Fuente: elaboración propia. 


\section{Región DEL Biobío}

\section{Tabla 23}

Resumen de indicadores Región del Biobío - IDERE 2019

\begin{tabular}{lcccccccc}
\hline & \multicolumn{9}{c}{ Dimensiones } & & & & \\
\cline { 2 - 7 } & $\begin{array}{c}\text { Bienestar } \\
\text { socio- } \\
\text { económico }\end{array}$ & $\begin{array}{c}\text { Conec- } \\
\text { tividad }\end{array}$ & $\begin{array}{c}\text { Actividad } \\
\text { económica }\end{array}$ & Educación & Salud & $\begin{array}{c}\text { Sustenta- } \\
\text { bilidad }\end{array}$ & $\begin{array}{c}\text { IDERE } \\
\text { Seguridad } \\
\text { y medio- } \\
\text { ambiente }\end{array}$ & \\
\hline $\begin{array}{l}\text { IDERE } \\
\text { Ranking }\end{array}$ & 0,545 & 0,278 & 0,600 & 0,680 & 0,589 & 0,775 & 0,328 & 0,538 \\
$\begin{array}{l}\text { Nivel } \\
\text { relativo de } \\
\text { desarrollo }\end{array}$ & 7 & 7 & 5 & 6 & 6 & 2 & 7 & 8 \\
\hline
\end{tabular}

Fuente: elaboración propia.

Figura 15

\section{Región del Biobío - Dimensiones IDERE 2019}

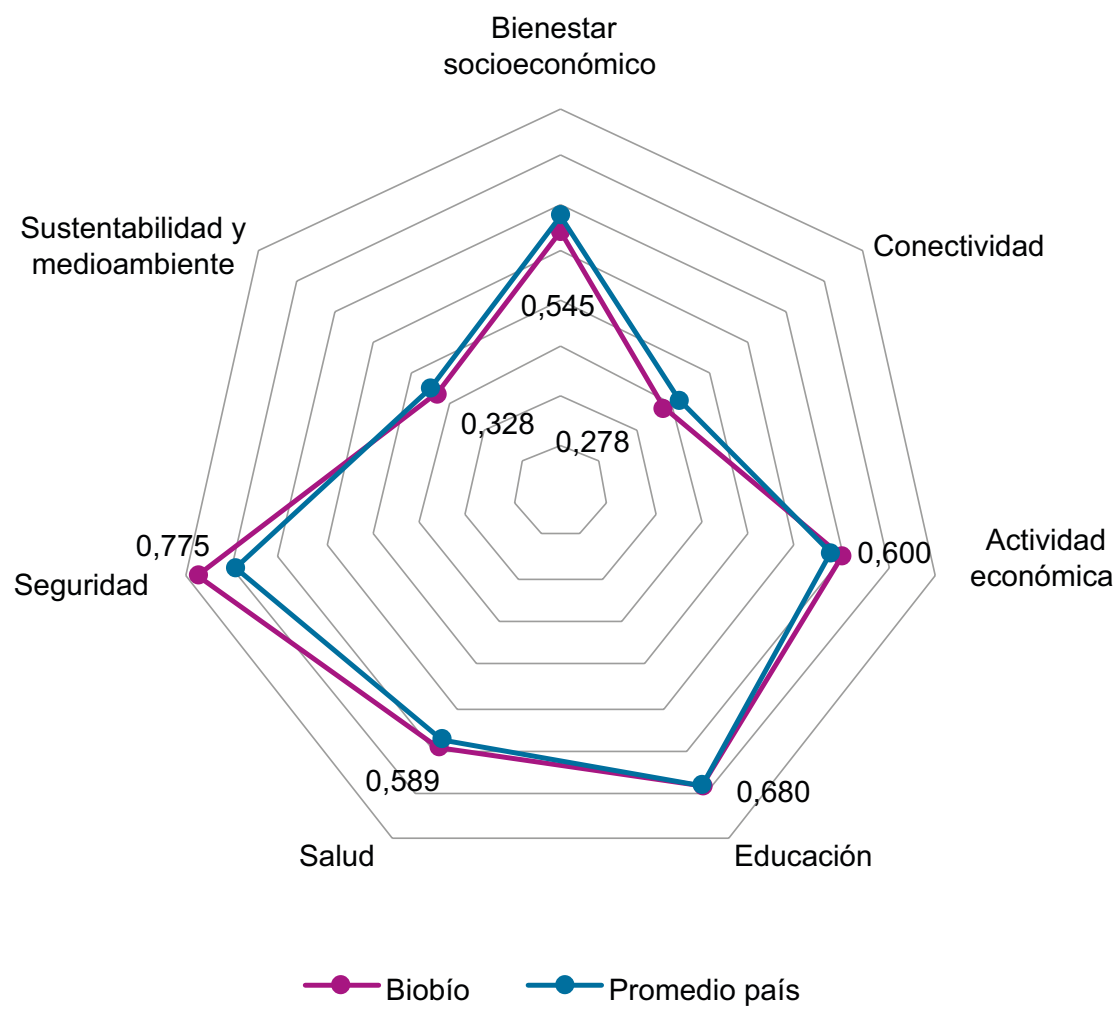

Fuente: elaboración propia. 


\section{Región de La Araucanía}

\section{Tabla 24}

Resumen de indicadores Región de La Araucanía - IDERE 2019

\begin{tabular}{|c|c|c|c|c|c|c|c|c|}
\hline & \multicolumn{7}{|c|}{ Dimensiones } & \multirow[b]{2}{*}{$\begin{array}{c}\text { IDERE } \\
2019\end{array}$} \\
\hline & $\begin{array}{c}\text { Bienestar } \\
\text { socio- } \\
\text { económico }\end{array}$ & $\begin{array}{l}\text { Conec- } \\
\text { tividad }\end{array}$ & $\begin{array}{l}\text { Actividad } \\
\text { económica }\end{array}$ & Educación & Salud & Seguridad & $\begin{array}{c}\text { Sustenta- } \\
\text { bilidad } \\
\text { y medio- } \\
\text { ambiente }\end{array}$ & \\
\hline IDERE & 0,434 & 0,157 & 0,505 & 0,635 & 0,541 & 0,742 & 0,319 & 0,458 \\
\hline Ranking & 15 & 15 & 14 & 12 & 14 & 6 & 8 & 15 \\
\hline $\begin{array}{l}\text { Nivel } \\
\text { relativo de } \\
\text { desarrollo }\end{array}$ & Bajo & Bajo & Bajo & $\begin{array}{l}\text { Inter- } \\
\text { medio }\end{array}$ & Bajo & Alto & $\begin{array}{l}\text { Inter- } \\
\text { medio }\end{array}$ & Bajo \\
\hline
\end{tabular}

Fuente: elaboración propia.

Figura 16

Región de La Araucanía - Dimensiones IDERE 2019

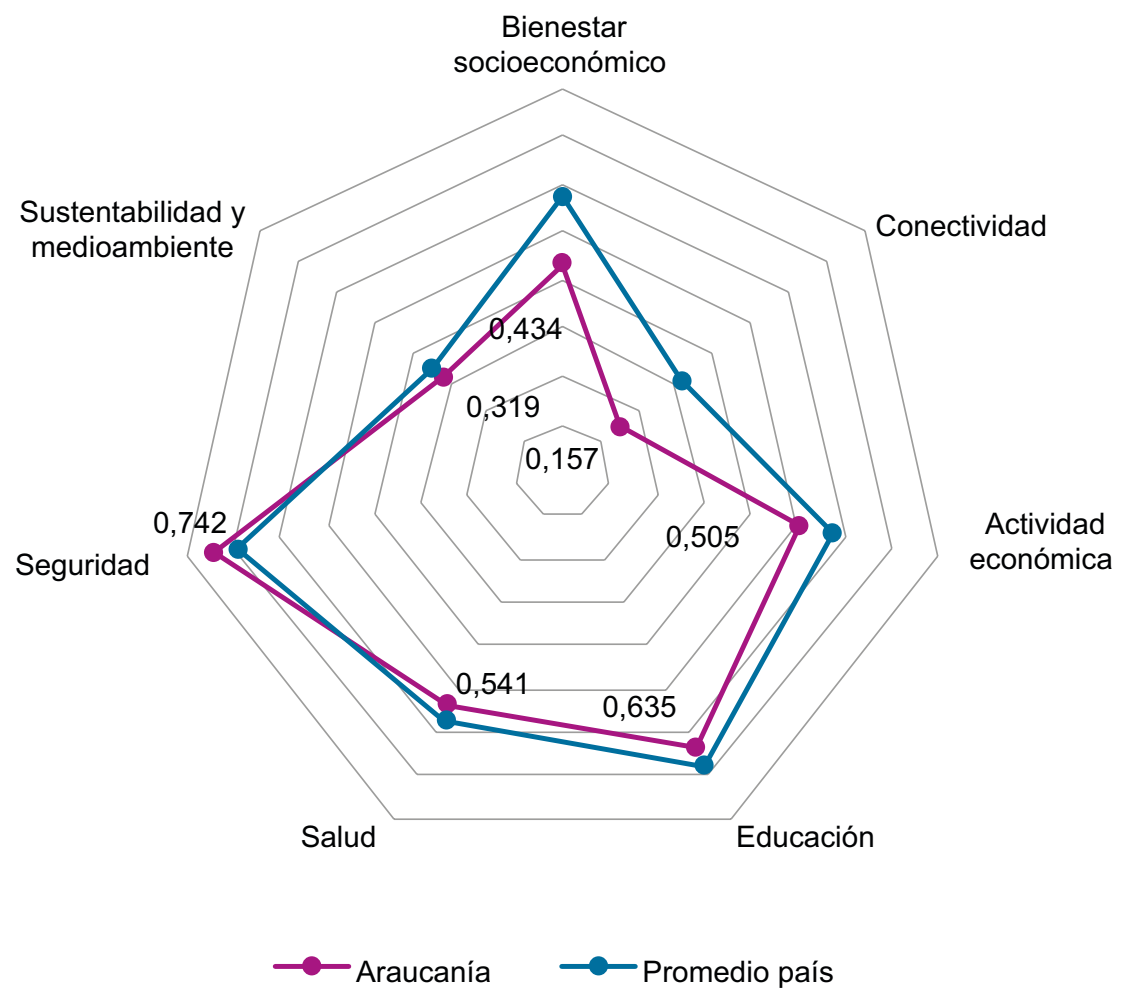

Fuente: elaboración propia. 


\section{REGIÓN DE LOS Ríos}

\section{Tabla 25}

Resumen de indicadores Región de Los Ríos - IDERE 2019

\begin{tabular}{|c|c|c|c|c|c|c|c|c|}
\hline & \multicolumn{7}{|c|}{ Dimensiones } & \multirow[b]{2}{*}{$\begin{array}{c}\text { IDERE } \\
2019\end{array}$} \\
\hline & $\begin{array}{c}\text { Bienestar } \\
\text { socio- } \\
\text { económico }\end{array}$ & $\begin{array}{l}\text { Conec- } \\
\text { tividad }\end{array}$ & $\begin{array}{l}\text { Actividad } \\
\text { económica }\end{array}$ & Educación & Salud & Seguridad & $\begin{array}{c}\text { Sustenta- } \\
\text { bilidad } \\
\text { y medio- } \\
\text { ambiente }\end{array}$ & \\
\hline IDERE & 0,532 & 0,269 & 0,612 & 0,652 & 0,560 & 0,766 & 0,437 & 0,542 \\
\hline Ranking & 9 & 8 & 3 & 11 & 12 & 3 & 3 & 5 \\
\hline $\begin{array}{l}\text { Nivel } \\
\text { relativo de } \\
\text { desarrollo }\end{array}$ & $\begin{array}{l}\text { Inter- } \\
\text { medio }\end{array}$ & $\begin{array}{l}\text { Inter- } \\
\text { medio }\end{array}$ & $\begin{array}{l}\text { Inter- } \\
\text { medio }\end{array}$ & $\begin{array}{l}\text { Inter- } \\
\text { medio }\end{array}$ & $\begin{array}{l}\text { Inter- } \\
\text { medio }\end{array}$ & Alto & Alto & $\begin{array}{l}\text { Inter- } \\
\text { medio }\end{array}$ \\
\hline
\end{tabular}

Fuente: elaboración propia.

Figura 17

Región de Los Ríos - Dimensiones IDERE 2019

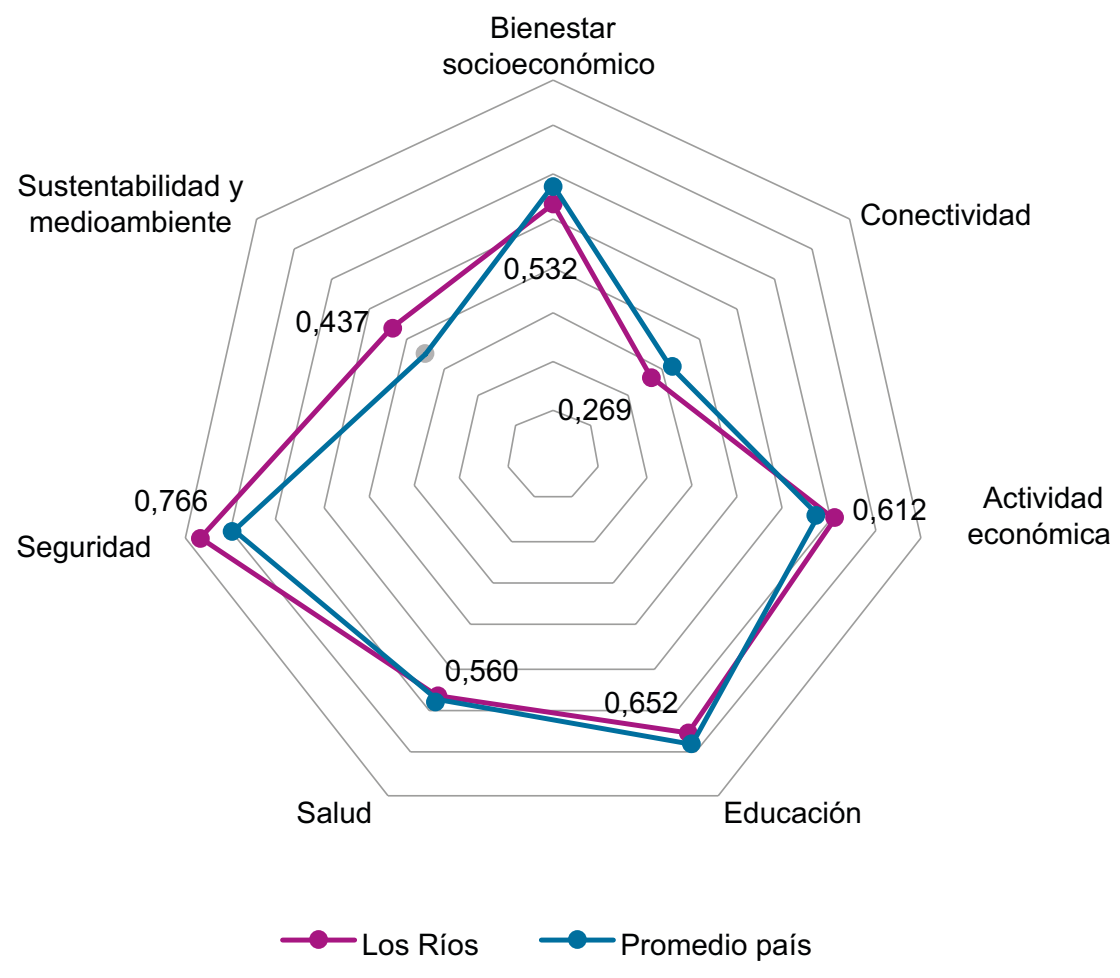

Fuente: elaboración propia. 


\section{REGión DE Los LAgos}

Tabla 26

Resumen de indicadores Región de Los Lagos - IDERE 2019

\begin{tabular}{lcccccccc}
\hline & \multicolumn{9}{c}{ Dimensiones } & & & \\
\cline { 2 - 6 } & $\begin{array}{c}\text { Bienestar } \\
\text { socio- } \\
\text { económico }\end{array}$ & $\begin{array}{c}\text { Conec- } \\
\text { tividad }\end{array}$ & $\begin{array}{c}\text { Actividad } \\
\text { económica }\end{array}$ & Educación & Salud & $\begin{array}{c}\text { Sustenta- } \\
\text { bilidad }\end{array}$ & $\begin{array}{c}\text { IDERE } \\
\text { y medio- } \\
\text { ambiente }\end{array}$ & \\
\hline $\begin{array}{l}\text { IDERE } \\
\text { Ranking }\end{array}$ & 0,514 & 0,256 & 0,594 & 0,656 & 0,518 & 0,736 & 0,330 & 0,510 \\
$\begin{array}{l}\text { Nivel } \\
\text { relativo de } \\
\text { desarrollo }\end{array}$ & 10 & 10 & 7 & 10 & 15 & 7 & 6 & 10 \\
\hline
\end{tabular}

Fuente: elaboración propia.

Figura 18

Región de Los Lagos - Dimensiones IDERE 2019

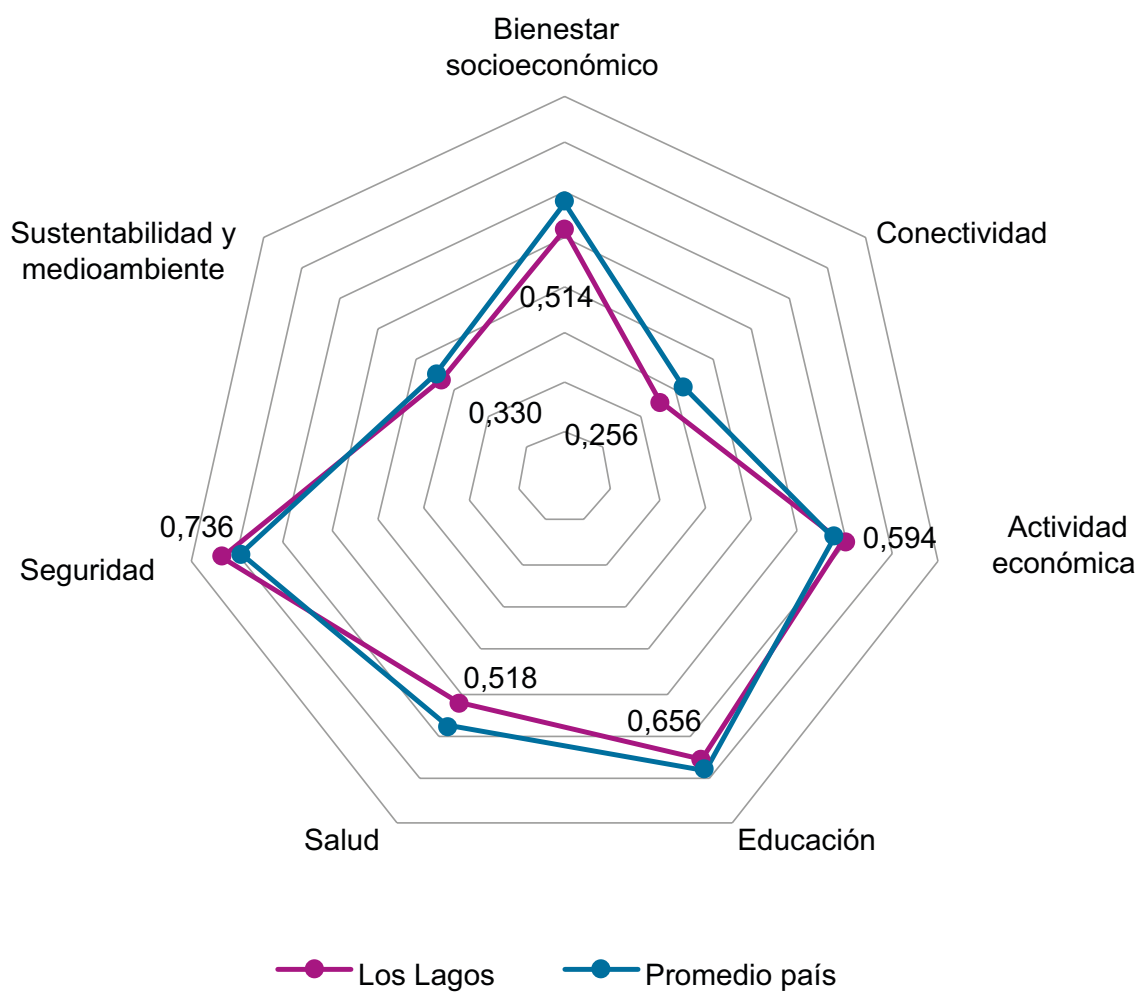

Fuente: elaboración propia. 
Región de Aysén

Tabla 27

Resumen de indicadores Región de Aysén - IDERE 2019

\begin{tabular}{lcccccccc}
\hline & \multicolumn{9}{c}{ Dimensiones } & & \\
\cline { 2 - 7 } & $\begin{array}{c}\text { Bienestar } \\
\text { socio- } \\
\text { económico }\end{array}$ & $\begin{array}{c}\text { Conec- } \\
\text { tividad }\end{array}$ & $\begin{array}{c}\text { Actividad } \\
\text { económica }\end{array}$ & Educación & Salud & Seguridad & $\begin{array}{c}\text { Sustenta- } \\
\text { bilidad } \\
\text { y medio- } \\
\text { ambiente }\end{array}$ & $\begin{array}{c}\text { IDERE } \\
2019\end{array}$ \\
\hline $\begin{array}{l}\text { IDERE } \\
\text { Ranking }\end{array}$ & 0,705 & 0,219 & 0,552 & 0,591 & 0,593 & 0,639 & 0,479 & 0,539 \\
$\begin{array}{l}\text { Nivel } \\
\text { relativo de } \\
\text { desarrollo }\end{array}$ & Alto & 13 & 10 & 15 & 4 & 12 & 2 & 7 \\
\hline
\end{tabular}

Fuente: elaboración propia.

Figura 19

Región de Aysén - Dimensiones IDERE 2019

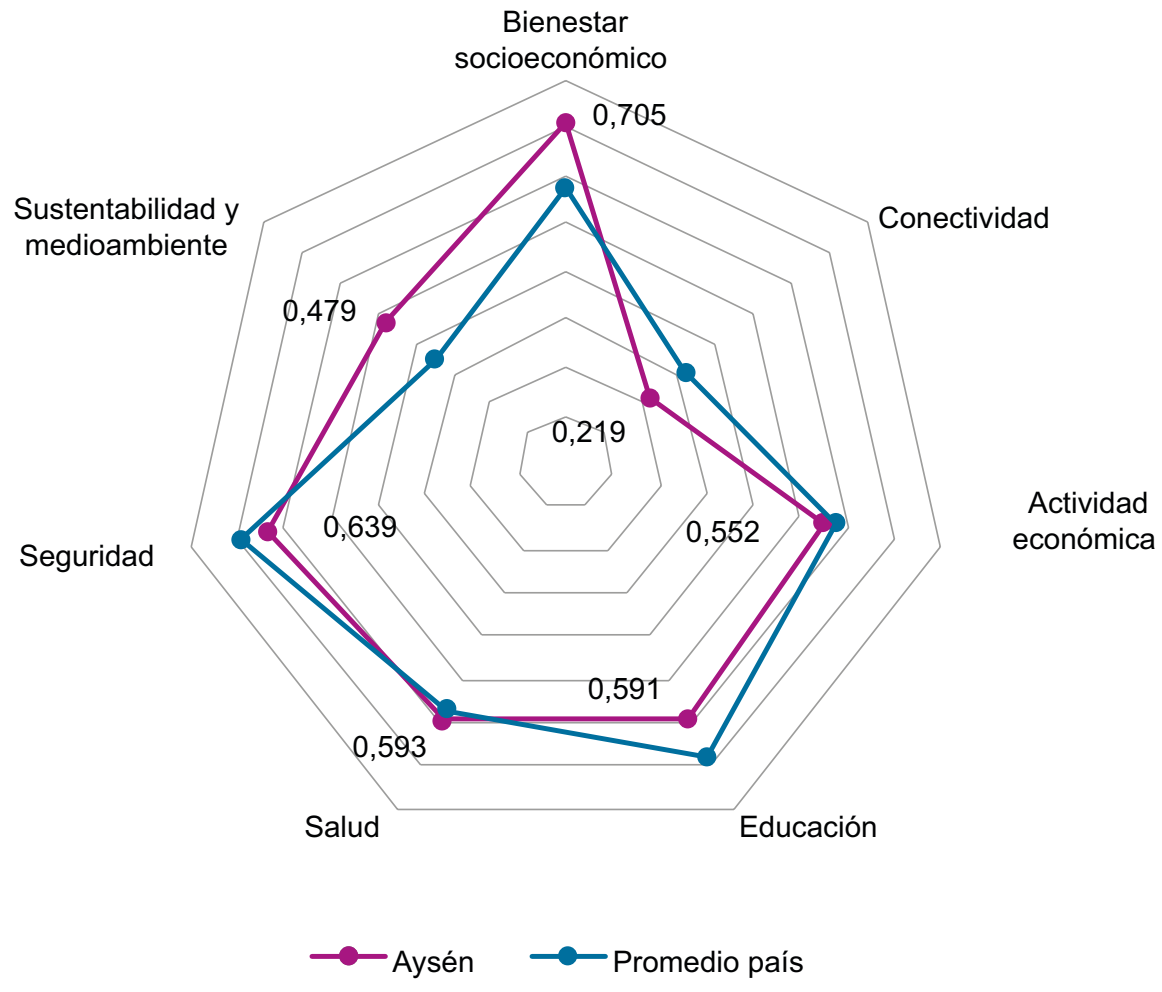

Fuente: elaboración propia. 
Región de Magallanes

Tabla 28

Resumen de indicadores Región de Magallanes - IDERE 2019

\begin{tabular}{|c|c|c|c|c|c|c|c|c|}
\hline & \multicolumn{7}{|c|}{ Dimensiones } & \multirow[b]{2}{*}{$\begin{array}{c}\text { IDERE } \\
2019\end{array}$} \\
\hline & $\begin{array}{c}\text { Bienestar } \\
\text { socio- } \\
\text { económico }\end{array}$ & $\begin{array}{l}\text { Conec- } \\
\text { tividad }\end{array}$ & $\begin{array}{l}\text { Actividad } \\
\text { económica }\end{array}$ & Educación & Salud & Seguridad & $\begin{array}{l}\text { Sustenta- } \\
\text { bilidad } \\
\text { y medio- } \\
\text { ambiente }\end{array}$ & \\
\hline IDERE & 0,732 & 0,432 & 0,706 & 0,709 & 0,573 & 0,813 & 0,570 & 0,648 \\
\hline Ranking & 1 & 3 & 1 & 5 & 8 & 1 & 1 & 1 \\
\hline $\begin{array}{l}\text { Nivel } \\
\text { relativo de } \\
\text { desarrollo }\end{array}$ & Alto & Alto & Alto & Alto & $\begin{array}{l}\text { Inter- } \\
\text { medio }\end{array}$ & Alto & Alto & Alto \\
\hline
\end{tabular}

Fuente: elaboración propia.

Figura 20

Región de Magallanes - Dimensiones IDERE 2019

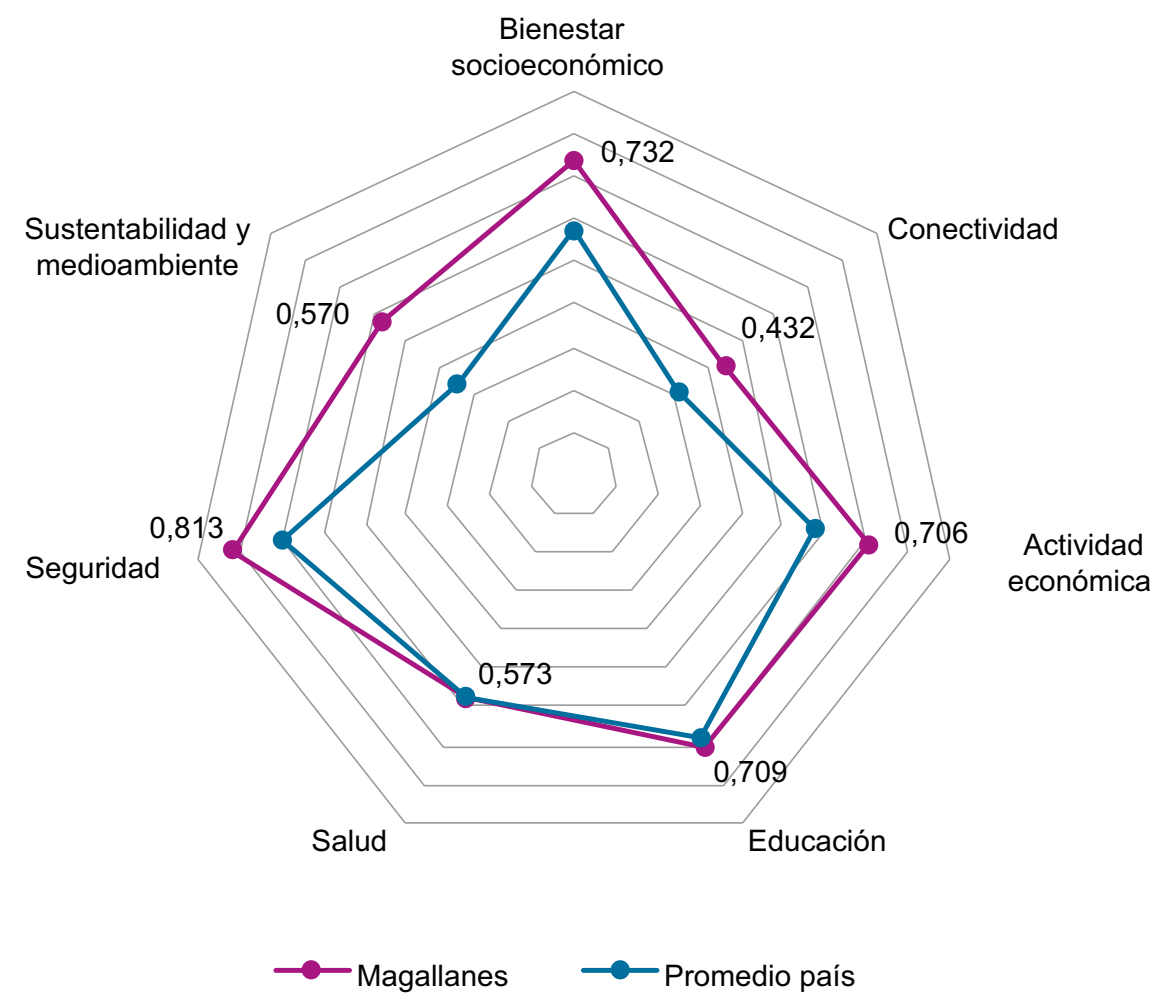

Fuente: elaboración propia. 



\section{ANEXO \\ DESCRIPCIÓN DE INDICADORES}



Índice De Desarrollo Regional • IDERE 2019

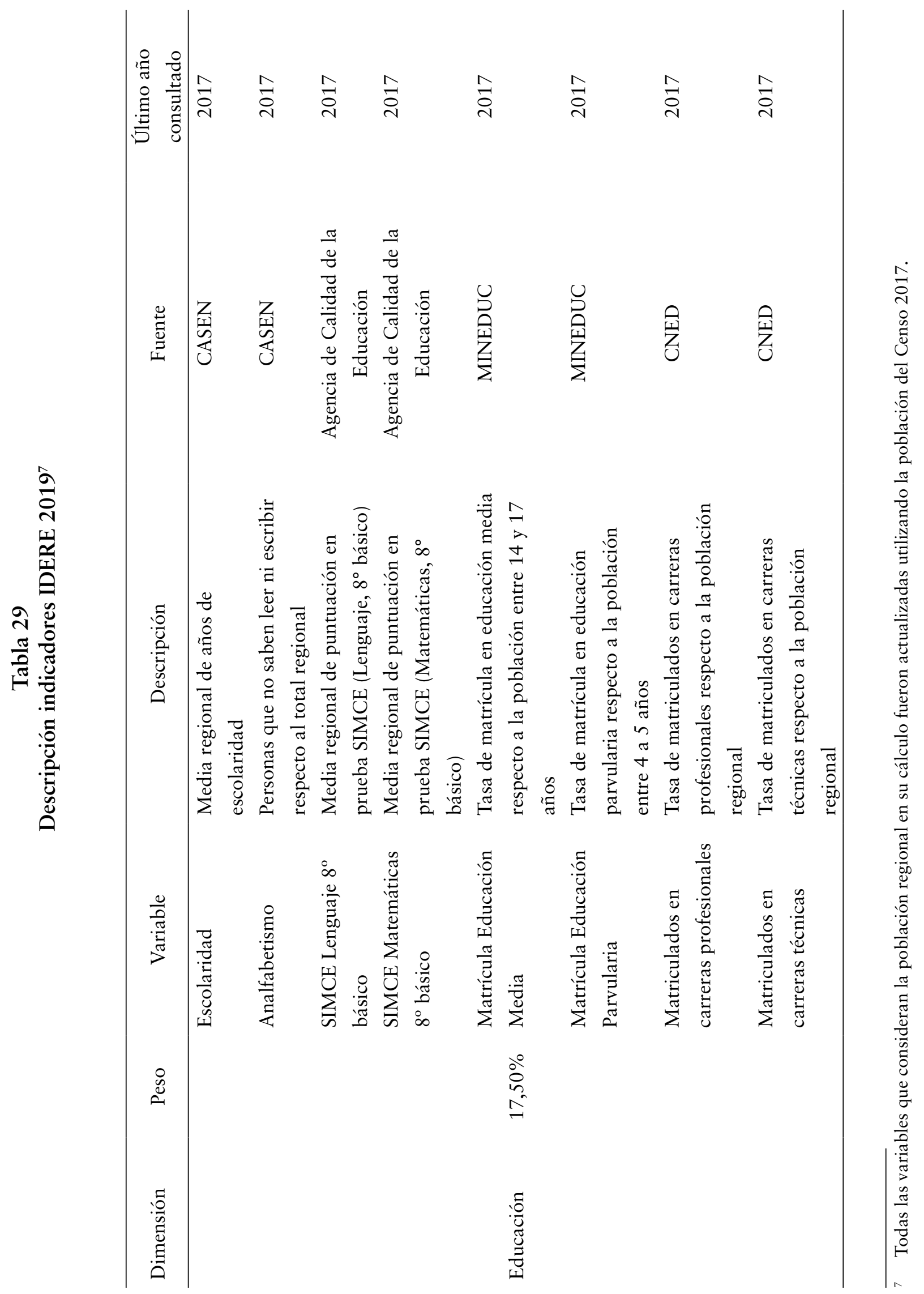


M. Camilo Vial Cossani (ed.)

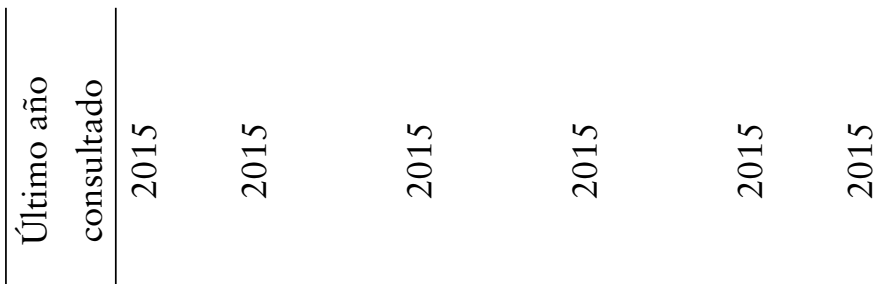

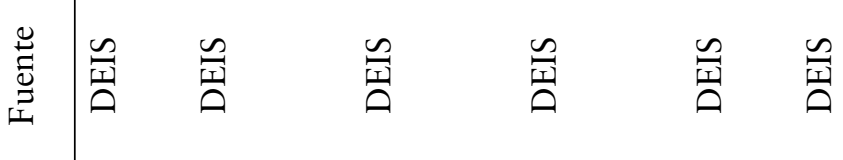

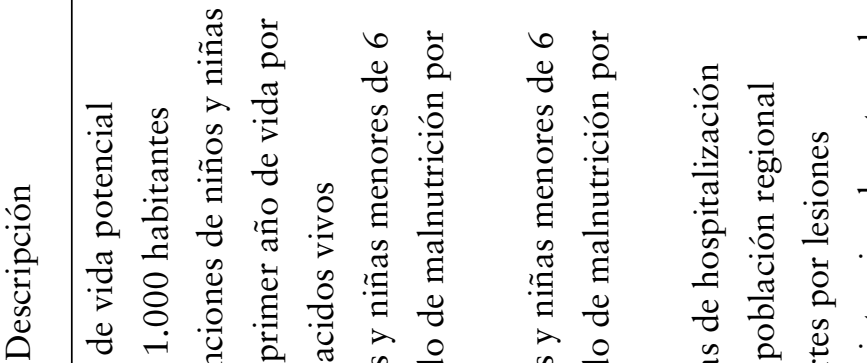

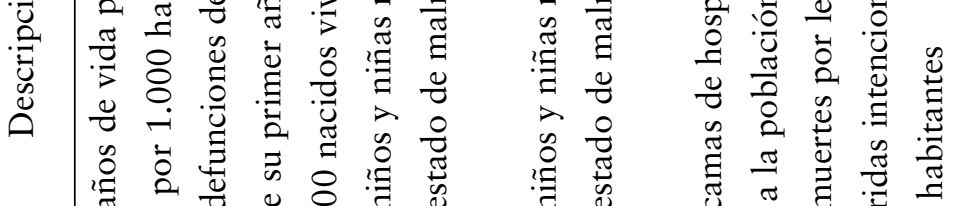

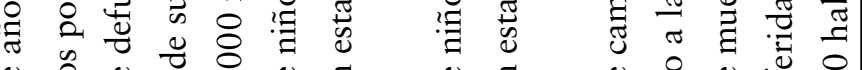

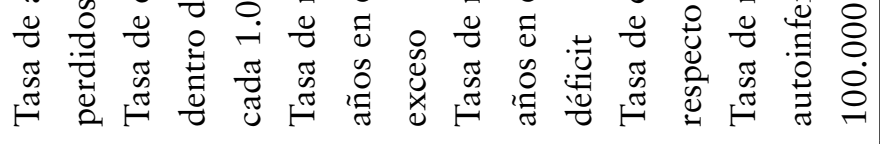

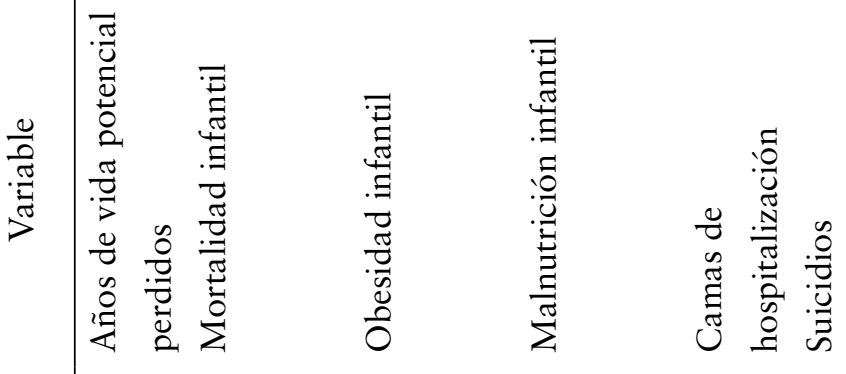

$$
\begin{aligned}
& \begin{array}{lll}
\circ & 0 \\
0 & 0 \\
0 & 0 \\
0 & 0
\end{array}
\end{aligned}
$$

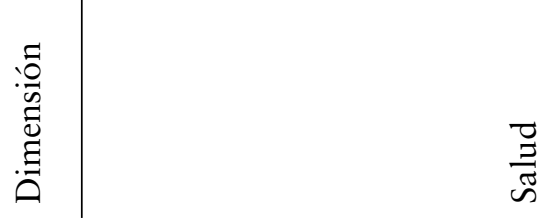


Índice de Desarrollo Regional • IDERE 2019

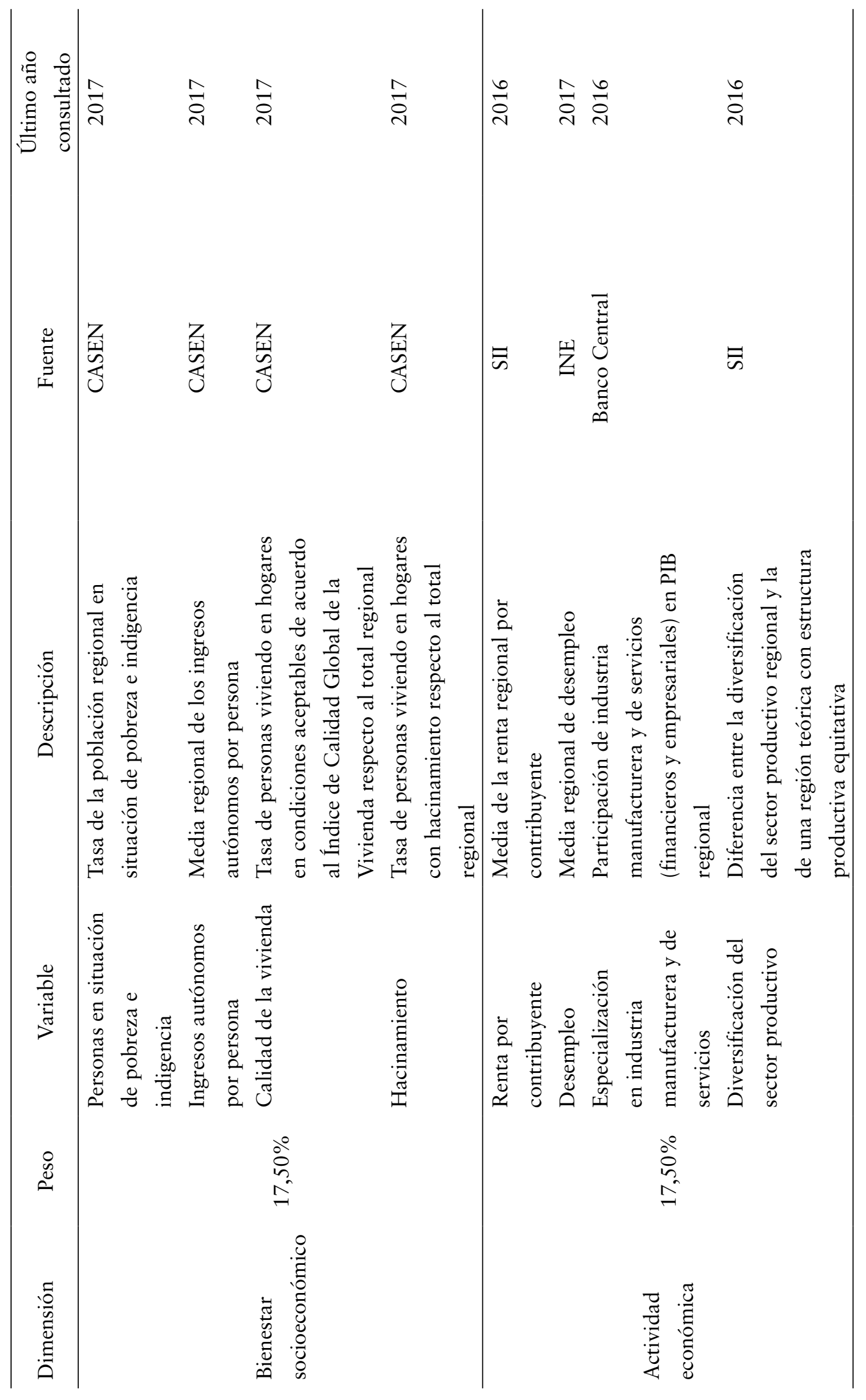


M. Camilo Vial Cossani (ed.)

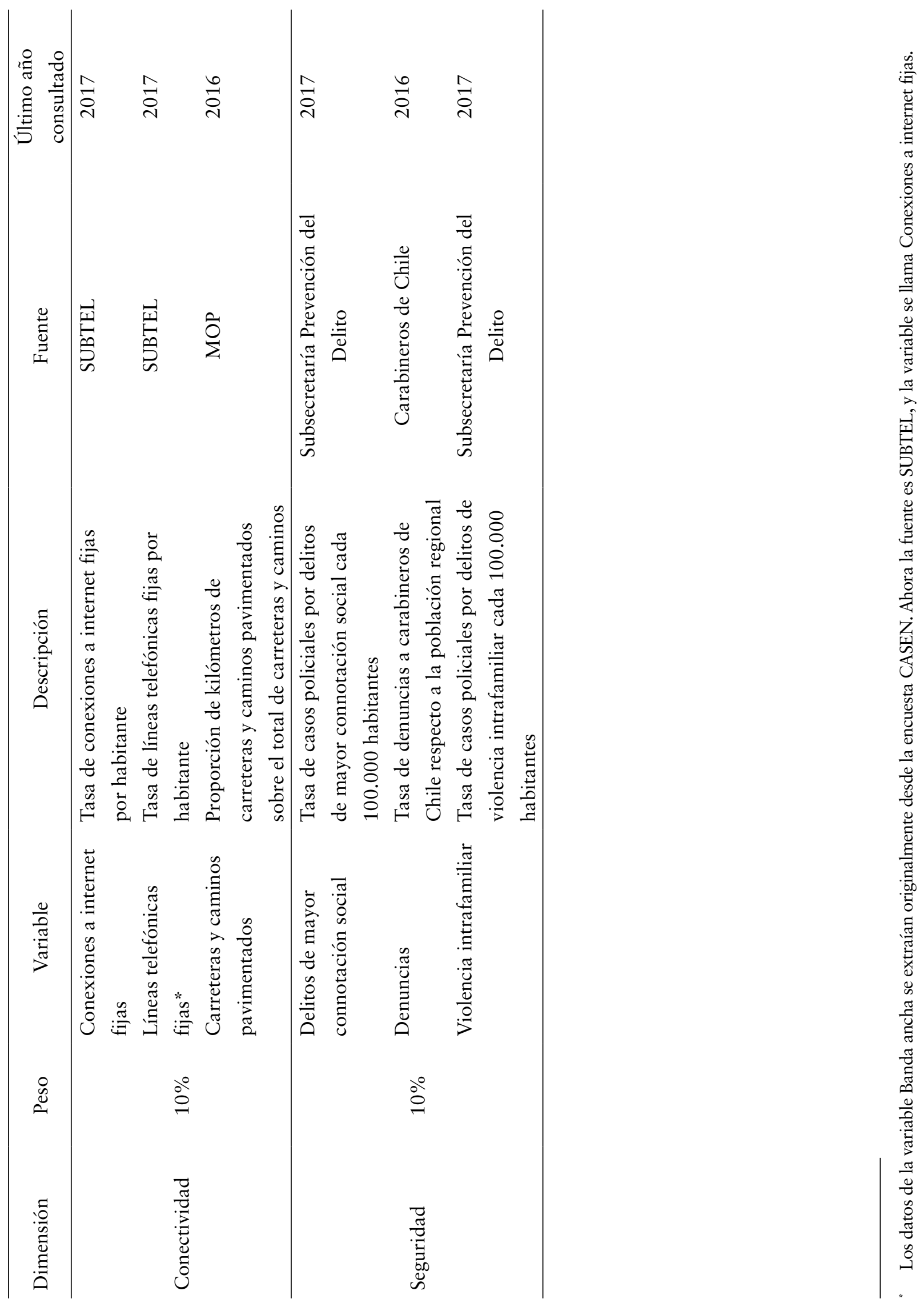


Índice de Desarrollo Regional • IDERE 2019

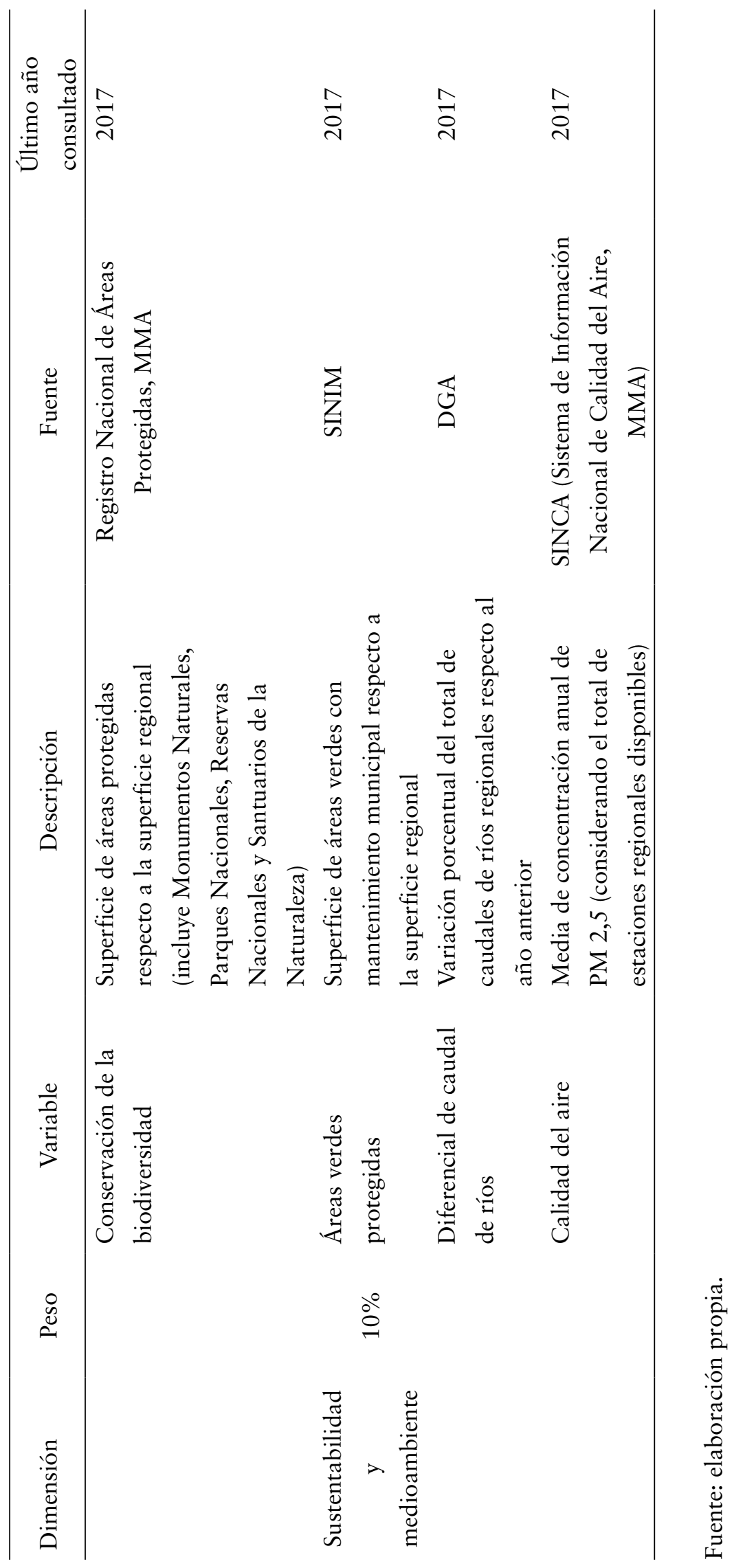





\section{SOBRE LOS AUTORES}

M. Camilo Vial Cossani es doctor en Ciencias Políticas por la Universidad Complutense de Madrid. Es Vicerrector de Vinculación con el Medio, de la Universidad Autónoma de Chile e investigador del Instituto Chileno de Estudios Municipales (ICHEM), de la misma casa de estudios. Fue director del ICHEM, editor de la Revista Iberoamericana de Estudios Municipales (RIEM) y jefe de División de Políticas y Estudios de la Subsecretaría de Desarrollo Regional y Administrativo (SUBDERE). Sus principales líneas de investigación son la descentralización y las políticas de desarrollo local y regional. Dentro de ese marco de estudios, es el autor intelectual del Índice de Desarrollo Regional.

Alejandra Parrao es geógrafa de la Pontificia Universidad Católica de Chile y magíster en Políticas Públicas del Georgia Institute of Technology (Atlanta, Georgia, Estados Unidos), con especialización en Políticas de Desarrollo Económico. Actualmente se desempeña como investigadora en el Instituto Chileno de Estudios Municipales (ICHEM).

Andrea Gartenlaub es doctora en Ciencias Sociales, magíster en Ciencias Políticas y Licenciada en Comunicación Social de la Universidad de Chile. Ha sido Visiting Research en el Center of Latin American Studies de la Universidad de Georgetown (Washington D. C.). Sus áreas de investigación son las políticas públicas, género, conservadurismo y partidos políticos chilenos. Es parte del Comité de Evaluación de la Revista de Estudios Políticos y Estratégicos de la Universidad Tecnológica Metropolitana. Fue asesora de contenidos del Gabinete del Fondo Nacional de Salud del Gobierno de Chile. Ha participado como columnista invitada en el suplemento «Enfoques» del diario Reforma de México. 




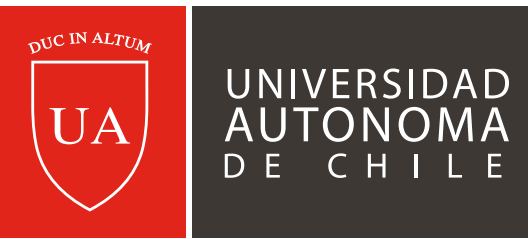

ormalmente se muestra a Chile como uno de los países con
mejores indicadores económicos y sociales de América Latina.
Sin embargo, no da lo mismo dónde nacer o vivir para acceder
al aparente exitoso 'Chile de los promedios'. Además de la ya conocida y estudiada inequidad socioeconómica del país, se debe considerar la significativa desigualdad a escala regional, expresada en una amplia gama de indicadores.

Con el objeto de visibilizar y analizar las desigualdades territoriales y brechas existentes en nuestro país, nació en 2016 el Índice de Desarrollo Regional (IDERE). Esta herramienta, que actualmente publica su tercera versión, mide el desarrollo a nivel territorial en siete dimensiones clave: Salud, Educación, Bienestar Socioeconómico, Actividad Económica, Conectividad, Seguridad y Medioambiente. Además, IDERE 2019 incorpora un estudio complementario que analiza las brechas de género a nivel regional, avanzando hacia una mirada más integral del desarrollo regional en Chile.

\section{$\square$ \\ RiL editores}

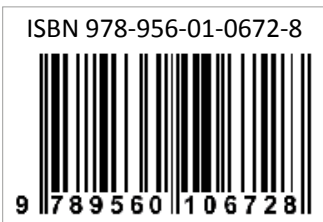

